\title{
UC-NRLF
}

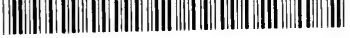

\section{B 4 I39 236}

Laboratory Guide

in

Experimental Pharmacology

Edmunds - Cushny

George Wahr-Publisher 

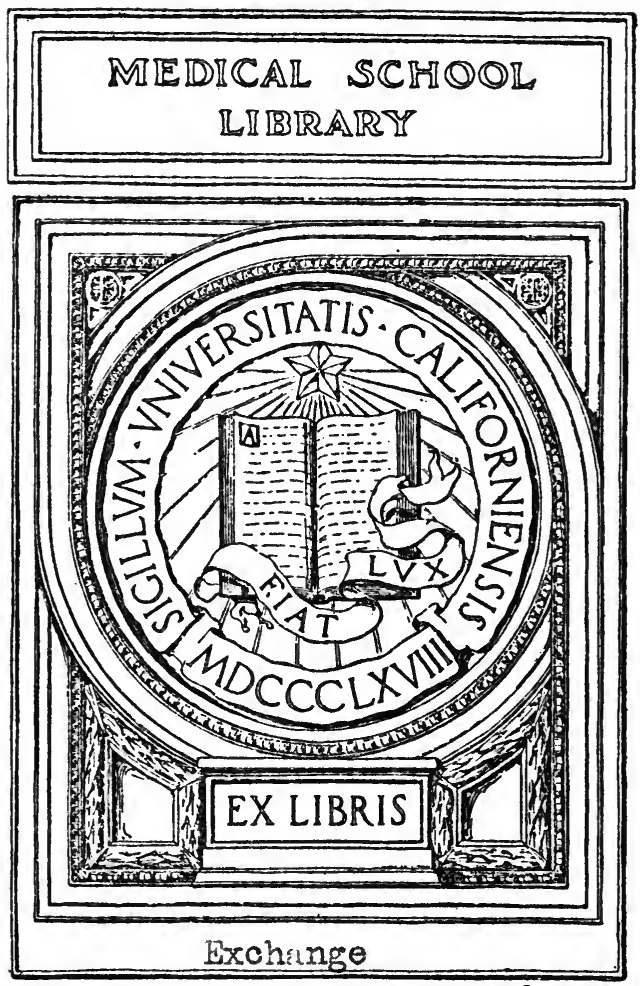

Detroit Public Library liedical Science Department 


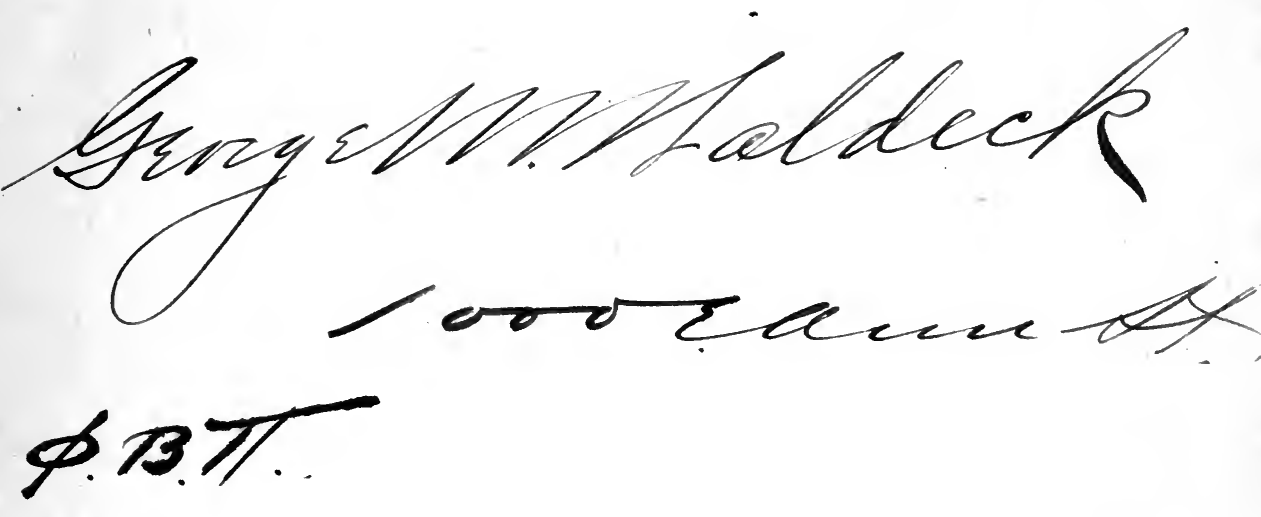

Lup. 


\section{Digitized by the Internet Archive in 2007 with funding from Microsoft Corporation}




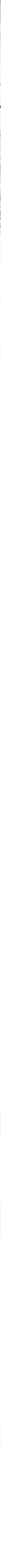





\section{Laboratory Guide}

\section{IN \\ Experimental Pharmacology}

DIRECTIONS FOR THE COURSE GIVEN IN THE

University of Michigan

BY

CHARLES W. EDMUNDS, A. B., M. D. INSTRUCTOR IN PHARMACOLOGY IN THE UNIVERSITY OF MICHIGAN

AND

ARTHUR R. CUSHNY, A. M., M. D. PROFESSOR OF PHARMACOLOGY IN UNIVERSITY COLLEGE, LONDON; AND LATE PROFESSOR OF MATERIA MEDICA AND THERAPEUTICS IN THE UNIVERSITY OF MICHIGAN

GEORGE WAHR PUBLISHER AND BOOKSELLER ANN ARBOR, MICH. 
Copyright 1905

Grorge Wahr

G. in.i. Groong m. Waldeck. 


\section{QP905 \\ E24 \\ 1905}

\section{PREFACE.}

The following course has been gradually developed in the pharmacological laboratory of the University of Michigan, and it has been suggested that if put in a more permanent form than hitherto it might be helpful to other teachers of this subject.

The practical course has hitherto been given as an introduction to the didactic lectures and it has been found advisable to limit the number of drugs examined to those possessing the most typical action. The object has been to train the student entering on the subject in the method of work and to impress on him that the study of drugs is to be approached in the same objective way as other branches of medicine.

The order in which the experiments are arranged is a purely arbitrary one, necessitated by the conditions of the laboratory, and can doubtless be modified with advantage to suit other classes.

A few days are devoted to purely pharmaceutical work, but the chief weight is laid on the experimental part of the course. The few hours devoted to pharmacy, however, train the student in observing the characters of the much larger number of drugs met in the lecture course, and have been found to be of considerable value. A beginning may be 
made in prescribing as occasion offers, but this, as well as the therapeutic applications of the results obtained in the pharmacological experiments, is better left to the teacher than expounded in the laboratory directions.

Arthur R. Cushny.

Charles W. Eidmunds.

Ann Arbor, March 18th, 1905.

We wish to express our thanks to Mr. Arthur J. Jones for his excellent drawings of the turtle, the dog's head and the frog with its heart exposed. 


\section{CONTENTS.}

PAGe.

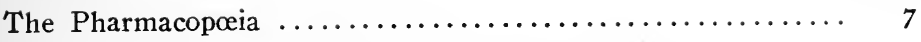

General directions for anæsthetics and operations.......... I I

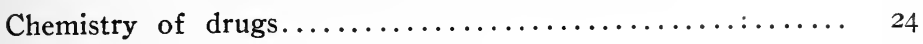

Physiology of frog's nervous system $\ldots \ldots \ldots \ldots \ldots \ldots \ldots \ldots . \ldots \ldots$

Soporifics or Hypnotics......................... 5 I

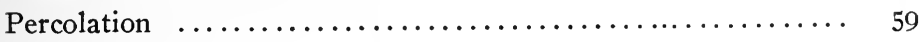

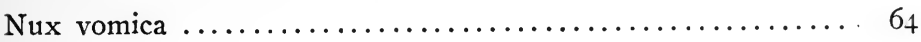

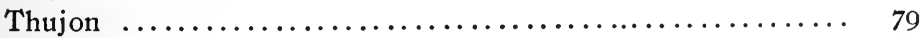

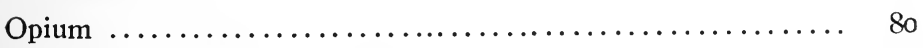

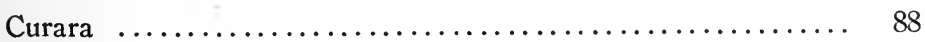

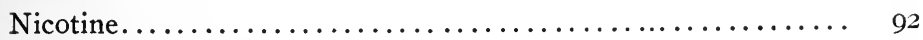

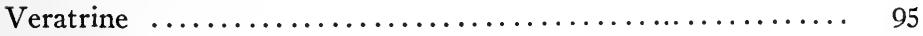

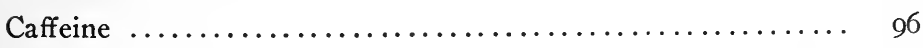

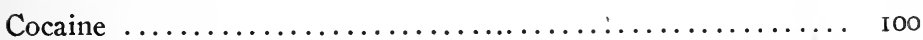

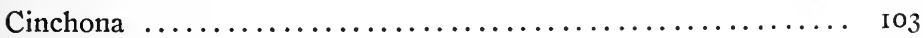

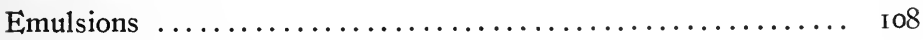

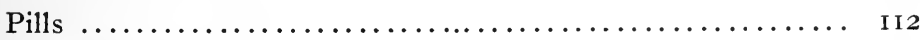

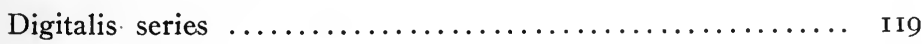

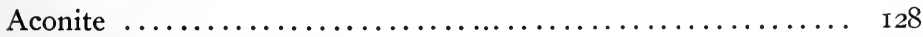

Drugs on the frog's heart.................... I32

Drugs on the rabbit's heart $\ldots \ldots \ldots \ldots \ldots \ldots \ldots \ldots \ldots \ldots$ I 35

Drugs on the turtle's heart.................... I 39

Drugs on the blood pressure................... I47

Drugs on the dog's heart...................... I5 I

Analysis of tracings.......................... 160

Perfusion of the kidney...................... I67

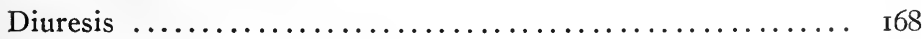

Belladonna series ......................... I79

Drugs on the sympathetic system............... I 87 


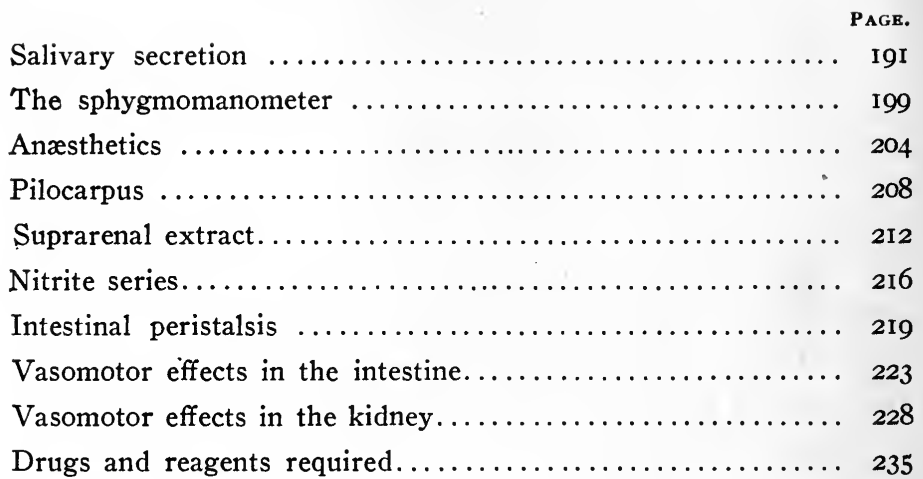




\section{The Pharmacopœia.}

When a physician prescribes a certain drug from time to time in his practice it is of greatest importance to him to know that his patients are always getting the same preparation, containing the same active principles in uniform strength. These requirements could not be carried out if there were not some standard recognized by the manufacturers and followed by them in the preparation of the various medicinal remedies. Most countries possess such a standard in their "Pharmacopœias," which are generally published by the government. In this country, the government does not issue the pharmacopœia, but it recognizes its authority. The book is revised every ten years by a Committee of Revision composed of members appointed or elected by a convention of various medical and pharmaceutical societies and colleges.

It need hardly be remarked that in such a work only such remedies are included as have become well established. These are designated as "official" remedies, while drugs not mentioned are "non-official."

The pharmacopœia gives, first, the Latin title of the drug followed by the English name, and in the case of chemicals the formula and molecular weight are given. Any synonyms are mentioned and wherever it is necessary, a short, concise definition of the drug is added, telling its nature and its source. The book then gives tests by which the identity of the drug may be recognized, and its purity and strength 
tested and finally mentions in what ways and in what doses it may be administered.

Official preparations are therefore made according to the directions given in the pharmacopœias and they should possess uniform strength and properties; such an'ideal, however, is hard to attain, as some of the crude drugs, even when collected according to pharmacopœial directions, differ in their content of the active constituents. 
EXPERIMENTAL PHARMACOLOGY. 


\section{General Directions.}

Before giving the specific directions for the experimental work a number of general directions are given for the commoner operations which are carried out on animals some of which are usually necessary in subsequent manipulations.

The various anæsthetics employed in experimental work are also clescribed.

\section{Anæsthetics.}

No animal is to be operated on unless it is under complete anæsthesia. Ether and chloroform may be used for this purpose, but have the disadvantage of requiring constant attention. They are therefore only used to supplement other anæsthetics which experience has shown can be used to give full anæsthesia in animals without the necessity of their being continually administered. For this purpose the following combinations of drugs usually give very good results, although in rare cases chloroform or ether may have to be given in addition.

Ancsthetic for Rabbits.

Paraldehyde, I.7 cc. per Kg. of body weight.

While your assistant holds up the animal by all four legs and head, place a gag in the mouth and pass a stomach tube ${ }^{1}$ through the opening in the gag, being very careful not to pass it into the lungs. Draw the paraldehyde into a pipette

${ }^{1} \mathrm{~A}$ stomach tube for rabbits and cats may be made from a semi-elastic catheter (No. 7 or No. 8) by cutting off the ivory tip and fitting in its place a short piece of rubber tubing. If preferred, the soft rubber catheter may be used. 
and place the point of the pipette in the opening of the stomach tube and blow the drug into the stomach, and then withdraw the tube.

Anasthetic for Cats.

Morphine sulphate, 0.040 to 0.060 G. Chloretone, 0.3 G. per Kg. of body weight.

Place the animal in a cat box, ${ }^{1}$ draw the head forward and with a hypodermic syringe inject the morphine solution under the skin of the neck.

Dissolve the chloretone in as small a volume of alcohol as possible and add about an equal volume of water. Keep the animal in the box and introduce this solution through the stomach tube in the way described under "Anæsthetic for Rabbits.”

Ancesthetic for a Dog.

Morphine sulphate, 0.2 G. to 0.25 G. Chloretone, 3 G. to $4 \mathrm{G}$.

Three or four hours before the animal is needed inject the morphine solution under the skin by means of a hypodermic syringe.

Just before operation, dissolve the chloretone in alcohol and add about an equal amount of water and give it to the dog by means of a stomach tube ${ }^{2}$ passed through a wooden gag.

\footnotetext{
${ }^{1} \mathrm{~A}$ cat box is of the greatest service as a means of protection to the operator whenever this animal is used. It consists of an ordinary wooden box about 30 or $35 \mathrm{~cm}$. long, $18 \mathrm{~cm}$. wide and 15 or $18 \mathrm{~cm}$. deep. It is provided with a sliding cover, which has a V-shaped cut in the middle of one end. In the corresponding end of the box a second $\mathrm{V}$ cut is made. When the lid is shut these two cuts leave enough room for the animal's neck. The lid is kept closed tightly by means of a nail passed through the opposite end of the cover into the end of the box.

${ }^{2}$ The average stomach tube, such as is used in clinical medicine, is about the right size for a dog. It should be about $75 \mathrm{~cm}$. long.
} 
EXPERIMENTAL PHARMACOLOGY. 


\section{Operations on Frogs.}

\section{Pithing.}

Before exposing the heart of a frog or carrying out any other operation upon the animal its brain is destroyed (pithed) in the following manner: Hold the frog in the left hand with its back upward, tip the head forward with the left index finger, and feel for the prominent angle made at the junction of the skull and spinal column. Just back of this angle make a cut with small scissors through the skin in the median line. Now push the sharpened end of a match forward through the foramen magnum into the skull, rotating it in the cranial cavity to destroy the brain.

\section{Injecting into a Lymph Sac.}

In the intact animal, drugs to be tested are usually injected into the anterior lymph sac. This is carried ott in the following manner: Lay the animal back downwards in the palm of the left hand. Hold one of its forelegs firmly between the thumb and index finger and the other foreleg between the middle and ring fingers. Draw its hind legs downward and hold them against the palmar surface of the hand by means of the little finger.

Having the drug in the glass injecting pipette, ${ }^{1}$ which is held in the right hand, force the animal's mouth open with the point. Pass the pipette into the mouth avoiding the tongue, which is attached anteriorly and direct the point to-

\footnotetext{
${ }^{1}$ To make a glass injecting pipette take a piece of glass tubing about $7 \mathrm{~mm}$. in diameter and about 20 or $30 \mathrm{~cm}$. long and heat the midd!e point in the Bunsen flame, rotating the tube constantly, and when it is red hot remove it from the flame and draw it out to a capillary size; cut it in the middle so as to leave a fine tube about $8 \mathrm{~cm}$. long. Heat the large end of the pipette to smooth it off so it will not cut the tongue or lips.
} 
ward the floor of the mouth which with a little pressure it will pierce, entering the lymph sac. As it is pushed down the sac the point can be seen beneath the skin of the abdominal wall. The finger is now removed from the upper end of the pipette and the drug allowed to flow into the sac, or if necessary blown in.

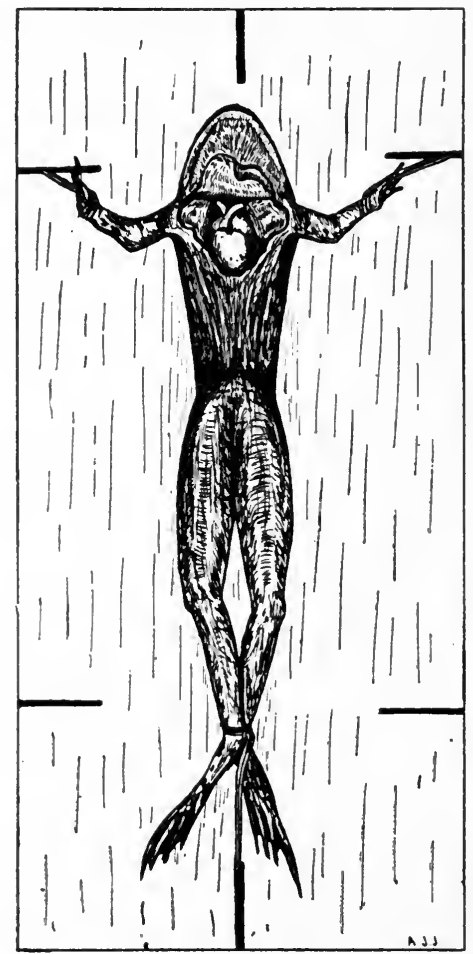

Fig. No. I.

To Expose the Heart.

Pith the frog and tie it on its back on the frog board. With a pair of forceps raise the skin in the median line of 
EXPERIMENTAL PHARMACOLOGY. 
the body just below the point of the sternum and make a nick in it with a pair of scissors. Starting. at this point cut up and outward on each side as far as the pectoral girdle and turn this V-shaped piece of skin upward toward the head. Raise the sternum by placing the forceps beneath the point and with scissors cut it through its entire length avoiding injury to the underlying heart. Tighten the strings on the fore legs so as to pull the sides of the sternum well apart. The heart is now seen enclosed in the pericardium, which may be carefully opened and cut away.

\section{Directions for Operations on Mammals.}

The following are the most common operations necessary in experimental pharmacology.

To Insert a Venous Cannula.

This is to allow of the intravenous injection of drugs.
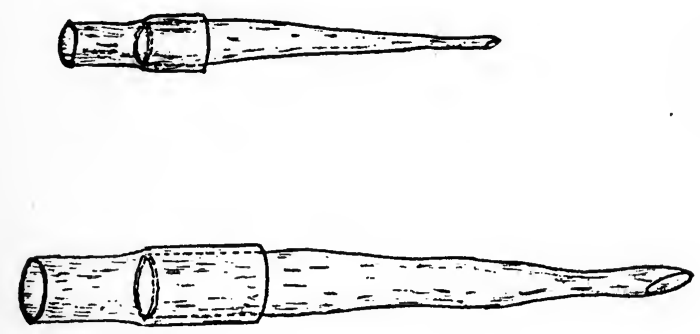

Fig. No. 2.

Two sizes of glass venous cannulas (with rubber tubing attached) are shown in Fig. No. 2. The larger is best suited. for a dog, while the smaller is used in a rabbit or cat. Various sizes should be provided.

Operation. When the anæsthesia is complete make an in- 
cision through the skin over the site of the vessel and deepen the cut through the fascia until the vein is exposed. Avoiding injury to the vessel from forceps or tearing, clear about two inches of the vein, removing all the fascia surrounding it so as to leave it entirely free. Pass two threads about a foot long under the vein and place "bull-dog" forceps on it toward the cardiac end of the cleared portion. This allows distention of the vessel by the blood. Tie one of the threads tightly around the upper end of the cleared portion. Hold the end of this ligature in the left hand and place the left index finger under the vessel, thus making it tense. With sharp scissors make a cut in the distended vein and place the tip of the cannula in it, and tie it in place with the loose thread previously placed around the vessel. Fill the cannula and vein with salt solution ( $0.8 \%$ ), taking great care that all air is expelled.

PRECAUTION. When drugs are injected intravenously it is of the utmost importance to see that no air is allowed to enter the veins. A small bubble of air is almost invariably fatal to rabbits. Be sure the cannula and syringe have all the air expelled.

\section{To Insert an Arterial Canmula. ${ }^{1}$}

This is to allow records of arterial blood pressure to be taken.

Operation. Expose and clear the artery, usually the carotid, in the manner described above for the vein. Pass two ligatures under the vessel and tie the thread which is distal to the heart. Now clamp the artery with the "bulldog" forceps, placing them on the "heart end" of the cleared

${ }^{1}$ Arterial cannulas are exactly like venous cannulas. Fig. No. 2. 
EXPERIMENTAL PHARMACOLOGY. 
portion. Place the index finger under the vessel as before and make a cut in it and tie a cannula in place with the loose ligature. This cannula is to be filled with sodium sulphate solution (page I47) to prevent clotting of the blood.

\section{To Insert a Tracheal Cannula.}

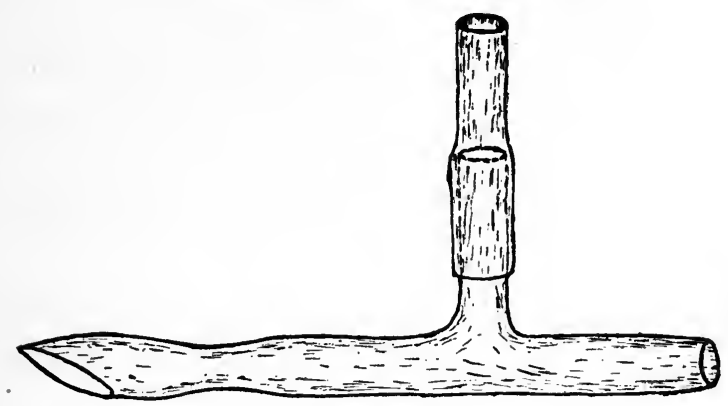

FIg. No. 3. Glass tracheal cannula with rubber tubing attached.

A tracheal cannula is inserted to allow of artificial respiration being carried on in case the chest is to be opened or if the anæsthesia is so deep that the respiratory center is seriously depressed or paralyzed.

A convenient form of tracheal tube is shown in Fig. 3 . They can be made of various sizes of glass tubing so as to fit the trachea of any animal. When in use the piece of rubber tubing shown in the cut is partially constricted to give the proper degree of inflation to the lungs.

Operation. Make a median incision in the neck through the skin and fascia beginning just below the thyroid cartilage. Expose the trachea by separating the muscles with the fingers or blunt hooks and dissect away all structures from around it. Pass a strong thread under it and then make a transverse cut with the scalpel between two rings about twothirds of the way through. Into this opening pass the tracheal tube and tie it in place with the loose ligature. 


\section{Chemistry of Drugs.}

\section{Alkaloids.}

Among the most important of the organic compounds employed in medicine is the group of vegetable bases known as Alkaloids. They are found in almost all parts of plants, but in greatest abundance in the seeds and roots. They constitute in almost all cases the active constituents of the plants in which they are found and some of them are among the most powerful poisons known.

The alkaloids contain carbon, hydrogen, nitrogen, and usually oxygen, but in a few instances the latter is not present.

In their chemical properties they resemble ammonia very closely, having an alkaline reaction and in uniting with acids without the elimination of hydrogen to form salts. These salts differ from the alkaloids in their solubility, and upon this fact is based one method of isolating them in a pure form from the plants in which they are found.

One of the most familiar alkaloids is quinine, which is derived from various species of cinchona bark, and it may be taken as a type of the group, as the reactions given by it are characteristic of most of the other alkaloids.

Taste quinine and quinine sulphate.

I. Test the solubility of a few crystals of quinine (alkaloid) and of quinine sulphate (alkaloidal salt) in ro cc. of each of the following: 
26

LABORATORY GUIDE IN

Ept.I-Qpporite tap

5. T. Lumin only sightly poluthe in matce. Ahight olkalice uaction. Alkalrid Fino alkaline neaction.

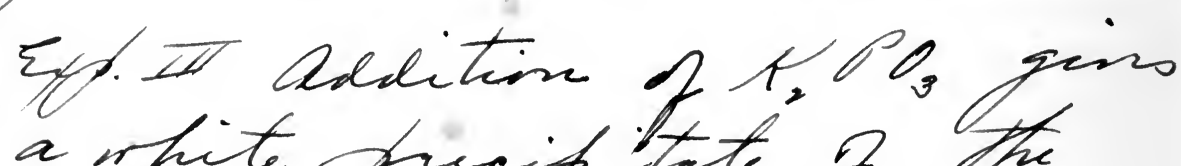
a wite pricifstate f the alkalnid. Addition?

acid apain disorlsis the alkallid.

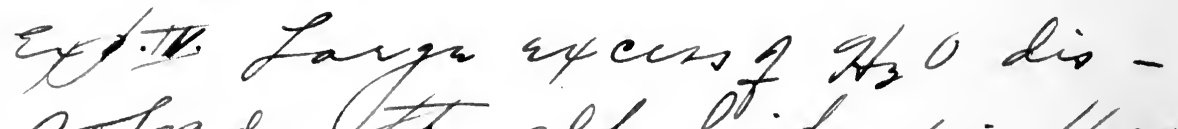
solme the alkalind. Im locols. 


\begin{tabular}{|c|c|c|c|}
\hline & Solvent. & Alkaloid solubility & $\begin{array}{c}\text { Alkaloidal salt solubility. } \\
\text { Sレ LPAATE }\end{array}$ \\
\hline $\mathbf{a}$ & Water. & - & \\
\hline b & Alcohol. & & \\
\hline c & Ether. & & \\
\hline d & Chloroform. & & \\
\hline
\end{tabular}

II. Add about $100 \mathrm{cc}$. of water to $0.2 \mathrm{G}$. quinine. Shake the flask and observe only a small part goes into solution. Test the reaction of the solution with litmus. How do you explain the reaction?

Add I cc. dilute sulphuric acid and shake until complete solution takes place. The sulphuric acid formed the bisulphate of the alkaloid. (Note the fluorescence of the solution which is characteristic of quinine.) Use this solution in making the following tests.

III. To $5 \mathrm{cc}$. of the solution add slowly potassium carbonate solution until a distinct alkaline reaction is obtained. What happens? Render the mixture acid with dilute sulphuric acid.

Alkaloidal salts are very feeble bases and are thrown out of solution by the addition of the fixed alkalies and their carbonates which unite with the acid of the alkaloidal salt. The precipitate therefore was the freed alkaloid which is insoluble in water and which on the addition of the acid formed the sulphate (or bisulphate) again, which passed into solution.

IV. To $5 \mathrm{cc}$. of the solution add potassium hydroxide until the reaction is alkaline. Add distilled water until the test tube is nearly full and then shake the mixture and see if the precipitate dissolves.

The precipitate here, as in No. III, is the free alkaloid. 
The alkaloids are spoken of as being insoluble in water, but this is only relatively correct, as they are soluble in a very large excess; in the case of quinine in 1600 parts of cold water.

In the first parts of experiments III and IV it was seen that an alkaloidal salt is thrown out of solution by the fixed alkalies and their carbonates. For this reason they should not be prescribed together in the same solution, because the alkaloid would fall to the bottom of the bottle and even if it was shaken each time before a dose was taken the chances are that the last dose in the bottle would contain a much larger amount of alkaloid than was intended, and alarming if not fatal symptoms might result. The same objection holds in regard to prescribing alkaloids and tannic acids together in solution (see Exp. V a).

This incompatibility of alkaloids and alkalies may be overcome by the presence of a sufficient amount of alcohol.

V. Put 5 cc. of the solution into each of 5 test tubes and add slowly small quantities of the following reagents; note the formation of any precipitate and if any occurs test its solubility by adding water and shaking as was done in Exp. IV. Tabulate the results.

\begin{tabular}{|c|c|c|c|}
\hline & Reagent. & Precipitate? & Soluble in water? \\
\hline a & Tannic acid. & & - \\
\hline $\mathbf{b}^{*}$ & Picric acid. & & \\
\hline c & Iodine in potassium iodide. & & -.11 .1 \\
\hline d & Mercury-potassium iodide. & twhi & - \\
\hline e & Phosphotungstic acid. & twhit & - \\
\hline
\end{tabular}

The precipitate in (a) was the tannate of the alkaloid; in (b) the picrate; (c) polyiodide (usually); (d) double 


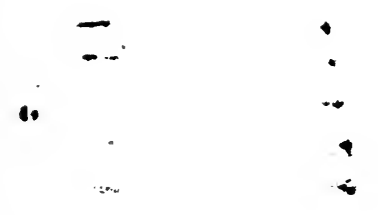


30

LABORATORY GUIDE IN

II. Alowing If th chloriforn

and sittin

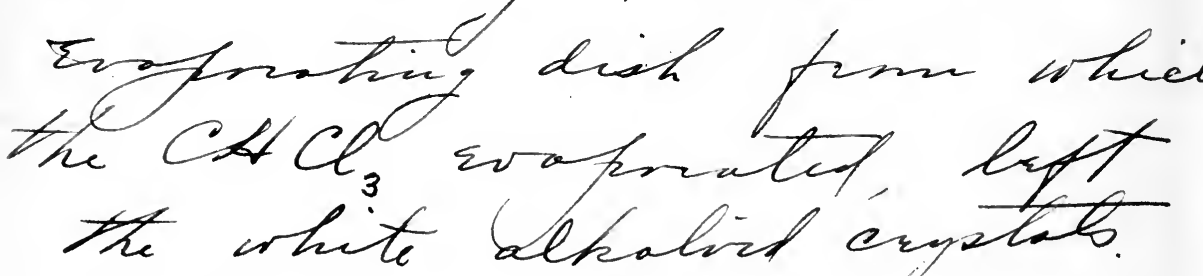

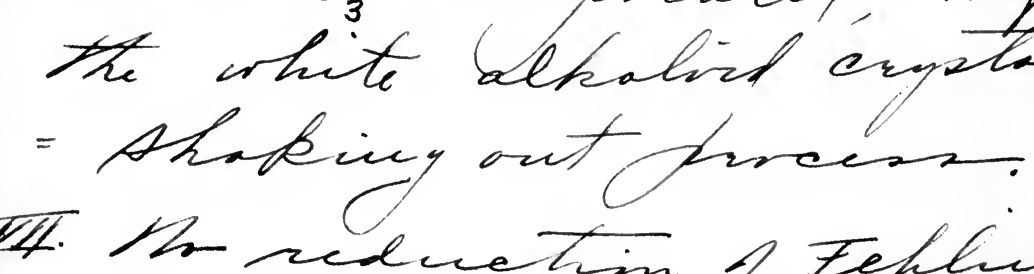

solutini

thin

I Fehluny:

shomet wo glverside 
iodide of the alkaloid and mercury; (e) phosphotungstate of the alkaloid. These five reagents, with a few others, of which the most important are gold chloride and platinum chloride, are known as the "alkaloidal precipitants" and they are largely used for the detection of the different members of this group.

VI. To ro $\mathrm{cc}$. of the quinine solution add potassium hydroxide until the reaction is alkaline. Now add 5 or ro cc. of chloroform and placing the thumb over the mouth of the test tube shake it vigorously for a minute or two or until the precipitate disappears. Set it aside for a short time until the chloroform settles in the bottom of the tube when it is to be drawn off from the water by means of a glass pipette and put into a clean evaporating dish and set aside to allow the chloroform to evaporate, leaving the alkaloid.

This experiment illustrates one of the methods used in separating an alkaloid from other bodies which are found present with it in the crude drug. It is known as the "Shaking out process" and will be more fully described later. (See nux vomica and belladonna.)

VII. Boil Io cc. of the quinine solution for a few minutes with a cubic centimeter of sulphuric acid; neutralize the acid with potassium hydrate and apply Fehling's test for glucose. ${ }^{1}$ Is there any reduction?

Absence of reduction shows no glucoside is present. Contrast next section (Glucosides).

\footnotetext{
1Fehling's test for glucose is carried out as follows: Mix in a test tube equal quantities (about I cc.) of two solutions, one, a solution of copper sulphate, and the other, a solution of potassium hydroxide and Rochelle salts. The resulting mixture is a clear, dark blue solution, which is to be boiled and the solution to be tested added to it. If glucose is present a red precipitate of cuprous oxide will be thrown down after the solution has stood for a short time. The precipitate may be clearly seen in the bottom of the test tube if a reducing substance is present.
} 
Examine specimens of other alkaloids and their salts :-

Strychnine, from the nux vomica bean (Strychnos nux vomica).

Morphine, from opium, the dried juice of the unripe capsules of the poppy (Papaver somniferum).

Caffeine, from the berry of coffee (Coffea Arabica), and from tea leaves ('Thea Chinensis).

Atropine, from deadly nightshade (Atropa Belladonna).

Berberine, ${ }^{1}$ from golden seal (Hydrastis Canadensis).

Coniine, ${ }^{2}$ from the fruit of the poison hemlock (Conium maculatum).

Nicotine, ${ }^{2}$ from tobacco (Nicotiana tabacum).

Notice that the names of alkaloids end in "ine," in Latin "ina," as for example, strychnina, morphina, etc.

\section{Glucosides.}

Next in importance to the alkaloids among the vegetable poisons rank the Glucosides. These are substances which break up when acted on by dilute acids or ferments, and yield as one of their decomposition products a sugar which in many cases is glucose ; in fact, glucosides may be regarded as salts of sugar. The other products differ in the different glucosides, in some cases being a volatile oil, in others an alkaloid, etc.

In the following experiments amygdalin will be employed. It is a glucoside which is found in bitter almonds, laurel leaves and in the bark of the Virginian prune or cherry.

Make $50 \mathrm{cc}$. of a $2 \%$ solution of amygdalin in water.

I. Apply Fehling's test for glucose (see page 31, foot-

${ }^{1}$ Berberine is one of the few colored alkaloids.

${ }^{2}$ Coniine and nicotine are the two most important liquid alkaloids. They contain no oxygen and are volatile. 


\section{EXPERIMENTAL PHARMACOLOGY.}


34

IABORATORY GUIDE IN

Eff. I. Ho reduetion If Felcing:

Lohetion showing that ghecoside

mas not hothen uf

that heree wr

mas fresert.

Epl.II Orsition necotins due

to gherse hisated from

the gluaside ify. Its 504

EtII: sec diagram $\rightarrow$

ExIV Enclsin huahs of

gherside and gins gherese hivee fositus reaction with Fillivipo sot. Briling kilb the funent and w heokicy uf- and wolution.

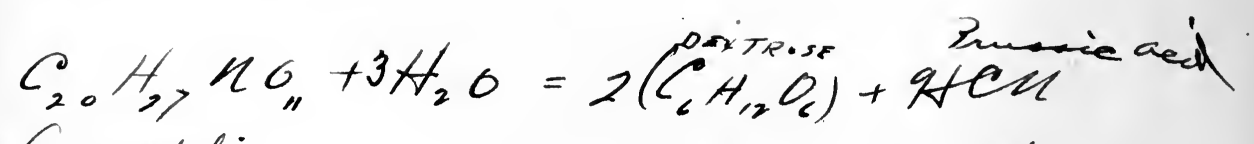

anyglalin $+C_{1} H_{C} \mathrm{O}+\mathrm{H}_{2} \mathrm{O}$ Benzaldinghe 
note) to $5 \mathrm{cc}$. of the amygdalin solution. Is a reducing substance present?.

II. Heat ${ }_{A}^{B}$ IO $^{\prime h} \mathrm{cc}$. of the amygdalin solution with I cc. of sulphuric acid (dilute) on a water bath for Io minutes. Neutralize with sodium hydrate and apply Fehling's test. Do you get any reduction? Compare with Exp. I, and explain.

III. Put about $5 \mathrm{cc}$. of the amygdalin solution into each of 5 test tubes and test each with the alkaloidal precipitants.

\begin{tabular}{|c|l|c|}
\hline & \multicolumn{1}{|c|}{ Reagent. } & Precipitate? \\
\cline { 1 - 2 } a & Tannic acid. & \\
b & Picric acid. & \\
c & Iodine in potassium iodide. & \\
d & Mercury-potassium iodide. & \\
e & Phosphotungstic acid. & \\
\hline
\end{tabular}

IV. Pulverize six bitter almonds in a dry mortar and note any odor present. Divide the powder into two parts placing one portion in a small beaker and add about Io cc. of warm, not hot, water to it. Boil about Io cc. of water in a test tube and add the second portion of the powdered almond to it and boil the mixture for two or three minutes. Set them aside for a short time and then see if there is any odor from either preparation. Test some of the fluid from each with Fehling's solution and see if any reduction takes place.

In the bitter almond, in addition to the amygdalin, is also found a ferment, emulsin. Explain therefore the presence of a reducing agent in one case and its absence in the other.

The odor found is due to the oil of bitter almonds formed by the decomposition of the amygdalin in the presence of 
water. This oil consists of benzaldehyde and prussic acid and is therefore extremely poisonous.

What reaction is characteristic of the glucosides?

Examine specimens of other glucosides:-

Salicin, found in the willow and poplar.

Digitalin, found in the fox glove (Digitalis purpurea).

Digitoxin, found in the fox glove (Digitalis purpurea).

The names of glucosides end in "in," in Latin "inum," as for example, salicinum.

\section{Volatile Oils.}

The group of volatile oils contains a large number of preparations which are extensively employed in medicine. They are also known as the Essential or Ethereal oils. They are found widely distributed in nature as the odor of the various plants and flowers is due to them or to their oxidized products. In their chemistry they differ greatly from the group of fatty or fixed oils from which they must be carefully distinguished, the latter being non-volatile. The volatile oils are not to be regarded as pure substances, like the alkaloids, but rather as mixtures of varying composition. Most of them are colorless when fresh and pure, but they tend to become colored after long exposure to light and air. In odor and taste they differ widely from one another, but in both cases these properties are generally characteristic of the individual oil. The majority of them are lighter than water, there being only a few heavier.

As a typical member of the group the oil of turpentine is to be employed in the following experiments. As a type of the fatty or fixed oils cotton seed oil will be used to illustrate some of the differences between the two series. 
EXPERIMENTAL PHARMACOLOGY. 
38

LABORATORY GUIDE IN

reatile vile we soluchle in alcohel, ether, Chlor form Cottm seed il and cusol wble in r t $_{3} 0$

Frited rils are cucotidble in $\mathrm{St}_{2} \mathrm{O}$ and $\mathrm{C}_{2} \mathrm{H}_{3} \mathrm{OAt}$, het solichle in $\left(C, H_{5}\right)_{2} 0$, CAtCl and oil of thitrueg.

III Ifp. itcaticy the irl sopprats it and the stain disapfen rith eothm seed il, the rith did wot ptreced as rapidly or as niveh as the ril of whtnery and dree not evatorate, henes the stain recceacis 
I. Solubility of volatile oils.

Into each of five test tubes put I cc. of the oil of turpentine and then add $5 \mathrm{cc}$. of the following reagents. Shake and note whether the oil is soluble.

\begin{tabular}{|l|l|c|}
\hline & \multicolumn{1}{|c|}{ Reagent. } & Solubility? \\
\cline { 2 - 3 } a & Water. & - \\
b & Alcohol. & + \\
c & Ether. & + \\
d & Chloroform. & + \\
e & Cotton seed oil. & + \\
\hline
\end{tabular}

II. Solubility of fixed oils.

Into each of 5 test tubes place I cc. of cotton seed oil and then add $5 \mathrm{cc}$. of the following reagents. Shake and note the degree of solubility as in I.

\begin{tabular}{|r|l|c|}
\hline & \multicolumn{1}{|c|}{ Reagent. } & Solubility? \\
\hline a & Water. & - \\
b & Alcohol. & + \\
c & Ether. & + \\
d & Chloroform. & + \\
e & Oil of turpentine. & + \\
\hline
\end{tabular}

What differences in solubility exist between the two series?

The two groups of oils resemble one another in leaving a greasy stain when dropped on paper, but that from the fixed oil is permanent.

III. a. Put a drop of oil of turpentine on glazed paper. Note the stain. Hold the paper from six inches to a foot above the flame of the Bunsen burner for a few minutes. Result? 
b. Repeat, using cotton seed oil, being careful not to use enough heat to char the paper. How does it differ from the previous experiment?

IV. Decomposition product.

a. Heat 5 drops of the oil of turpentine in a test tube. Note the odor.

b. Heat strongly 5 drops of cotton seed oil in a dry test tube. Note the odor.

In the latter case acrolein is formed from the partial decomposition of the fat and is recognized by its irritating and disagreeable odor resembling burnt fat.

V. Add I cc. oil of turpentine to $5 \mathrm{cc}$. water and shake the mixture well for a minute or two. Allow the oil and water to separate, and then draw off the latter with a pipette into a clean test tube. Note its odor and taste, which are due to the turpentine, of which the water has taken up a small amount, forming a preparation recognized in the Pharmacopœia as an "Aqua." These waters flavored by the various volatile oils are largely used to give a pleasant taste and smell to medicines.

The "Syrupi" are solutions of sugar and water to which is often added a small quantity of a volatile oil as in the aquæ.

Spiritus, spirits, are solutions of a volatile oil in alcohol (Exp. I b.) ; they are largely used in medicine as flavoring agents.

Examine specimens of the different volatile oils named below and compare them with the oil of turpentine as regards odor, taste, color, etc.

Oleum Menthæ Piperitæ (oil of peppermint).

“ Gaultheriæ (wintergreen oil).

“ Lavandulæ Florum (oil of lavender). 
I:XPERIMENTAL PHARMACOLOGY.

EffII Qil 7 flutury heated

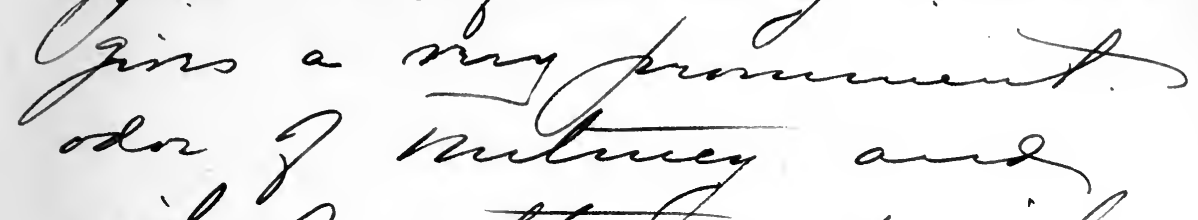

oil 9 cettron aced.

sins the divagnentle and initating ben $p$ acrlein

Eyt. I len and taste gnutung are fercystitle. 
42

LABORATORY GUIDE IN 
Oleum Eucalypti (eucalyptus oil).

" Caryophylli (oil of cloves).

Resins, etc.

Among the less important chemical compounds used in medicine are the Resins. This is a miscellaneous class characterized by the smooth, shining fracture. As a class they are insoluble in water, but soluble in chloroform, ether, the volatile oils and some of them in alcohol.

Examine the Resin of jalap.

Resin of copaiba.

Oleoresins are solutions of resins in volatile oils.

Examine Turpentine.

Burgundy pitch.

Copaiba.

Balsams are like oleoresins, but contain also benzoic and cinnamic acids.

Examine Balsam of Peru.

Balsam of Tolu.

Gum resins are mixtures of gums and resins, containing usually in addition some volatile oil.

Examine Asafœetida.

Gums are amorphous transparent substances belonging to. the group of carbohydrates. Some dissolve in water while others only swell to a jelly. They are insoluble in alcohol.

Examine Acacia.

Tragacanth. 


\section{Physiology of the Nervous System of the Frog.}

In order to study the action of a drug upon the nervous system of a frog it need hardly be pointed out that it is of prime importance to understand the physiology of the different parts of that system. To illustrate, a certain drug will depress the cerebrum, while a second drug will stimulate the spinal cord and a third may paralyze the peripheral nerves; now, only by knowing the normal functions of these divisions of the nervous system can we recognize and interpret the symptoms arising from an increase or diminution in their activity, and thereby locate the point of action of the drug employed.

First, examine the normal frog, observing its spontaneous movements and the method of leaping and what degree of irritation is necessary to make it move. Note also its coordination of the muscles in swimming; its recovery of balance when slowly turned on a sloping board, its recovery when placed on its back, its reflexes when the toe is pinched, the croaking when its back and sides are stroked, the rate of respiration and heart beat. (The latter can usually be counted when the animal is turned on its back and placed in a good light, a slight shadowy movement of the skin being seen in the cardiac region with each pulsation of the organ.)

Having studied the intact animal, separate the cerebral hemispheres from the optic lobes by thrusting the point of a scalpel through the roof of the skull on a line joining the posterior borders of the eyelids, gently rocking the scalpel from side to side so as to completely sever the hemispheres from their inferior connections. As will be seen from the 
EXPERIMENTAL PHARMACOLOGY.

45

Pesferation of fro was 6? hel nuivet and heart hat 32 fer muncele.

Atroteing on mperiging vides eansed crokt. Nimnuch pull croudiuatef rir surimuniy and recossy. fin. fosition is gucich Peumal If Cuchi hy serving then fim lihs canses in indriatrin of unseles. inobility to croak on and towning to the left cuticually.

Reyains

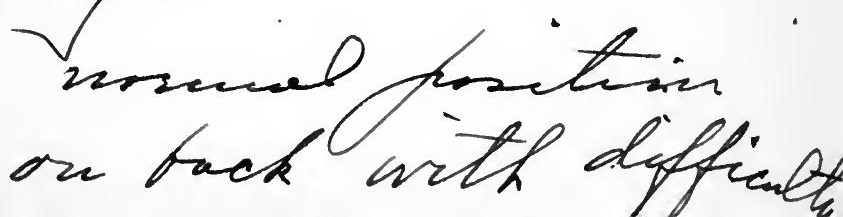

whenght on back with diffindt 
46

LABORATORY GUIDE IN

Reural if oftic liks.

Cundition secuced afuct the

sance sucepf that he seewed

to lose sighx and cntrol?

his head-corndivated

reflex was lists

Buflex fim piriaking toro and fin aced was noukerd

Westruetion of croh caured ale reflexis t stop Ey cupt finm slectrical stincation. Stearts ontiovef fraling. 


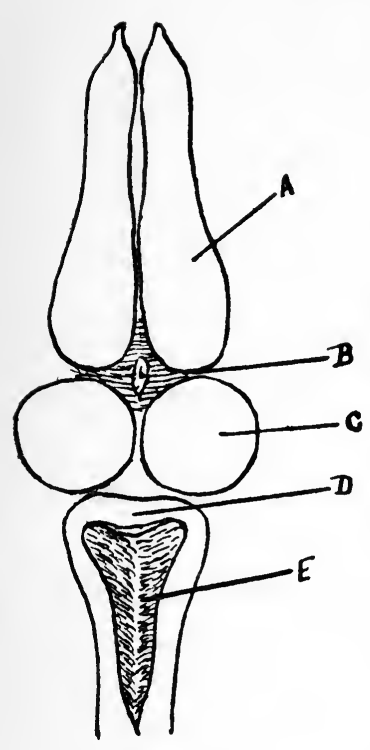

FIG. No. 4. Frog's Brain. a. Cerebral hemispheres; b. Optic thalami; c. Optic lobes. d. Cerebellum. e. Medulla. (Steiner)

accompanying figure, such a cut will also destroy the optic thalami and some symptoms will result from such destruction, but for all purposes here, the differences in results obtained are not important. After allowing the animal a few minutes to recover from the effects of the shock of the operation (which must be done in all cases) compare its condition with that of the normal animal.

Make full notes of all changes seen.

Next remove the optic lobes from the same animal by cutting as before with the point of a scalpel on a line joining the centers of the tympanic membranes.

These membranes are seen on the sides of the head posterior to the eyes as two flat circular surfaces about $3 \mathrm{~mm}$. in diameter. Wait a short time as before and then study the effects of the operation. Hang up the animal by means of a wire hook passed through the lower jaw and observe the reflexes on pinching the toes or on dipping the toe in very dilute acid (made by adding dilute sulphuric acid to water). Wash off the acid with water.

Using the same frog thrust a fine wire down the spinal canal so as to destroy the cord. Observe any change in the reflexes. What is the condition of the heart and respiration?

Examine the activity of the peripheral nerves in the follow- 
ing manner; hold the frog back upwards in the hand and apply the electrodes from the induction coil (tetanizing current) to the lumbar spine. Observe how long the muscles will stay contracted before fatigue sets in.

Dissect out the sciatic nerve by an incision along the posterior surface of the thigh and stimulate it with the electric current as before.

Lay a few crystals of sodium chloride on the nerve and moisten them with a drop of water. Observe any change in the muscles. Explain.

Expose the gastrocnemius muscle and stimulate it directly with the electric current and also with salt crystals.

Describe the functions of the different parts of the nervous system in the frog as learned from the symptoms arising from their removal. 
EXPERIMENTAL PHARMACOLOGY.

49

afflication of slectrodes to hunbes

Camper maskred cutraction so secuses hifore fuetijue setsin.

Atimulation of the scratie ness canoce intraction I) musctes, as also When jasturenen ens was otrintatey Hace cansed tiriteling and shilit cutractine due to the HaCl aborticing hursture ferin the veres 12 nuscle as the care may ts. 
50

LABORATORY GUIDE IN

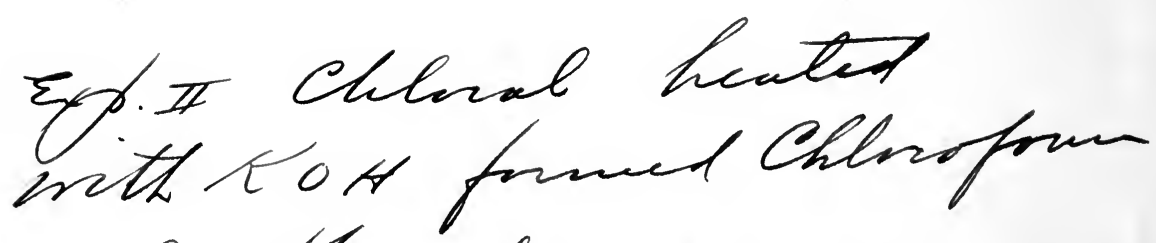
and the odor mas noticable sir the former 


\section{Soporifics or Hypnotics.}

Soporifics or Hypnotics are drugs which are used to produce sleep. They comprise a very large and important group of substances which are extensively employed in medicine. In their action they are closely related to chloroform and ether, but they are not used to produce anæsthesia in man owing to the fact that it is impossible to regulate sufficiently accurately the depth of the anæsthesia induced by them.

Chloral (chloral hydrate), the most important member of the "series, was introduced into medicine by Liebriech in I869, and as a pure hypnotic drug is probably the most reliable in use today. The other members of the group which are of greatest importance are Sulphonal and Paraldehyde.

Examine each drug as to appearance, odor and taste.

I. Examine the solubility of the following soporifics:

\begin{tabular}{|l|l|c|c|c|}
\hline & & Chloral. & Sulphonal. & Paraldehyde. \\
\hline a & Cold water. & + & + & + \\
b & Hot water. & + & + & + \\
c & Alcohol. & slight & + & + \\
d & Ether. & + & + & + \\
\hline
\end{tabular}

Wrap up a few crystals of chloral in paper, set aside and examine them after a few days.

In what ways would you think these drugs could best be prescribed in practice?

II. Put a few crystals of chloral in a test tube and add a small amount of potassium hydrate solution and heat gently. Note the odor of the fumes. What is formed? 
$\mathrm{CCl}_{3}-\mathrm{CHO}-\mathrm{H}_{2} \mathrm{O}+\mathrm{KOH}=\mathrm{H}-\mathrm{COOK}+$ ?

Chloral hydrate.

Potassium formate.

III. Select four frogs of about equal size and mark each frog in some way so that it can be recognized. (This is probably done most easily by tying a piece of string loosely around one of the legs of each animal.) Examine them, making a record of the heart rate and respiration in each.

Inject into the anterior lymph sac (page 15) of one frog $2 \mathrm{mg}$. of chloral dissolved in water; into the second, inject ro $\mathrm{mg}$. chloral ; into the third, inject $20 \mathrm{mg}$. ; and into the fourth frog, inject $50 \mathrm{mg}$. These amounts may be obtained most accurately by making 5 or Io cc. of a $5 \%$ solution and then diluting small quantities ( $\mathrm{I} \mathrm{cc.}$ ) so as to get the required doses.

Make a record of the time when each injection is made. Replace the animals under the bell jar and observe. Examine them frequently (especially those with the larger doses) as to spontaneous movements, co-ordination, reflexes, respiration, heart beat, etc.

Keep a careful record of the condition of each frog at each examination.

This can be done most systematically, not only in this experiment, but also in those to follow, by keeping a record of the time when each examination is made and the conditions found. By doing this it also gives some idea of the length of time it takes the drugs to act when given in different sized doses.

Such a record would start something as follows:

Feb. 10, '05-Frog. 23 G. String on right front leg.

$2: 30$-Heart 56 , respiration 30 per minute.

$2: 32$-Injected $20 \mathrm{mg}$. chloral in water into anterior lymph sac.

2:35-Frog quiet, apparently normal; reflexes, normal; heart, 54; respiration, 28.

2:40-Frog jumps if urged strongly, does not regain sitting position easily when it alights; has difficulty in turning over when placed on back. Reflexes lessened; heart, 40; respiration, 15, etc.

Such a record should give an accurate picture of the condition of the animal at each stage of the drug's action. 
EXPERIMENTAL PHARMACOLOGY.

53

$$
\begin{aligned}
& \mathrm{CCl}_{3} \cdot \mathrm{CAO} \cdot \mathrm{A}_{2} \mathrm{O}+\mathrm{T}_{\mathrm{O}} \mathrm{A}+\mathrm{heat} \\
& =A C O O N+C A C C_{3} \\
& \text { Polaserimate clelorpin }
\end{aligned}
$$

ELP.III. FAt $19-1906$

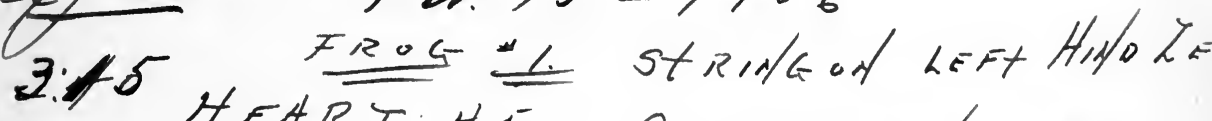

HFART 45 RESPIRATIOA - 60

3, to Inficted $10 \mathrm{mg}$ Chloval in water into ant.

3.50 Resp. 54 teant- Tw tim bach with difficulty. Riflexter

$4 .=$

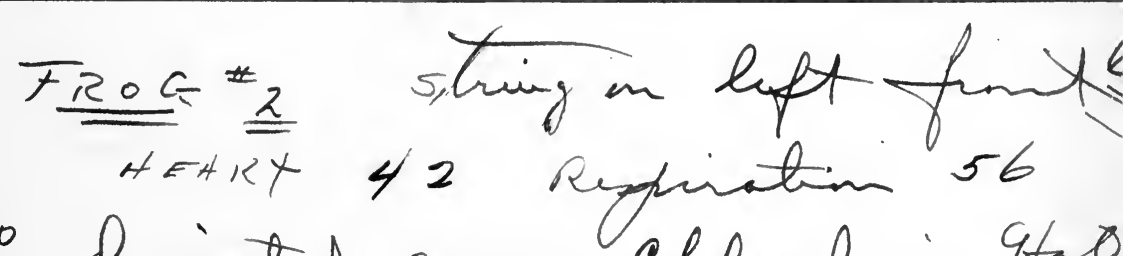

3:20 dujected zong. Chloral in 9tso lintel Aut. Eyough sace.

3.40 Frog quit neppiratin 30 heat 40 . Reflle slow fut marke

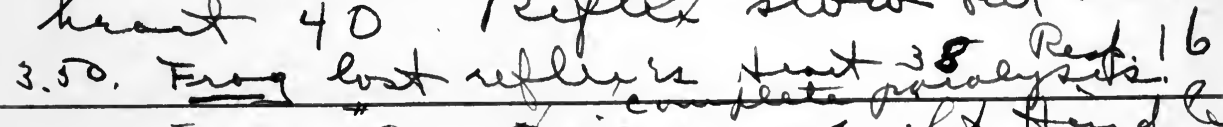
Feces s trivy on rught tind

3.25 dejiated $50 \mathrm{mg}$ chloral

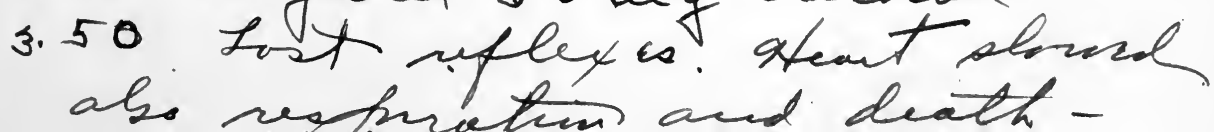




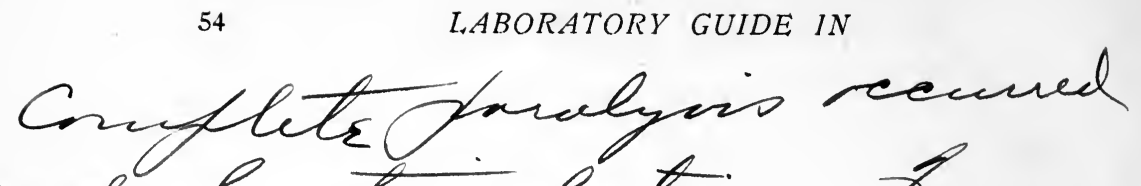

The bu stwinlation 8

thi twachar ase wa got that

the travolysio

curtal

Elarming the hant ohomel 12 fun micoste

Ex.IT dujuetion of faraldehyde canned trabysis, hat healt hat was not effected. The regpination tabling and the reflexes not responding.

to aciel or frivhing of ons curcult pars reflexs ontraction 8 naceles shoving that the cuetul nerms spstein wis iffected satter Hiven the serstiesal 
If complete paralysis occurs in any animal determine whether the action is on the central nervous system or is peripheral.

This is done by stimulating over the lumbar spine with the electric current and if the muscles of the leg contract the paralysis must be central; if they do not contract see whether the trouble is in the nerve or in the muscles by stimulating the latter directly with the current.

Also in an animal thus paralyzed, expose the heart (page I6) and examine and record its condition.

With the knowledge gained of the physiology of the nervous system study the records of the four frogs and from the symptoms recorded determine the points of action of the drug in the varying doses.

IV. Inject into the anterior lymph sac of a frog I cc. of a Io\% solution of paraldehyde in water. Compare the symptoms shown by this animal with those manifested by the chloral frogs in Exp. III. Pay particular attention to the condition of the heart, which can probably be sufficiently well studied (as to its rate) through the chest wall without exposing it. Keep the animal, as it will probably recover.

The difference in action of the two drugs upon the heart is explained by the difference in the constitution of the two molecules. The chloral molecule contains chlorine and these chlorine compounds all have a decided action on the heart muscle which is absent in the case of paraldehyde, whose molecule, $\mathrm{C}_{6} \mathrm{H}_{12} \mathrm{O}_{3}$, contains no chlorine. Compare the action of chloroform and ether on the heart (page 132 ).

Other members of this group are, Trional.

Tetronal.

Urethane.

Chloretone.

Chloralose, etc. 


\section{Therapeutics. ${ }^{1}$}

The chloral group of drugs depresses the central nervous system. For this purpose it would be used in cases of insomnia and of nervous excitement. Chloral and its allies are very valuable also in delirium and in various forms of convulsions, as for instance, those due to poisoning with certain drugs or those due to specific diseases (tetanus). In certain forms of insanity (mania) and in some nervous diseases with increased activity of the brain and spinal cord (chorea or St. Vitus's dance) the quieting effects of these drugs are largely made use of.

On account of its action on the heart chloral must be employed with care in persons who are already affected with certain forms of heart disease and its effect on this organ must also be watched with care in case of its prolonged use, or better, some non-chlorine containing soporific may be used in its stead.

\footnotetext{
${ }^{1}$ At the conclusion of the study of a drug group a short discussion of the therapeutic uses of the drugs contained therein will be given. Such discussions are not intended to give complete resume of all the therapeutic uses of the drugs studied, but only those will be mentioned as would be indicated by the results obtained in the foregoing experiments. The student will thus be shown how the knowledge gained by the science of Pharmacology is transferred to and made use of in the Therapeutic art; or, in other words, in rational medicine.
} 
EXPERIMENTAL PHARMACOLOGY. 


\section{Percolation.}

The U. S. Pharmacopœia gives the following definition of this process: "The process of percolation or displacement consists in subjecting a substance or mixture of substances, in powder, contained in a vessel called a percolator, to the solvent action of successive portions of a certain menstruum in such a manner that the liquid, as it traverses the powder in its descent to the receiver, shall be charged with the soluble portion of it, and pass from the percolator free from insoluble matter."

The liquid with the soluble portions of the drug dissolved in it is known as the percolate.

The drug to be percolated is usually ground to a fine powder in order to break up the vegetable cells, etc., so that the menstruum can penetrate it easily, and the menstruum is allowed to pass through the drug only very slowly, giving it time to dissolve the soluble constituents. To still further aid this penetration, a common plan is to moisten the powder with a small quantity of the menstruum and to allow it to remain tightly covered (macerate) for twenty-four or fortyeight hours before beginning the percolation. This also gives time for the drug to swell, as is likely to occur in some cases.

Percolators ${ }^{1}$ are usually cylindrical, or conical, and vary in size with the amount of drug to be exhausted. The lower orifice is to be closed with a tightly fitting cork,

\footnotetext{
${ }^{1}$ For all purposes in this course the cylindrical percolator of the following dimensions is large enough: Length, $28.2 \mathrm{~cm}$.; internal diameter at top, 3.7 cm.; capacity, $275 \mathrm{cc}$. It should be provided with an ordinary iron stand and ring, the latter being padded with cotton.
} 
which is best put in from the inside, but this is not necessary with the small percolators. Through this cork passes a small glass tube $(5 \mathrm{~mm}$. in diameter), the inner end of the tube being flush with the top of the cork. To the outer end of the tube is fitted a piece of rubber tubing. One method of regulating the flow of the percolate is to have this tubing of sufficient length to reach nearly to the top of the percolator and to have the free end fitted with another glass tube; the latter can be raised or lowered until the percolate escapes at the desired rate. The other method, which probably is not quite as good, is to have the rubber tube about an inch long and to regulate the flow by means of a small screw clamp.

Having fitted the cork and tubing the percolator is ready to pack if the drug has macerated the required length of time. The packing is done by means of a plunger, which is made by taking a cork with a diameter about half as great as the diameter of the upper opening of the percolator and sticking into it a glass rod which is a little longer than the depth of the percolator.

Place in the bottom of the percolator a small piece of absorbent cotton and press it loosely in place. Only a small amount of cotton should be employed, as its only use is to keep the powdered drug from passing down and clogging up the exit tube. Now put in the drug, packing it uniformly in place with the plunger. Do not use much force or the drug will be so tightly packed that it will be very hard for the menstruum to pass through. Very little more force will be required than would be given by dropping the plunger from a height of a few inches. Experience together with a knowledge of the physical and chemical constitution of the different drugs can alone teach how much force to employ. When the drug is in place cover it with a piece of filter paper cut 
so as to roughly fit its upper surface and weight it down with a small glass stopper. Pour in the menstruum to the top of the percolator and cover the latter with a small glass plate. If the lower orifice is open the menstruum will soon penetrate through the drug and begin to drop from the rubber tube. In cases in which the formula prescribes that the drug is to macerate for a certain length of time in the percolator, the clamp is closed, or if a long tube has been used the end is raised to a level which will prevent any outflow. At the end of the prescribed time allow the percolate to escape, receiving it in a bottle or flask. Regulate the outflow so that it shall not escape faster than ten or fifteen drops in a minute. It is best after once starting percolating to keep a layer of menstruum above the surface of the drug so as to prevent the access of air to its interstices. If the latter happens the drug contracts into irregular masses leaving furrows and fissures, and when more menstruum is added it will naturally flow through these channels and will not penetrate the drug evenly.

The U. S. P. gives general directions for percolation and also in the cases of the individual drugs specifies the size of the powder and the number of grams to be used together with the amount and character of the menstruum. It also gives directions as to the length of time the drug is to macerate before percolation.

Percolation is one of the most important processes employed in pharmacy, as by it are prepared extracts (page I79); fluid extracts (page 64); and tinctures (page I I9). In addition it is one of the steps employed in the isolation of alkaloids. 


\section{Nux Vomica.}

Nux Vomica, the seeds of Strychnos nux vomica, an East Indian tree, contains two alkaloids upon which the activity of the drug depends. By far the more important of the two is Strychnine which is present in from .9 to 2. per cent; the second alkaloid, Brucine, is present in slightly smaller quantities. In action the two alkaloids resemble each other very closely excepting that strychnine is about forty times as strong as brucine. For this reason the activity of nux vomica may be considered as dependent upon the amount of strychnine present and in the following experiments it alone will be considered.

Examine the nux vomica bean and taste a little of the powdered drug.

I. Place a small amount of the powdered drug in a beaker and pour upon it Io cc. of boiling water and let it stand until cold. Set this watery extract (infusion) aside and use it in the experiments given below (Exps. IV, V, VI). Place a drop of the infusion on the tongue.

II. Prepare the fluid extract of nux vomica in the following manner :

Nux vomica, No. 60 powder-50 grams.

Alcohol and water in the proportion of $2: \mathrm{I}$.

Moisten the powder with $25 \mathrm{cc}$. of the diluted alcohol and let it macerate in a well covered vessel in a warm place for 48 hours. Pack it in a percolator (see percolation, page 59) and gradually pour on diluted alcohol until the drug is exhausted. Reserve the first $35 \mathrm{cc}$. of the percolate and evaporate the remainder over a water bath to a soft extract. Dis- 
EXPERIMENTAL PHARMACOLOGY.

65

Ey. I. Hew Pruica has a ny hitte
taste

EfplI A fhid extract is a

tolution o a dicy in

which, ece. If the robution entains isram of the drug. 
66

LABORATORY GUIDL IN

A curition of ofisthotures result fom shychine Ansinin, due to tovio curtaretion

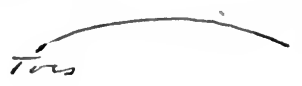

Eqp. III

alkaloid + $A_{2} 0=$ Aft. 8 alnaloid 7 alkaliid + Acil = falt sol. in $t_{2} O$ $\begin{aligned} S a l t+1 / H_{4} O A= & \text { Alkaloid folutin } \\ & \text { in } \mathrm{CA} \mathrm{Cl}_{3}\end{aligned}$

Tst for hucice by the addition of $\mathrm{AnO}_{3}$ thumad that riserive sas present a hijtt Clueng hed âfreaning. 
solve this extract in the $35 \mathrm{cc}$. saved and make the total bulk up to $50 \mathrm{cc}$. with diluted alcohol.

Define a fluid extract.

III. Reserve $5 \mathrm{cc}$. of the fluid extract made in Exp. II. and from the remaining $45 \mathrm{cc}$. isolate the strychnine in the following manner:-

Dilute the fluid extract with about its own volume of distilled water and pour it into a separating funnel and render it alkaline with ammonia. Add about $25 \mathrm{cc}$. of a mixture of chloroform and ether in the proportion of 2: I and shake gently for three minutes and set the funnel aside to allow the chloroformic solution to separate. When separation has taken place, draw the chloroform and ether off into a beaker and repeat the agitation of the watery extract, using a fresh supply of chloroform and ether. Draw this off as before into the beaker with the first solution. The watery extract can now be thrown away. Pour the chloroform and ether into the separating funnel, which has been washed, and add about $25 \mathrm{cc}$. of water and enough dilute $\mathrm{H}_{2} \mathrm{SO}_{4}$ to make the solution distinctly acid, shake gently for a few minutes and then separate the water and chloroform as before, placing the acidulated water in a flask. Repeat the agitation of the chloroform and ether with fresh acidulated water, adding the latter when separation has taken place, to the first lot in the flask. (The waste chloroform is to be poured into a large bottle provided for it and later redistilled.) If the acidulated watery solution is much colored it should be shaken in the flask with charcoal and filtered. Render the filtrate distinctly alkaline with ammonia and shake it out twice as before in the separating funnel, with small quantities of the mixture of chloroform and ether. When this has been done, pour this chloroformic solution into a glass evaporating dish, 
add to it 2 or 3 drops of concentrated hydrochloric acid and stir it well with a glass rod or put the mixture in a small flask and shake it well. The solution becomes milky from the formation of strychnine hydrochloride, which is thrown out of solution and may be separated from the chloroform by allowing the latter to evaporate spontaneously or by warming it gently over a water bath.

CaUtion.-In this process two things are of prime importance in determining the success of the manipulations:First, to agitate sufficiently the chloroform and ammonia or sulphuric acid solutions to allow thorough intermingling of the solutions. Three to five minutes should be devoted to each shaking. Second, make sure that the correct reaction is present. Test with litmus paper each time and after shaking for a minute or two, test again. (See Alkaloids, Exp. No. II.) The reaction must be distinct each time.

Explain why each step in the manipulation was carried out. (Compare Alkaloids, Exp. Nos. I, III, VI.)

The crystallized strychnine hydrochloride is to be used in tests given below. (Exp. Nos. IX, X, XII.)

IV. To a few cubic centimeters of the infusion made in Exp. I add a few drops of ferric chloride solution. The dark color of the mixture is due to the tannic acid present in the nux vomica bean uniting with the iron to form ferric tannate. (To a dilute solution of tannic acid add ferric chloride.)

V. Boil a small amount of Fehling solution and add 3 or $4 \mathrm{cc}$. of the infusion and see if there is any reduction.

NotE.-There is a reducing substance found in the nux vomica bean.

VI. Inject I cc. of the infusion into the lymph sac of a frog, and replacing the animal under a bell jar, observe the 
EXPERIMENTAL PHARMACOLOGY.

69

E.II. An ink-like color is froduced hy the addition $7 F_{2} C_{3}$ of the mex miea sifusin = furie tanate A sinilar reactim is trouglex

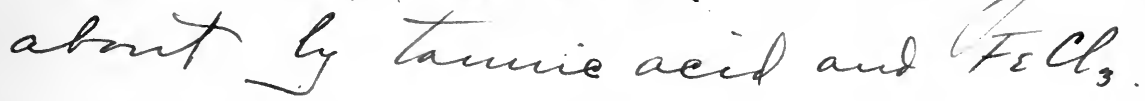

Ex. I. Fchlinizi Arhetion was resy. shiptly rediced by nuy osicia insion.

Ex. II

2.50 duficted cre. ant. buyth sae.

2.58 Conisins started. Hecat iritability to sliglitrax Incoh 2.60 Curching ticame trajer muscles teree. Heart hat trong 3.02 Reward cerchim. Mo bifference in iffuct. Wo reflexs tom aicid oz punchier of toro 3.05 Dumnd oftic lohe - no changs 3.10 thetrigat end. Ativinlati. Electricily caused cuitraction oflé. 
70

LABORATORY GUIDE IN

atplied to lunelas cond

shouriag, that cenctial

nermes systemenas iffected

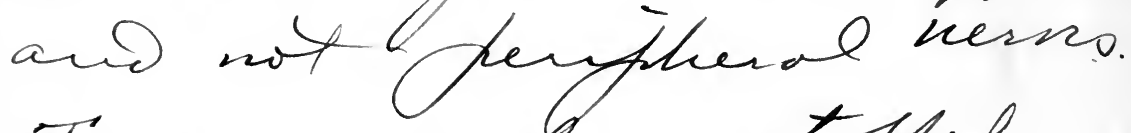

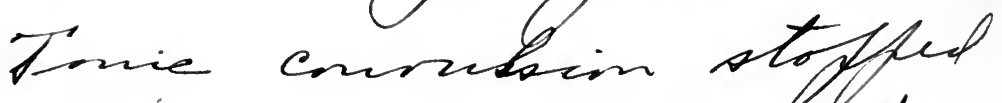
ythen remural of end.

Ef. IIII Elaborform lesscies

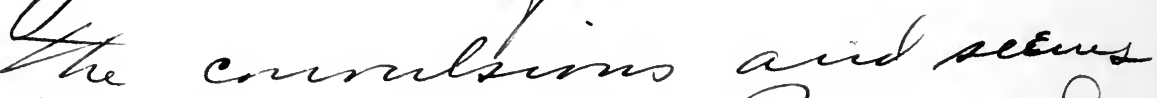

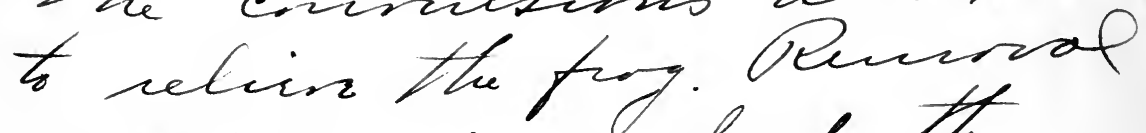

$\rightarrow$ Sat $\mathbb{Z}_{3}$ himp taen the

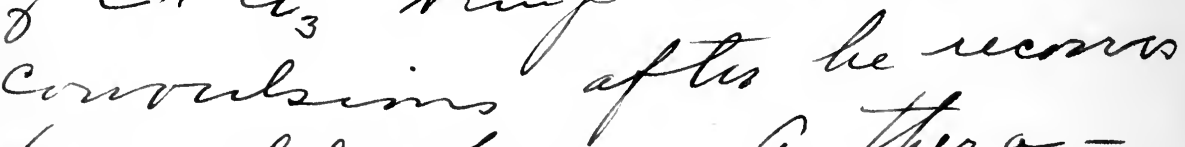

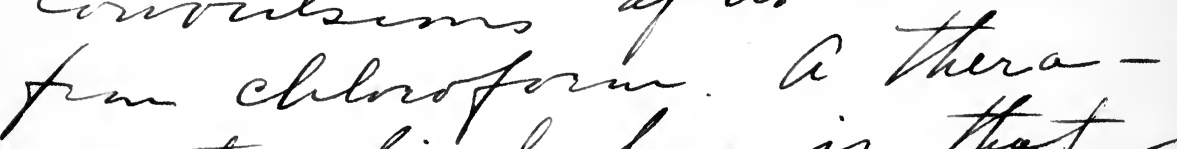
remtie tivef here is that in

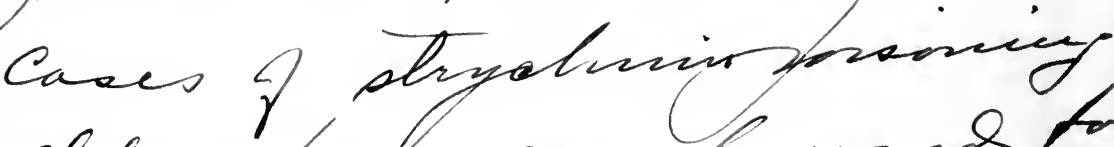

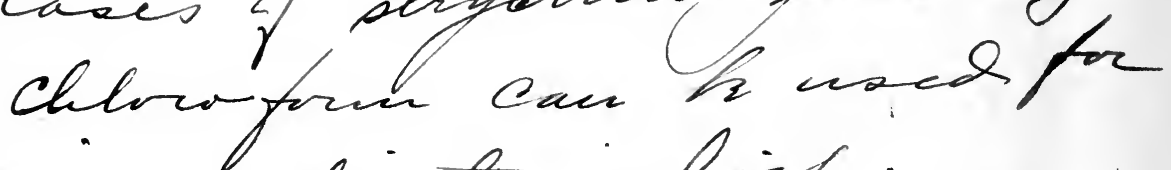
maned ate retirf.

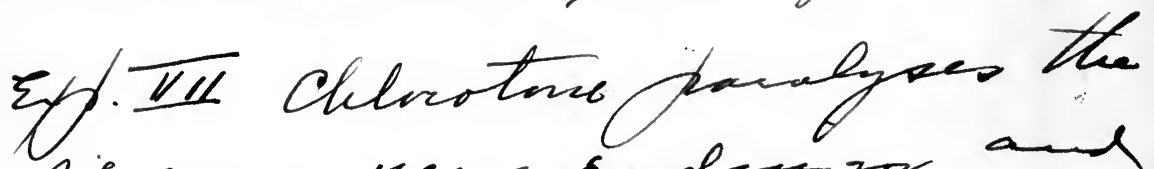
Aicury nespres

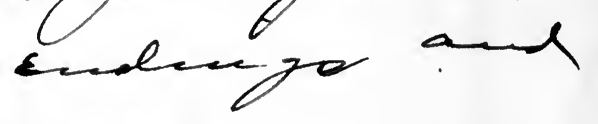

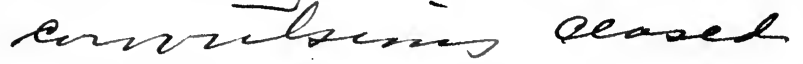


effect. Keep full notes. If any convulsions come on, after studying them carefully, try to find out the point of action of the drug by dividing off in turn the cerebrum, optic lobes, and finally destroying the cord, watching the effect of each operation on the symptoms. The strychnine convulsion is "tonic" as distinguished from the "clonic," which is caused by some drugs and occurs in some diseases. (Compare Thujon, page 79).

VII. Inject into the lymph sac of a second frog O.I cc. of the fluid extract (prepared in Exp. II) diluted with physiological salt solution to make a convenient amount. In this animal, as in the previous experiment, study the early effects of the poison before convulsions come on. Look for changes in irritability, in reflexes, etc. If convulsions come on, place the animal in a beaker which has been partly filled with water into which has been stirred some chloretone. (The latter drug acts in this case as a local anæsthetic.) Does it alter the character of the convulsions?

If paralysis should occur in any of the frogs used in these experiments see if it is due to central or peripheral action, as was done in chloral, Exp. III.

VIII. Inject into a small frog $\mathrm{I} / 20 \mathrm{mg}$. of strychnine. When convulsions come on place the animal under a bell jar with some absorbent cotton upon which has been poured some chloroform. Observe whether any change takes place in the convulsions. If they become lessened, remove the chloroform from the bell jar and allow the animal to recover from its effects. Do the convulsions return?

Is any therapeutic hint contained in this experiment? In experiments Nos. VI, VII and VIII, it was noticed that the same effects were induced whether the poison was employed as the infusion, as the fluid extract, or as the pure alkaloid. 
IXa. Put one or two crystals of the strychnine hydrochloride, prepared in Exp. III, on a porcelain cover and add to it two drops of concentrated sulphuric acid, mixing the two with a clean glass stirring rod. Put beside the strychnine-sulphuric acid mixture on the cover a minute crystal of potassium bichromate and with the glass rod (which has been washed and dried) draw the bichromate crystal through the strychnine mixture. Observe the changes in color. This "oxidation-reaction" or "fading purple test" for strychnine is most delicate and characteristic. It is said to be capable of detecting I/200ooth of a grain of the alkaloid. The order of the color changes is very important in making the test. The purple, which should first appear, changes to a crimson, which turns to a cherry red that is fairly persistent.

IXb. Carry out the same experiment as above, using manganese dioxide instead of potassium bichromate. Compare the results with Exp. IXa.

This reaction is obtained with almost any oxidizing agent, such as potassium permanganate, potassium ferricyanide, or lead dioxide. Manganese dioxide is one of the best as the changes in color take place very slowly, in some cases lasting some minutes.

If much brucine is present in the preparation, this color test is much interfered with and it may be impossible to get the correct changes.

IXc. After testing your own alkaloid with the two reagents named, make the same tests on some pure strychnine which will be furnished you. Compare the colors with those obtained with your preparation.

$\mathrm{X}$. Dissolve the rest of the strychnine hydrochloride (Exp. III) in about $20 \mathrm{cc}$. distilled water and employ it in the following tests. 
EXPERIMENTAL PHARMACOLOGY. 
74 LABORATORY GUIDE IN

IEp.

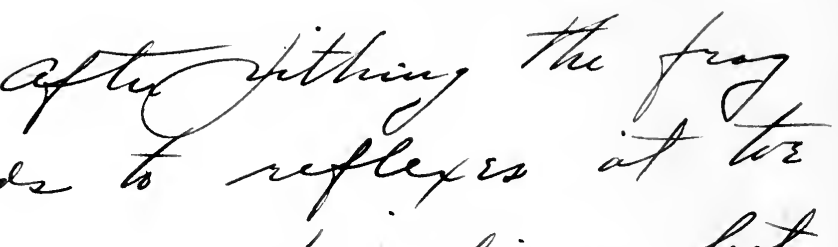

as acid

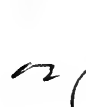

treceling, het

teid

drawice

fin acid as

stiffurs it whorle body and

st tans lige to full Ef tant. 
Inject $0.5 \mathrm{cc}$. of the solution into a frog. Pith (page 15 ) the animal and hang it up by the jaw on the hook for reflexes. When the strychnine symptoms appear test the animal's reflexes by pinching the toe and by dipping the foot in acid. How do the reflexes differ from those in a normal animal?

XI. ${ }^{1}$ The object of the experiment is to apply strychnine to the cervical portion of the cord while leaving the lumbar cord unaffected. Instead of pithing a frog as usual, remove the brain entirely by cutting off the head with a pair of scissors. Put the lower blade in the mouth and the upper blade over the top of the head, incline the scissors backward slightly and make a quick cut. Expose the heart and remove it from the body in order to stop the circulation. The upper part of the cord will be exposed by the cut first made and a drop or two of a moderately strong strychnine solution (o.I\%) is to be applied to it at short intervals. Test frequently the reflexes by pinching the fore and hind legs. If the experiment is successful a normal reflex should be obtained by pinching the toes of the hind foot, while a typical strychnine convulsions involving the entire animal should be brought on by irritation of the fore limbs.

How would such results help to locate the point of strychnine activity?

(.See Pharmacology and Therapeutics, Cushny, Edit. III, page 200.)

XII. Put the remainder of the solution of strychnine hydrochloride into 5 test tubes, diluting with a little water

\footnotetext{
${ }^{1}$ This experiment is not always successful when carried out by students and may be omitted if thought best. However, if successful, it is of so much interest and importance in locating the point of action of the drug as to merit a place in these notes.
} 
if necessary and test the solutions with the various alkaloidal reagents.

\begin{tabular}{|c|c|c|c|}
\hline & Reagent & Precipitate? & $\begin{array}{l}\text { Limit of delicacy of } \\
\text { reagent }\end{array}$ \\
\hline a & Tannic acid. & + mol & \\
\hline b & Picric acid. & tyole & $1-20,000$ \\
\hline c & Iodine in potassium iodide. & 473 & $1-100,000$ \\
\hline d & Mercury-potassium iodide. & + white & $1-150,000$ \\
\hline $\mathbf{e}$ & Phosphotungstic acid. & + white & $1-200,000$ \\
\hline
\end{tabular}

XIII. With a hypodermic syringe inject subcutaneously into a rabbit I $\mathrm{mg}$. of strychnine sulphate. Watch the effect on reflexes, etc. If convulsions come on control them with a few drops of chloroform on cotton held close to the animal's nose.

Compare the convulsions in this animal with those seen in the frog. Note the efficiency of chloroform in controlling the convulsions of strychnine.

\section{Therapeutic uses.}

On account of their intensely bitter taste, preparations of nux vomica are employed in cases of loss of appetite and malnutrition. By their action on the taste organs they probably increase reflexly the secretion of the gastric juice and thus aid digestion.

Strychnine is largely used as a stimulant to the central nervous system, being useful in various conditions in which depression of the brain or cord is found. It is employed in shock or collapse, and in failure of the respiratory or of the vaso-motor center. By stimulating the activity of the spinal cord to a slight extent it increases the "tone" of the muscles and of the blood vessels whose muscular coats are 
EXPERIMENTAL, PHARMACOLOGY.

77

El. II Ahros that the sffect o staychinice acte htomen the Arstivin not ganglia aced the auturin hoder cells.

Efp: XIII U VabbiX was effeatef bivilarly to fog. Piry invitable, follined Iy hice cumblams - the acuind hemeicy rejid with lack hut or head hut haek and leys stretckef Atraeglix out. Oneathing stoffud neacese of em traction

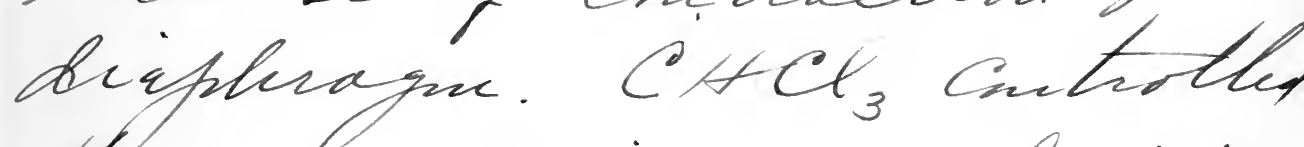
the ennutsons whech ceased after a tices rely to cune m a jan in tef animal Mas arencithe lazed 
78

LABORATORY GUIDE IN

Thusin

I. Cat mas mijected by neans 2 stimas ftik and jag.

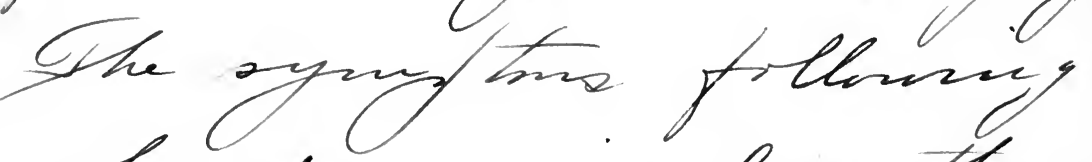

shond univation, then great distress trewers herve unaterlf and regfiration homes noy rofind as high as 200 fer nuinte: Cath dies after narked Clonie spasus frolound ly fors sation.

Thifin actet on amse Ant of the cerchine 2 lomer pait if the haice 
controlled by the spinal centers. Perhaps more than any other drug it deserves the name "tonic."

\section{Thujon.}

Thujon is the poisonous principle derived from the volatile oils of sage, tansy and absinthe. It is an isomere of camphor $\left(\mathrm{C}_{10} \dot{\mathrm{H}}_{16} \mathrm{O}\right)$ and may be taken as an example of that series, as it acts in the body. in a manner closely resembling that drug.

I. Place a cat in a cat-box (page 12) and pass a tube through the mouth gag into the stomach and inject by means of a pipette about I cc. of thujon. The end of the pipette containing the thujon is inserted into the opening of the stomach tube and the drug blown in and afterward washed down with some water. The stomach tube and gag are now removed and the animal is freed and placed in a cage. Compare the symptoms with those caused by strychnine in the rabbit. It will be seen that the convulsions caused by thujon are of a distinctly different type from those following a poisonous dose of strychnine. Those caused by the latter drug are tonic in type and are due to an action on the spinal cord. On the other hand, the thujon (and camphor) convulsions are "clonic" and are caused by stimulation of some unknown part of the cerebrum or lower part of the brain.

\section{Therapeutic uses}

Thujon is not employed in therapeutics. Its pharmacological action would indicate that it would be of value as a stimulant to the central nervous system and especially to 
the respiratory center. As such it would be of value in shock and collapse and perhaps in narcotic poisoning.

Camphor has long been used in shock and collapse.

\section{Opium.}

Opium is the inspissated juice obtained from the fruitcapsules of the white poppy (Papaver somniferum). The capsules are incised while yet unripe and the milky juice allowed to exude and dry by spontaneous evaporation until it becomes a brownish gummy mass.

The poppy is grown in Turkey, Asia Minor, Persia, India and China, but that obtained from Smyrna and Turkey is by far the most valuable. Persian and Indian opium is $1 \mathrm{~m}$ ported mainly as sources of the opium alkaloids and the Chinese opium is consumed entirely in that country.

Opium contains about twenty alkaloids of which Morphine and Codeine are the most important, and, indeed, it may be said that the value of opium depends upon the per cent of morphine which it contains. The U. S. Pharmacopœia specifies that the crude opium when moist shall contain not less than 9 per cent of crystallizable morphine, while the dried product must assay from $\mathrm{I} 3$ to 15 per cent. Opium from the different localities varies exceedingly in its morphine content.

Morphine was discovered in $18 \mathrm{I} 7$ by Seitürner, of Eimbeck, Germany, and was named by him morphium. It exists in the opium principally in combination with meconic acid, although some may be present as a lactate or a sulphate, both of these acids being found in the crude drug. Meconic acid is of most importance as it is strictly characteristic of 
opium and its preparations, and its positive detection is proof of the presence of some opium preparation.

In their solubilities morphine and codeine differ widely, from the other alkaloids, for morphine is almost insoluble in chloroform and only very slightly soluble in ether ( $\mathrm{I}-6 \mathrm{IO0})$; codeine, on the other hand, is more soluble in water than any other alkaloid.

\section{Morphine Reactions.}

I. Put a few crystals of morphine on a porcelain cover and add a drop or two of pure concentrated sulphuric acid and mix the two with a clean glass rod. No color should be formed if the morphine is absolutely pure, but occasionally a faint pink tint is seen. Heat the mixture very gently. At about $150^{\circ}$ a dirty green or rose-red color is developed, and on still further heating, the solution becomes almost black. Allow it to cool and add some water, when a greenish blue color appears which changes to green when ammonia is added in excess.

II. Put a few crystals of morphine on a cover and mix them with a drop or two of concentrated sulphuric acid as in Exp. I. To this add a drop of distilled water which will heat the mixture. Now treat with a drop of concentrated nitric acid, which should give a rose-red color, changing to brown.

(This reaction for morphine is very delicate, being well shown by 0.0 I milligram of the alkaloid.)

III. To a drop of concentrated nitric acid on a porcelain cover add a minute amount of morphine. An orange-red color is obtained, which changes to yellow on heating.

IV. (a) Mix a small amount of morphine with about twice its weight of cane sugar. By means of a glass rod add 
a drop of concentrated sulphuric acid. This should produce a purple color, changing gradually to blood-red and brownish-red and becoming an olive-brown on dilution with water.

(b) The above test can be modified as follows:-To a solution of morphine add cane sugar until the solution is saturated. Now pour this solution carefully down the side of a second test tube in the bottom of which is concentrated sulphuric acid. By inclining the second tube the solution can be poured in so that no mixture of the two fluids takes place and a purple or rose-red ring will form at their junction. This ring becomes more intense on standing.

V. Dissolve some morphine sulphate in a little water and add it to a solution of iodic acid. What color does it turn? Add to the resulting mixture some thin starch paste. What was the first color due to?

NorE.-In order to color the starch paste blue morphine must be present in the strength of $I$ to rovo. If no blue is obtained mix the solution well and pour down the side of the test tube some very dilute ammonia. A double ring will be see; at the junction of the two fluids; it will be blue below and brown above.

VI. To a few cubic centimeters of water add some morphine sulphate and to this solution add a few drops of ferric chloride solution. A deep blue color is obtained.

-Tat for tincture of opium diluted with a little water add two drops

- of ferric chloride solution. What color does the solution become? If the color is obscured by a precipitate, filter the solution.

VIII. Inject into the anterior lymph sac of a frog $25 \mathrm{mg}$. of morphine sulphate. Replace the animal under the bell jar and observe. Examine it from time to time, comparing the effects with those caused by chloral or strychnine. 
EXPERIMENTAL PHARMACOLOGY.

85

Ey II Additoin ? dodic acid ums sol. seddesh ray due to Dadice. Addetion 7 stwech parte gins beg blece.

Exly Menic acied reacturi grize a checolate color. ED TIII.

2.50 - Dyjected mith $25^{5} \mathrm{mg}$ mothine sulfhate 2.05. Reflexsolessued. Aetinty brsened. Vat I refiration beerave 3.00. Findeney to liv donnant. Retains most any preitrin foct in sy-eft when flaced on boik. Aminal is viry lofiy. 3.20 Regfiratim 20 der seend vy lor beflexes initafle Topping hach caused sy tursain lige.

- Arsitability nicreased. 
NorE.-This experiment (VIII) should be begun early in the laboratory session as it sometimes takes two or three hours for the full effects to appear.

Among the alkaloids found in opium which are of less importance than those studied is thebaine, which resembles strychnine very closely in its pharmacological action. In fact, many of the alkaloids of opium may be arranged in a series with the depressant, morphine, at one end of the series and thebaine at the opposite end.

IX. Inject subcutaneously into a dog $50 \mathrm{mg}$. of morphine sulphate and observe the effects.

$\mathrm{X}$. Inject 30 to $40 \mathrm{mg}$. of morphine sulphate subcutaneously into a cat. Put the animal in a wire cage and compare the effects with those seen in the dog.

The peculiar action of morphine on the cat is not confined to that animal, but is found in all the members of the cat tribe, and also in the horse and ass.

Examine a. crude opium,

b. powdered opium,

c. extract of opium,

d. tincture of opium (Laudanum),

e. camphorated tincture of opium (Paregoric),

f. powdered opium and ipecac(Dover's powder),

g. and codeine.

Note the odor of all the opium preparations and taste $d$. $e$, and $f$.

\section{Therapeutics.}

The symptoms induced by opium in man resemble more closely those in the dog than those in the other animals. It depresses the brain, and for this reason is used in cases of sleeplessness when this condition results from pain, because in depressing the cerebrum it acts on the pain centers, for 
which it seems to have a special affinity. In the dog the respiration was slowed in the later stages of the action from depression of the respiratory center, and opium preparations are often employed in cough mixtures to allay excessive irritability of this part of the medulla. The numerous other purposes for which opium and morphine are used cannot be illustrated experimentally.

\section{Curara.}

Curara, the South American arrow poison, varies in composition with the different localities from which it is obtained. The best known product comes from Guiana and is prepared from the bark of Strychnos toxifera, a tree native to that country. Curara as obtained in commerce consists of dark brown, shining, brittle masses which contain vegetable extracts in addition to two alkaloids, tubocurarine and curine. The characteristic action of the drug is dependent principally upon the first alkaloid mentioned, the latter having quite a different action and being much weaker.

Not only do solutions of curara ${ }^{1}$ deteriorate on keeping, but, what is of greater importance, the crude drug, as obtained in the market, varies greatly in strength, many of the preparations being entirely inert. There is no chemical method by which the activity of curara can be estimated; the only test is pharmacological. Each solution to be used has to be "standardized" by tests on animals and the dose necessary to produce characteristic effects ascertained.

I. Inject into a frog a poisonous dose of a standardized solution of curara. Study the effect on spontaneous move-

\footnotetext{
${ }^{1}$ The curara solution should be made up in physiological salt solution to which some thymol has been added.
} 
EXPERIMENTAL PHARMACOLOGY.

89

Curase Fit $\$ 6-1906$

2.1 Fl\%. Dijicted it juam

$3 / 4$ c. curara (standarbigal sol.)

2:20 Fing incetin and afferess defry

2:3e Nuable to tum ose fin tack

2:35 TAtaizing current canves

entraction for zo acenses.

Puflexis absent pin toppling rith finize.

2.40 nuscles retayed - bit still a refley from acid in frot

2:40 Antraction due to tetanzing current lasto 10 secusdo only $\therefore 50$ Cutraation ouly tar scench 2:55 to longer int enctraction due to curvity stersing that curara nust aef on ind llates of The nerns wir dell swobahlity. Egl. II showariey that it dis not wet m the wen truek. 
90

I.ABORATORY GUIDE IN

Ey. II. An a pithad farg w whieh me ley has hece ligated as ceftetin. She secatie nesw, offon sojection aftes aw while the tetanizing corrent caused a manked unumal custroctir if the ligated lig, while the other liy did not cespond rising to the actring the curarai Urm cutting of the ley, learsing the swak ot the seiatie nesn attakbed to the revined ley, it showid that by afyplying ecrasa to the tewch aind ficiding that it lad no aetion ne the wern trisch, that the action wast $k$ on the wers inds. Difping nuscles ir eurara and striulating gars no refley 
ments, reflexes, ability to turn over when placed on its back, and length of time leg muscles will remain contracted when stimulated by applying the tetanizing current to the lumbar spine. If paralysis should occur see if it is due to central or peripheral action (see Soporifics, Exp. III, page 55). This animal is to be replaced under the bell jar and kept moist, as it will probably recover in a few days.

II. Pith a frog, tie it on the frog board and expose the sciatic nerve and artery along the back of the thigh by a short longitudinal incision through the skin, and careful separation of the muscles with the dissecting needle. Separate the sciatic nerve from the surrounding tissues along a short distance of its course and then pass a thread under the nerve and tie it tightly around the rest of the thigh as high up as possible.

Free the animal, inject curara as in I, and from time to time compare the reflexes in the hind legs. Stimulate the lumbar cord with the electric current and note any differences between the two sides. See whether the reflexes remain equal in the two legs and whether cross reflexes can be obtained.

If the experiment is successful the operated leg should not be affected by the poison and should respond to electrical stimulation. In such a case cut off the leg just above the knee, leaving attached to it the sciatic nerve which has been carefully separated from the thigh muscles and cut toward the upper part of its course. Holding the leg preparation by the severed end of the femur lay the hanging sciatic nerve for a few moments in the curara solution. Remove it and stimulate it with the electric current. Does curara affect the nerve trunk? Dip the muscle in the solution and after a few moments stimulate the sciatic nerve again. Is there 
any change? If so, test the activity of the muscles by direct stimulation. Where does curara act?

Examine the heart of the animal in Exp. II.

Examine Curara.

\section{Therapeutics.}

The main importance of curara is in physiological experiments. It has been suggested, and in some few cases used, to allay the convulsions due to tetanus or to strychnine poisoning. It is not recommended for such conditions as its action is too uncertain and too dangerous.

\section{Nicotine.}

The alkaloid, nicotine, is obtained from the dried leaf of the tobacco plant (Nicotianum Tabacum) in which it is found to the extent of from 2 to 8 per cent. The pure alkaloid is a colorless, oily fluid, which, on exposure to air, becomes yellowish or brown. It has a strong, unpleasant odor resembling somewhat that of tobacco. When tobacco is smoked, only a small amount of the alkaloid appears in the smoke, the larger part is decomposed in the process and it may be that some of the effects of smoking are due to the absorption of these decomposition products rather than to the nicotine itself.

In an aqueous solution the alkaloid gives a strong alkaline reaction and it unites with various acids to form salts.

I. Inject I cc. of nicotine chloride solution ${ }^{1}$ into the anterior lymph sac of a frog. Observe the effects, noting especially the posture of the animal in the early stages of

\footnotetext{
${ }^{1}$ The nicotine chloride solution is formed by neutralizing a small quantity of nicotine with I-20 normal hydrochloric acid. Each cubic centimeter will then contain about $4 \mathrm{mgs}$. of nicotine.
} 
EXPERIMENTAL, PHARMACOI.OGY.

93

as the druy had acted ne the

cud flates of the nesses

aced

powblyged then, henen in got

nor resforse finen the cumit

grant hat has dicicared

to 1 gle numite.

$$
\text { licozin }
$$

Aujiction of necotive cause a draning logether of the whole hidy Giv the sarb stages of Mpreming. Jates

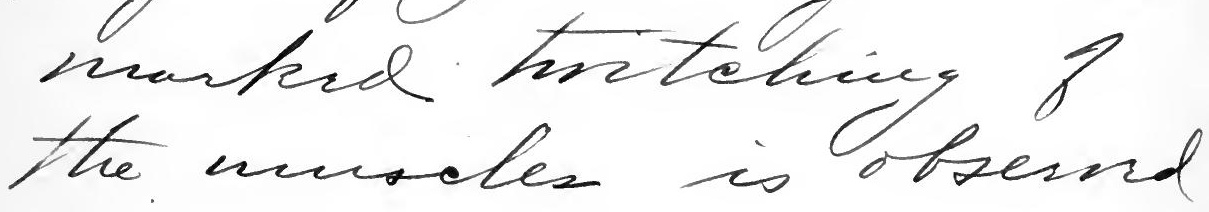
Pasulysis ther canes no Syotwer is at fiset Can whtely ravalyzad, then deriftieral haraly ris 
LABORATORY GUIDE IN

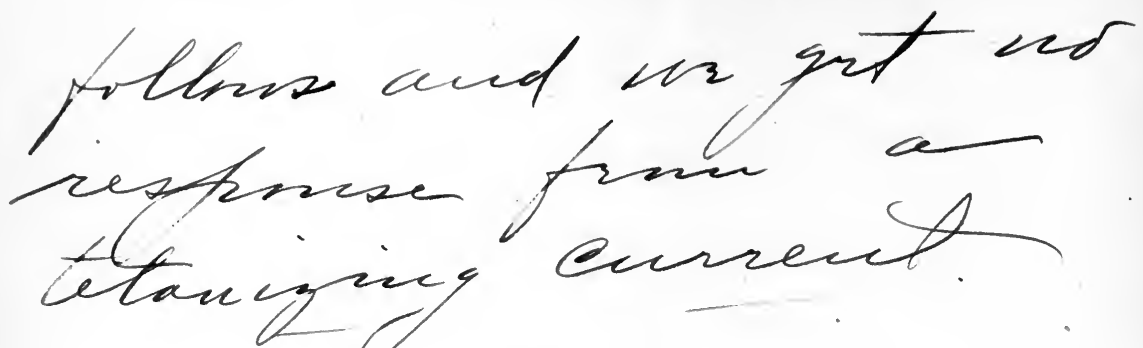

Pratries

Frog som ofter unjection tecones ner arfewart and chmosy and in fouffing heads in sne dircetion and foimpere to the side. Ifis reflexs are quial in reforse bit the reaning is Nuy slow. En bach he is afle to reyai rntion sly with difficilly. Muscles and sides are Ploated He secus to show Tric Cnosclacins Bunnal I crebsur, fitic thes and destruction of end mohe no difference in the respina 
poisoning as this is very characteristic of nicotine action. In addition, watch for any twitching of the muscles, and if paralysis should come on see whether it is due to central or peripheral action.

The action of nicotine upon the sympathetic nervous system is studied later (pages I87, I95).

\section{Therapeutics.}

Nicotine is not employed in therapeutics.

\section{Veratrine.}

Veratrine is an alkaloid prepared from the seeds of Asagrœa officinalis. It is a grayish powder which causes very marked irritation when even a minute quantity is inhaled.

The alkaloid is not of great medical importance but is of pharmacological interest, owing to a peculiar action it possesses which can be best studied in cold-blood animals, although the same effect may be elicited in mammals.

I. Inject I mg. of veratrine sulphate ( I cc. of O.I \% sol.) into a frog. Watch and describe the effects. Observe the awkwardness of its movements which appears in a few minutes. When the clumsiness is well developed locate the point at which the drug acts by removing the cerebrum, optic lobes, and finally destroying the spinal cord if the symptoms do not disappear earlier. Stimulate the sciatic plexus with single shocks from the induction coil, comparing the results with those seen in a normal frog. Finally, stimulate the muscle directly, using single shocks. At what point does the drug act? 


\section{Therapeutics.}

The phenomena seen in this experiment give no hint as to the use of the drug in therapeutics; it is employed for external application, and internally to a limited extent for its effects on the circulation.

\section{Caffeine.}

Caffeine differs from the other alkaloids in the fact that it is contained in a number of plants belonging to different species. It is obtained from the berry of the coffee (Coffea Arabica); from the leaves of tea (Thea Chinensis), besides being present in the kola nut of Central Africa; in the Paraguay tea and Guarana paste of South America and in the Apalache tea of Virginia and Carolina.

In some of these plants it is associated with two closely related alkaloids, Theobromine and Theophyllin, which resemble caffeine very much in some of their actions. All three alkaloids are derivatives of xanthine, which in turn is closely related to uric acid.

Caffeine is a very feeble base and forms salts only with difficulty and these salts, as a rule, are very unstable, being easily decomposed, even by water.

I. Test the solubility of caffeine in

\begin{tabular}{|c|c|c|}
\hline & Reagent. & Solubility. \\
\hline a & W ater, cold. & $t$ \\
\hline b & “ hot. & + \\
\hline c & Alcohol. & $t$ \\
\hline d & Chloroform. & $T$ \\
\hline
\end{tabular}


EXPERIMENTAL PHARMACOLOGY.

97

to the sinigle ghircho of the

inductint Cirl. Recumal

8 the current cansea a masked enctraction

Cafferive

Sheobmine ho frow n-Cerchun - otherinie

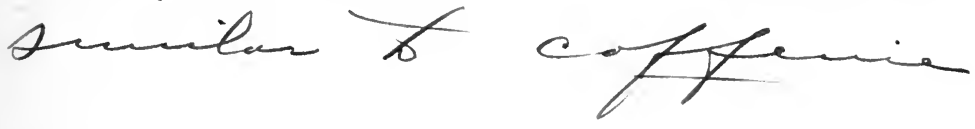


98

LABORATORY GUIDL: IN

Ep. III. A firple colos lenlegs due to avisurnicion

purpurate which shors Hismer of xacthin bodies.

Eff IV Fron shors nereased ivitubility and regfmos to refleyss quickly. Niscles hand it the tweh in entrost to muscles sis Mcativic prosining where flaceid. Rumal of hain made no tureptitle difference. bestruction of cnd steffind reflexes, and shring that efferive acted mainly on

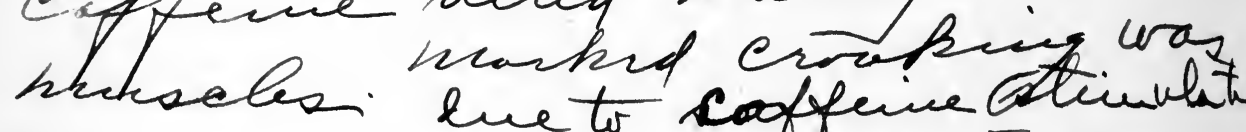

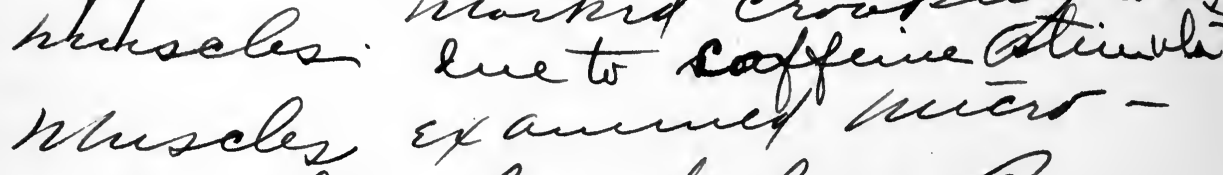
seciciall slined loss of striatim and maikent pacualisatin 
II. Apply the various alkaloidal reagents to a I\% soluof caffeine.

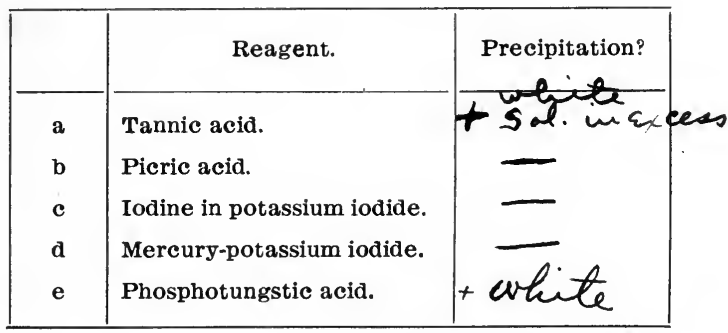

NorE.-In its reaction to $c$ and $d$ caffeine differs from all other alkaloids except theobromine and colchicine.

III. Murexoin test. To a few crystals of caffeine on the porcelain cover add a drop of concentrated nitric acid. Hold the cover with a pair of forceps some distance above the flame of a Bunsen burner and thus gently evaporate the mixture to dryness. Allow the residue to come in contact with strong ammonia fumes and note the color obtained.

This reaction is given by the members of the xanthine series and is practically identical with that given by uric acid.

IV. Inject $5 \mathrm{mg}$. of caffeine (I cc. $0.5 \%$ sol.) into a frog. Study and describe the symptoms comparing them with those induced by strychnine and veratrine. See whether the peculiar change in the muscles is due to an action on the nervous system by destroying its various parts as was done with veratrine. Excise a small piece of the affected muscle and tease it in salt solution on a microscopic slide. Examine it under the microscope, using the low power lens, and compare its appearance with normal muscle prepared in the same way. (For an explanation of the changes consult Pharmacology and Therapeutics, Ed. III, page 248.) 
The action of caffeine on the heart and on the kidney will be studied later (pages I39, I59, I72).

Examine the Coffee bean (Coffea Arabica);

Tea leaves (Thea Chinensis);

Caffeine citrate;

Theobromine.

\section{Therapeutic Uses.}

Caffeine is largely employed as a central nervous stimulant. The stimulant action on the highest parts of the brain is more noticeable in man than in the frog as the cerebrum in the latter is not as highly differentiated and the principal symptoms are due to cord action. In man, however, caffeine (usually taken in the form of coffee or tea) stimulates the cerebrum and the medulla and, to a less extent, the spinal cord. It is of great use in cerebral depression, such as is found in shock and collapse. In narcotic poisoning, also, its action on the medullary centers is especially valuable. Both caffeine and theobromine are largely used for their stimulant action on the kidneys by which they increase the urine. They are, therefore, of service in removing abnormal collections of fluid from the body, such as œedema or ascites, whether of cardiac or renal origin.

\section{Cocaine.}

Cocaine is the principal alkaloid derived from the leaves of Erythroxylon coca, a shrub which is a native of Peru and Bolivia and of other parts of South America. It is very unstable, being quite prone to undergo chemical change, so that preparations of the drug frequently contain the products of its decomposition. For this reason there are no very 
EXPERIMENTAL PHARMACOLOGY.

101

Cnelensonin
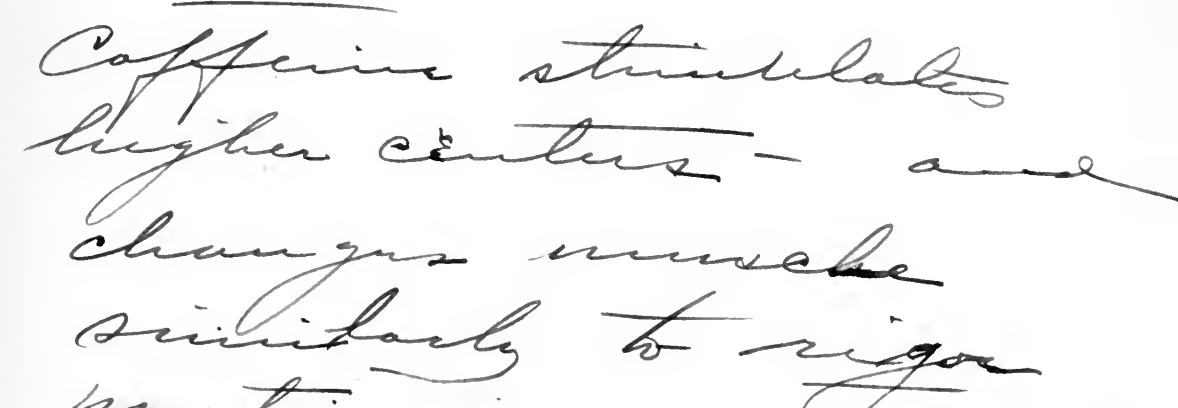

nuter.

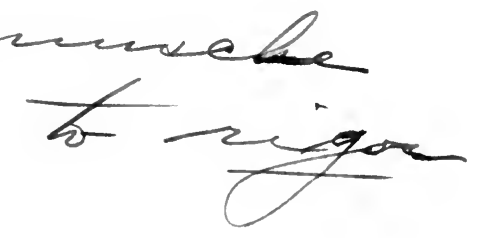


102

LABORATORY GUIDE IN

Scaive acts ne seusry nern-auds and as a result the Impue is insusible to tiveh, hiot and sibler tasto. and cold are noticrable in sfite of cocaine reat. ment 
delicate or distinctive chemical tests by which the drug may be identified. Being an alkaloid, it is thrown out of solution by the various precipitates of the group, and in its behavior to solvents it resembles in general the other alkaloids.

Cocaine has an important local action upon the terminations of sensory nerves, which makes it of very great use in medicine.

I. Take a piece of filter paper 2 or $3 \mathrm{~cm}$. square and moisten it with a few drops of a $4 \%$ cocaine hydrochloride solution and place it upon the tip of the tongue. Retain it in this position for two or three minutes and then examine the condition of that part of the tongue exposed to the drug, testing it especially as to the sense of touch, temperature, and taste. Contrast its effect on the taste of sugar and of nux vomica.

\section{Therapeutic Uses.}

Cocaine is most largely employed in medicine for its action in paralyzing the sensory nerve endings causing a local anæsthesia, permitting of operations being performed without pain.

\section{Cinchona.}

In the plants belonging to the cinchona family are a number of species the bark of which yields some twenty-five alkaloids. Quinine is by far the most important of these. The Cinchonacæ are natives of South America and, as far as is known, were introduced into medicine about 1630 .

Quinine may be regarded as a typical alkaloid and its behavior towards various solvents and precipitants has already been examined (page 24). . 
In addition to those properties, which it shares in common with the other alkaloids, it shows a few reactions of its own which are more or less characteristic.

Taste quinine and quinine hydrochloride.

I. Weigh out o.I G. quinine, the same amount of quinine sulphate, and of quinine hydrochloride and put them separately in three test tubes. Add Io cc. of water to each test tube and shake. Which is the most soluble? If either preparation does not dissolve in this amount of water, add more water, a definite amount each time $(25 \mathrm{cc}$.) and see if you can ascertain approximately the solubility of the different preparations.

II. To o.I G. quinine sulphate in a test tube, add about Io cc. distilled water and about I cc. of dilute sulphuric acid. Note the change in solubility compared with I and describe the solution formed. Solutions showing this peculiar fluorescence are also formed by a few of the other cinchona alkaloids.

III. Make a solution of quinine sulphate in a test tube, adding a drop or two of sulphuric acid if necessary. Add very carefully potassium hydroxide to make the solution as nearly neutral as possible (not alkaline!). Add a few drops of chlorine water and after shaking add ammonia to excess. Observe the greenish coloration of the solution or the green precipitate which will be formed if enough quinine is present.

This reaction is of importance, as it can be employed in testing for quinine in the urine in cases in which it is important to know that the drug is being absorbed.

IV. Take 0.3 to 0.5 G. quinine sulphate and test a sample of the urine passed within the next twelve hours for the presence of quinine according to the above method. Note 
EXPERIMENTAL PHARMACOLOGY.

105 Ey. I. Lumin hydroblaride Dnimin triffhate is soluble in 700 daits cold water and the alkolind Munin itrelf sin 1600 paits.

E.p.II. Additim o dilute Prso. causer a nunhel inerease. in the solublity and froduces a blusis solutim with a deculiar flowsencence Smivis. finmed

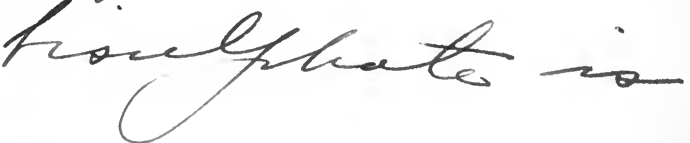


whether any symptoms on part of the eyes or ears are observed.

Examine Cinchona bark.

Tincture of cinchona.

Compound tincture of cinchona.

Therapeutic Uses.

The tinctures of cinchona are largely employed in medicine on account of their bitter taste; they are given especially in cases of lack of appetite. The other therapeutic uses of cinchona and its alkaloids cannot be demonstrated experimentally in the laboratory. 


\section{Emulsions.}

Emulsions are aqueous preparations in which oils, resins or insoluble powders are suspended by means of gummy substances (emulsifiers).

The object of emulsification is to render substances insoluble in water freely miscible in that fluid, so that any disagreeable taste may be more easily disguised and the absorption of the oil rendered more easy. In nature, some. emulsions exist already formed, as for example, milk, the juice of plants, the yolk of eggs, etc.

There are a large number of substances which can be used as emulsifiers, the most important being acacia. Condensed milk and yolk of egg are superior to acacia for this purpose, but possess the disadvantage of becoming stale.

In some substances, as for instance in gum resins, the gum needed to form an emulsion is found present with the resin. In the seeds of some plants albuminous substances are found and these act as emulsifiers of the oils present in the seed, rendering the addition of gums unnecessary.

The various types of emulsions are prepared according to the following directions:

I. Seed emulsion prepared from bitter almonds.

Take four or five bitter almonds and remove their skins. This may be done in two ways. They may be dropped for a few moments in very hot water and then in cold, when the skins can be slipped off. The danger with this method is that the boiling water may destroy the ferment, emulsin, which aids in the emulsification. To avoid this, the seeds 
may be soaked in lukewarm water for half an hour, or until their skins are loosened.

Break up the seeds and put them in a clean mortar and add a small quantity of water (one part to ten of seeds) and with the pestle rub the seeds up into a thick, creamy paste which shall be free from lumps. More water can be added now, gradually, until a milky solution is formed, which may be strained if necessary.

II. Emulsion of a gum resin.

Prepare $100 \mathrm{cc}$. of the emulsion of asafœtida according to the U. S. P.

III. Emulsion of a fixed oil.

Among the various methods employed in making emulsions, that known as the Continental is probably the most satisfactory, and is to be used in the following experiment.

Prepare $60 \mathrm{cc}$. of a $50 \%$ emulsion of castor oil.

In this method a primary emulsion or nucleus is first formed with certain proportions of the ingredients and this nucleus can then be diluted with water without the fear that separation will occur.

The proportion by weight is as follows:

Oil ..................... 4

Water ....................... 2

Gum (powdered acacia)............ I

Using this formula, calculate the amount of each ingredient needed and weigh them out carefully in clean vessels. Pour the oil into a clean, dry mortar and add the acacia, and with the pestle stir the two together rapidly until a uniform mixture is obtained. (This must be done quickly, as otherwise the oil and acacia remain in contact too long and the latter tends to become hard and insoluble. The object is merely to get each particle of gum incased in oil.) To the 
oil-acacia mixture add all the water (as determined by the above formula) and triturate the mixture rapidly until it becomes a thick, white, creamy emulsion. In the trituration, which should take from 3 to 5 minutes, no pressure is needed, but a rapid motion is very important. The pestle should be held loosely between the thumb and first two or three fingers and the motion given not only from the shoulder and elbow, but also from the wrist and fingers. It is best to move the pestle always in one direction, but it is not essential to do so.

When the nucleus is complete it can be poured into a bottle and water added to make up the required bulk. It should then be well shaken.

Such an emulsion may separate after some hours into two layers without showing any separated oil. Shaking will restore the uniform appearance. Such separation is entirely analogous to that which occurs in milk when the cream rises to the surface.

Emulsions can be flavored by various agencies, such as the volatile oils, but, as a general rule, some of the less powerful flavors will disguise the taste of the oil better, as for instance, liquorice extract, coffee, vanilla, or chocolate. They may be sweetened by small quantities of sugar or saccharin.

Acids, alcohol, or glycerin, if added in any except the smallest quantities, cause the emulsion to separate (break).

\section{Pills.}

Pills are spherical or ovoid masses of medicinal substances of a size convenient for swallowing. In weight they should not exceed 0.3 G., the average being about $0.2 \mathrm{G}$.

This method of administering solid medicinal substances 
EXPERIMENTAL PHARMACOLOGY. 
114

LABORATORY GUIDE IN 
is perhaps more common than any other, partly on account of convenience and also because substances which have a disagreeable taste may be given most agreeably in this way. Drugs which are corrosive or are very deliquescent or which have to be given in very large doses should not be given in pills. Those which are best suited for administration in this form are powders and extracts.

The first step in pill making is to form the pill mass, which should be of doughy consistency but not sticky. The mass consists of two parts; the active ingredients which are to be incorporated in the pill and some substance (the excipient) which will give the proper degree of consistency and adhesiveness. The excipient will vary with the character of the active ingredients. Some of the powdered extracts only require water to give them the proper consistency, while dilute alcohol may be needed in other extracts. Some fluid preparations may be made into pills by using an inert powder and on the other hand a non-adhesive powder may be made into a pill mass by the use of soft extracts or by the use of such an excipient as a combination of glycerin and tragacanth (glycerite of tragacanth). The choice of an excipient is very important, as it largely determines the usefulness of pills if they are kept for some time. For example, a pill made with acacia as excipient may become so hard that it will pass through the body unchanged, while with other excipients the pill may dry out and crumble to pieces after they have been made for a short time. The formation of a pill mass may be learned best by filling the following prescription, which calls for ten pills to be made from a gram of extract of gentian.

R. Extracti Gentianæ, I.

Divide in pilulas, No. X. 
Counterpoise two slips of paper on the scale pans and weigh out the correct amount of extract, which is then transferred to a mortar. (If some of the extract sticks to the piece of paper moisten the opposite side of the paper with water and wait a few moments, after which the remains of the extract may be easily scraped off.)

Make the extract into a pill mass of the character described above. If it is too hard add a little water or dilute alcohol; if too soft add a small quantity of a powder, such as starch or the powdered extract of liquorice. Triturate the mass thoroughly so as to get the two substances uniformly distributed through each other. When the mass is completed, work it up with the hands into a short cylinder and transfer it to the pill slab, over which has been scattered a small quantity of a dusting powder, such as lycopodium. Roll out the mass with the wooden roller into an even cylinder of the right length to correspond with the scale on the slab (in this case roll out to 10), taking care that the ends of the cylindrical mass are "squared up." With the cylinder over the scale, cut it with the spatula into the required number of pieces, taking care that the spatula is always held at right angles to the mass. The little sections of the pill mass are now to be moulded with the thumb and fingers into spherical shape and then placed in the pill box with a small amount of lycopodium and shaken about so that they may be completely covered by powder which will prevent them sticking together. Discard the excess of powder.

To mask the taste of the pills they are usually coated with some substance such as gelatin, sugar, chocolate, etc.

Examine the pills after a day or two and see if they have retained their shape or if they have flattened out. Weigh five pills and see how nearly they correspond in weight. 
EXPERIMENTAL PHARMACOLOGY. 
118

LABORATORY GUIDE IN

regitalis

I. A tircture is an alcobolie solutin of the non rolatile phituin

f a berug

II A clnuly frecifilate frous ufm standing.

It a dack grumish-blue color

shond tresence of Tarwie acid

IL tha precifitate frimed ohorning

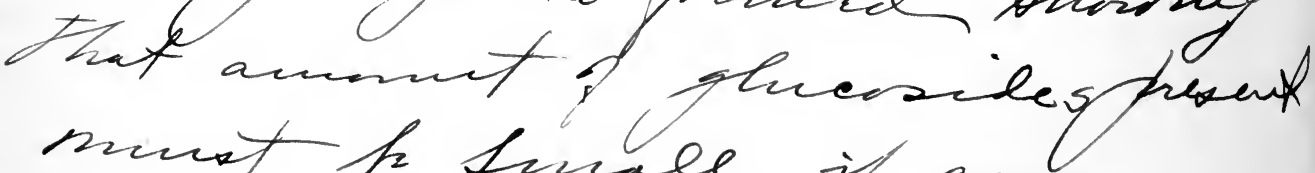

mut to tinale if auy

I ho precipitate was frined

meicating that digitalis is wh an alkalind m dres i Entain an aldabid. 


\section{The Digitalis Series.}

This series embraces a large number of drugs which resemble each other in their pharmacological action. While they act on various organs in the body, the cardiac action is characteristic of the group and distinguishes it from all others. The members of the series are derived from plants widely distributed in nature and as widely separated in their botanical relationships.

The most important is digitalis, which is obtained from Digitalis purpurea (purple fox glove); strophanthus from Strophanthus hispidus; and squills from Scilla maritima.

I. Prepare the tincture of digitalis according to the U. S. $\mathrm{P}$., using $5^{\circ} \mathrm{G}$. of the powdered drug and the proportionate amount of dilute alcohol.

NoTE.-For the strength of "dilute alcohol" consult the U. S. P. under "Alcohol Dilutum."

Define a tincture.

This tincture is to be used in the following experiments:

II. To $5 \mathrm{cc}$. of the tincture add $5 \mathrm{cc}$. of distilled water. Is a precipitate formed? Cork and set aside the mixture and examine it after a few days.

III. Examine the tincture for the presence of tannic acid by adding ferric chloride.

IV. To $5 \mathrm{cc}$. of the tincture add $3 \mathrm{cc}$. of tannic acid solution and let it stand for a time. Is a precipitate formed?

(Digitalis "contains glucosides some of which are precipitated by tannic acid.)

V. To $5 \mathrm{cc}$ : of the tincture add a few drops of mercury- 
potassium iodide. Is a precipitate formed? What does the result indicate?

VI. Evaporate over a water bath Io.cc. of the tincture to about one-half its volume and then make up the concentrated tincture to the original bulk by adding physiological salt solution.

Now, pith a frog and tie it on a board. Expose the heart and inject into a lymph sac I cc. of the modified tincture. Record all changes in the heart.

Describe any change in the rate of the organ and also any differences in the size of the various chambers or in their manner of contracting or dilating.

VII. Pharmacological assay of tincture $^{1}$ of digitalis.

Digitalis preparations vary considerably in their strength and it is impossible to standardize them by any chemical means such as can be employed in the cases of those drugs whose activity depends upon alkaloids which may be isolated in pure form and weighed.

It is very hard to isolate the glucosides in pure form as they are likely to break up, making the results obtained very unreliable. For this reason a pharmacological estimation of the strength of a preparation is employed as follows:-

Evaporate Io cc. of the tincture over a water bath to about half volume and then make it up to the original volume by the addition of physiological salt solution. Select 3 frogs of about the same size, weigh them carefully and mark them with string so as to be able to identify them. Into the anterior lymph sac of one of the frogs inject by means of a glass pipette $0.3 \mathrm{cc}$. of the modified tincture diluted with

\footnotetext{
${ }^{1}$ The assay of the tincture may be performed by one-half the class while the infusion of digitalis (page 124) is assayed by the remainder.
} 
EXPERIMENTAL PHARMACOLOGY.

Eff.III - m weyt frage (122) 
122

LABORATORY GUIDE IN

III

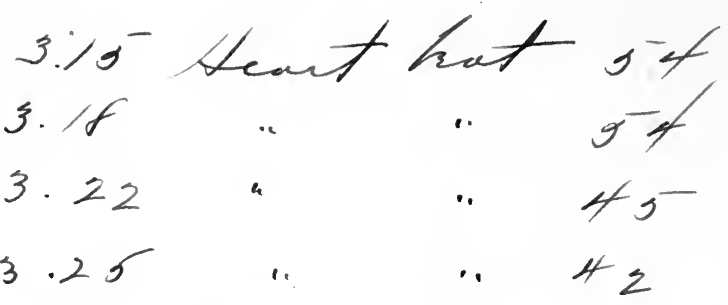

Antractines oting-nicicle

groving dwalk than insual and auriles bistereded.

3:28 Acart hat 24 - Pentivide.

sumblen and Eytansin in biastole slijht Auriolegreath diotured. Menticiele apguars irhite in syotole.

3:30 Acartfrat if - Prutriel nor entracted and iregular in sjoto not always folloving aurcular syotole

3:33 Heart but 19-. Aryan Ins now elevate itrelf funther, searcely altaring it prisitim 3.36. Heant trat 9. Aurich bating
turice to rintricle na

3:3 \& Beat 6-Potims Prntrically 
salt solution; into frog No. 2 , inject $0.2 \mathrm{cc}$; and into the third frog, o.I cc. (These small quantities may be most accurately measured by diluting the modified tincture still more with salt solution and then injecting the proportionately larger dose.)

Keep a record of the time when each injection is made. Replace the frogs under the bell jar and at the end of one hour from the time of each injection examine the condition of each frog's heart. Pith the animal if necessary, tie it on the frog board and expose the heart according to the usual method. To have a correct "end reaction" the heart should have just ceased beating with the ventricle in systole and the two auricles markedly distended with blood. (Compare Exp. VI.) If all three hearts are still beating when they are examined the doses were too small and must be increased in fresh frogs of corresponding weight. If, on the other hand, the frogs have been dead for some time, the doses were too large and must be made smaller in other frogs.

For moderate sized frogs ( $15-20$ G.) the toxic dose will probably be between the limits given, viz.: $0.3 \mathrm{cc}$. to $0.1 \mathrm{cc}$. By varying the quantity given the standard for a frog of a certain weight may be ascertained.

Calculate the dose of your tincture necessary to kill a standard frog of $20 \mathrm{G}$. weight in an hour. Why did you evaporate the tincture to one-half its volume?

The method of assay described is of considerable importance as it is employed by pharmaceutical firms for the standardization of many cardiac remedies.

The remainder of the tincture is to be saved to be used in subsequent experiments on blood pressure, etc.

The effects of digitalis on the mammalian heart and on the arterial blood pressure are studied later. (Exps., pages I59 
and $\mathrm{I}_{5} \mathrm{I}$ ). Its effect on the excretion of urine (diuretic action) may be studied in the rabbit (note, page I75), and the vascular changes in the intestinal and renal vessels according to directions given on pages 227 and 232).

\section{Infusion of Digitalis.}

Another preparation of digitalis which is largely used in some parts of the world in place of the tincture and which it resembles in most of its actions is the Infusion.

I. Prepare the infusion of digitalis according to the U. S. P.

Define an infusion.

II. Test the infusion for glucosides with tannic acid.

III. Fill a test tube about half full with the infusion, place the thumb over the mouth of the tube and shake it up thoroughly. Note the soap-like character of the foam. The infusion contains a glucoside, digitonin, which possesses the property of forming a frothy solution and of holding insoluble bodies in suspension.

IV. Pith a frog, tie it on the board and expose the heart as usual. Inject into a lymph sac I cc. of the infusion. Compare the effects with those noticed in the experiments in which the tincture was employed.

V. See foot note, page I20.

Assay the infusion of digitalis by the method described under "Tincture" (Exp. VII, page I2O), employing, instead of 0.3 cc., 0.2 cc. and 0.1 cc. of the tincture, 2 cc., I. 5 cc. and $\mathrm{I}$ cc. of the infusion. Also, in making the assay, it will not be necessary to evaporate the preparation as was done with the tincture. Why?

VI. Save about Ioo cc. of the infusion and examine it 
EXPERIMENTAL PHARMACOLOGY.

125

hat at racidon-syutote mug fint

4.2 Lost nutricilar syetrle

Fry dies with rintrick greatly contracted and aurciles groatly

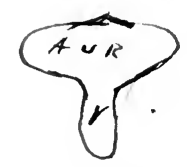

Wigitalis acts dircetty me heait nuscle. Lisons the dilatation and canses a otinger Cuctraction-

$$
\text { IAFUSIOI of DiGtial is }
$$

I Au nufusin is an aguedus solutini $f$ a druy, the actars priciple' o which has tere obtanued by tominicy triticy uater mis the cicle drily.

Eft. If a Otraifilate showed that a ghenvide

Ef? II Froth truned lue dejitanic a gleccoside 
126

LABORATORY GUIDE IN

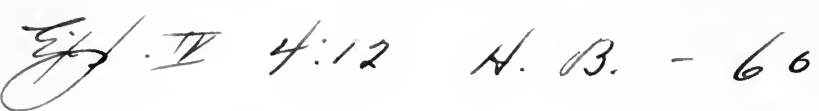

H. 18 . .

4.23 ". 45 - Frodual

decrcase in hat rith entrastir

$\eta$ renticicle and suyongenent

Pinilar to actin f Aireture

Assay. of rigitalis nifuoim

Frog mighing so g. died fin a dise of 2 c.c. Lijitalio the heart stiffing it hat

$20: \chi:: 30: 2$ c

$$
\begin{aligned}
30 & =40 \\
\mu & =1.33 / 3 c_{0}=f_{0} \text { tab }
\end{aligned}
$$

dose for a 20 gram firy in/ knse 
from time to time and note any changes taking place in it.

Examine digitalis leaves (Digitalis purpuræ);

strophanthus seeds (Strophanthus hispidus);

and squills, the sliced bulb (Scilla maritima).

Also examine the following preparations:-

Tincture of strophanthus ;

Tincture of squills;

Syrup of squills.

\section{Therapeutic Uses.}

Digitalis and its allies are employed principally in certain affections of the heart. When a valve of the heart is diseased so that it does not perform its functions properly, the heart has an increased amount of work to do. In most cases its walls increase in thickness (hypertrophy) to allow of the extra work being done, in other words the heart becomes "compensated." But an unusual demand is made on the heart before it has time to hypertrophy, the walls stretch on account of their weakness, and the heart is said to become "dilated." Whien this"occurs the contractions are weak and imperfect and the result is that the circulation becomes slowed and the blood tends to cothect on the venous side of the vascular system, resulting in a passive congestion of the organs, and in marked cases a generalized œdema of the body may follow.

In such conditions digitalis is of the greatest value As was seen in its effect on the dog's heart, it increases the strength of the contractions and in some cases lessens the extent of dilatation. The heart begins to pump out more blood into the arteries raising the arterial pressure and thus supplying more nutrition to the body cells. One of the first organs to be benefited is the heart itself through its coronary 
arteries. From its improved blood supply it becomes stronger and may be able to hypertrophy and thus carry on its increased work without the further use of digitalis. The improved circulation results in a disappearance of the congestion of the organs and of the œdema.

The removal of the œdema is also aided by the diuretic action of the drugs belonging to this series; this appears to be due mainly to the cardiac action (cardiac diuretic).

\section{Aconite.}

Several alkaloids are derived from plants belonging to the Aconitum genus, and among them Aconitine is the most important. It is obtained from the root of the monk's hood (Aconitum Napellus).

The most important preparation containing aconitine is the tincture of aconite, the alkaloids being very rarely used as different preparations vary considerably in activity, owing to the fact that aconitine decomposes with great readiness.

I. To 2 cc. of the tincture of aconite add an equal amount of water. Try to dissolve the precipitate formed by adding some $95 \%$ alcohol. The precipitate in this case consists of resinous bodies (extractives) which are thrown out of solution by the water but which are redissolved by the alcohol.

II. Add 6 drops of tincture of aconite to about I cc. of distilled water in a clean beaker. Take the solution in the mouth and retain it there without swallowing for about a minute, after which it may be ejected and the mouth rinsed with water. Observe whether any unusual sensation comes on in from five to ten minutes in that part of the mouth with which the aconite solution has come in contact.

These symptoms, which are due to stimulation of the sen- 
EXPERIMENTAL PHARMACOLOGY.

129

Acmite -

Ef! T. Aleohol dessolns the frecifitate prescions bodies

Ep. It Alution sin waseth cursed a hrobling seudation aud nacked numbress

En.III- The heart of the pitt id firy, shomel an mereased wate in hat witt the systote of the puctriele

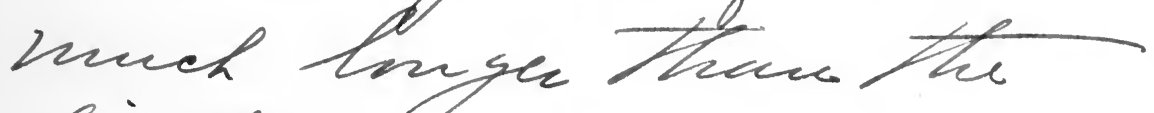
diastole. Heart heot inciasese

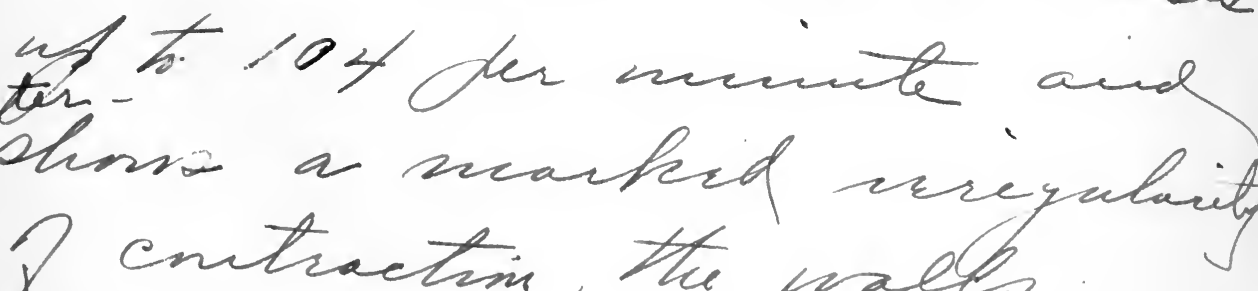
$\checkmark$ entractin, the entracting hit not sinvetareonsly - delinim \& the heart - 
sory nerve endings, are characteristic of two drugs, aconite and veratrine.

III. Pith a frog, tie it on the board and expose the heart by the usual method (page I6). Inject into a lymph sac 3 drops of tincture of aconite and keep a record of all changes taking place in the organ, noting not alone changes in rate, but also in the character of the contractions.

Examine the root of Aconitum Napellus.

The effect of aconite on the mammalian heart is studied later. (Page I39). 


\section{The Effect of Drugs on the Frog's Heart.}

Pith a frog, tie it on a board and expose the heart as usual. Dissect out the vagus nerve and stimulate it with $\mathbf{a}$ weak tetanizing current from the induction coil. To find the vagus nerve in the frog: expose the heart as usual, split the pectoral girdle entirely and draw the anterior limbs well apart. Carefully remove the skin and connective tissue in the neck and two large nerves ( 9 " and $12^{\prime \prime}$ ) will be seen on either side passing forward. Trace these backward and they will be found to take a turn outward to enter the base of the skull. The vagus in this position lies between them, running parallel to them in this part of their course.

Describe the changes in the heart caused by vagus stimulation.

NoTE.-In a certain number of cases the vagus in the frog is not active and it will therefore be impossible to affect the heart by its electrical stimulation.

In this frog or in a second one if necessary, examine the action of chloroform by putting the animal, with the heart exposed, under the bell jar in which there is a piece of absorbent cotton soaked in chloroform.

Record all changes seen in the heart, whether changes in rate or in the condition of the various chambers.

If the effects become very marked, remove the animal from the bell jar and allow the heart to recover. Keep it moist by dropping on it a small amount of physiological salt solution.

When the organ has recovered repeat the experiment, using ether instead of chloroform.

Compare the actions of the two drugs. (See Anæsthet- 
EXPERIMENTAL PHARMACOLOGY.

133

Nagus stiur ulation stofficed the heart in diastole.

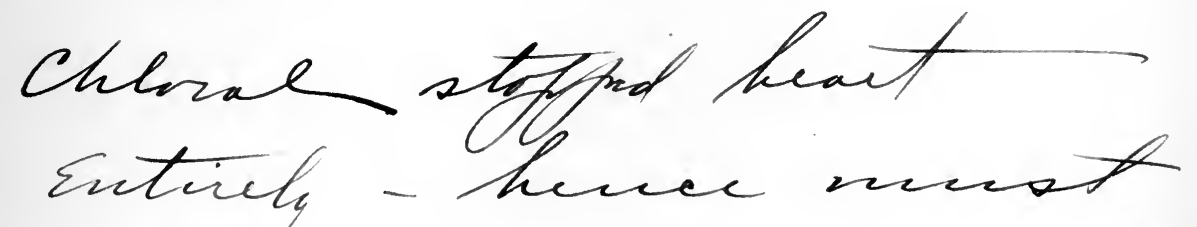
to stingen thane sther rCAfG, Aer touge 204 to CACP 
ics, page 204). Also compare the action of chloral on the heart. (Page 55).

After the heart has returned once more to normal, put a drop of a pilocarpine (or muscarine) solution on it and note any change in rate. After a few minutes add a few more drops of the same solution and note any further change. Compare the appearance of the heart with its condition under vagus stimulation. If the heart should stop contracting, put two drops of an atropine solution on the organ and if necessary, after a few minutes make a second or third application of atropine.

If the heart begins to beat once more apply pilocarpine solution again and see if it will stop it. Also try stimulation of the vagus nerve. If pilocarpine will not stop the heart, try chloroform by exposing the organ to the fumes as before.

From your knowledge of the anatomy and physiology of the vagus nerve try to account for the effects induced by the drugs as seen above, considering them in the following order, pilocarpine, atropine, pilocarpine and chloroform.

The effects of digitalis, aconite, chloral and paraldehyde on the heart are studied elsewhere. (Pages I2O, I3I and 55).

\section{The Effect of Drugs on the Rabbit's Heart.}

Anæsthetize a small rabbit or cat as described elsewhere, (page II). When anæsthesia is complete tie the animal on the operating board and insert a tracheal tube (page 23), and a venous cannula in the jugular vein (page 19). Find one of the vagus nerves, separate it gently from the other structures in the carotid sheath and pass a' thread under it. Tie the thread and cut the nerve above the ligature so as to allow of stimulation of the peripheral end. 
Make an incision down the thorax in the median line as far as the end of the sternum and deepen the cut to the bone, taking care to keep exactly in the middle line. Start artificial respiration with the bellows, after which split the sternum longitudinally by strong scissors and draw its two halves apart by fish hooks, securing them to the sides of the board. The heart is then seen within the pericardium, which is opened with scissors.

Examine the contractions of the normal heart and then stimulate the vagus with both weak and strong currents, observing the changes in the beat.

In a small evaporating dish place $5 \mathrm{mg}$. of pilocarpine (I cc. of $0.5 \%$ solution) diluted with salt solution to a convenient bulk (about $5 \mathrm{cc}$.). In a second dish place I $\mathrm{mg}$. of atropine sulphate (I cc. of o.I \% solution) diluted with salt solution.

Inject the pilocarpine solution into the jugular vein (see precautions page 20) by means of a hard rubber syringe, noting the effect on the heart. If the latter is very much

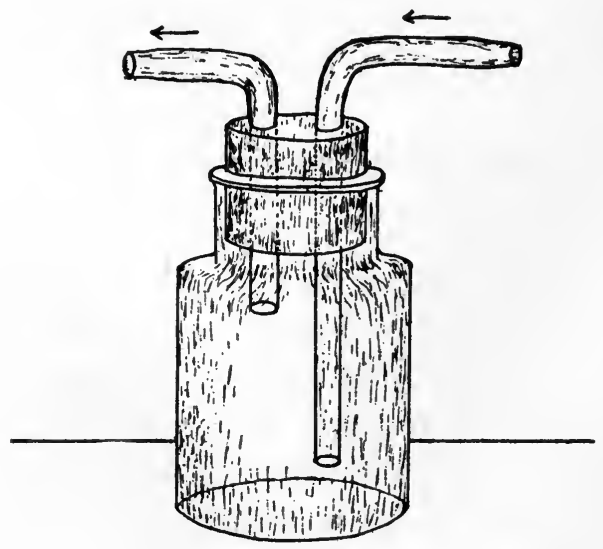

FIG. No. 5 . 
EXPERIMENTAL, PHARMACOLOGY.

137

Paftit' monal heart

inse

has 1 to fer miverte the brat

utum feuring $p$ the Therax

mas resulor, the anreico

entructing it folloned \&

the syotsle 1 the nutruales

A mak current afplict

tragus carred iricyolas

makened cuthateins, and. slowicy.

sting curnot prodrecel

enchlowin enctacteris and

stifined the teative

Silocaptio the hate heming liss in much s. and trenus theres.

Otifinis

li tinslaboving the sud plates

I the palyes and a eurrent afplied now cunses us Atoffr 
138

LABORATORY GUIDI: IN

$\mathrm{CACO} \mathrm{CH}_{3}$

the hat

land

mly a fur whifto mese aduinistered. Afurt mas als. dilated.

Ether stroduced shroving also but less suarkerly.

Offrive cansed sliglet dilitim and wicreasep rofility

Adrenahir cursed nereased rate $q$ hat.

$\mathrm{CaCl}_{2}$ frist camsed decuas ard Ther stinger hat

NCl cairsed warkat diliation and decruse of hat.

Acmite caures nusk of dilotaten

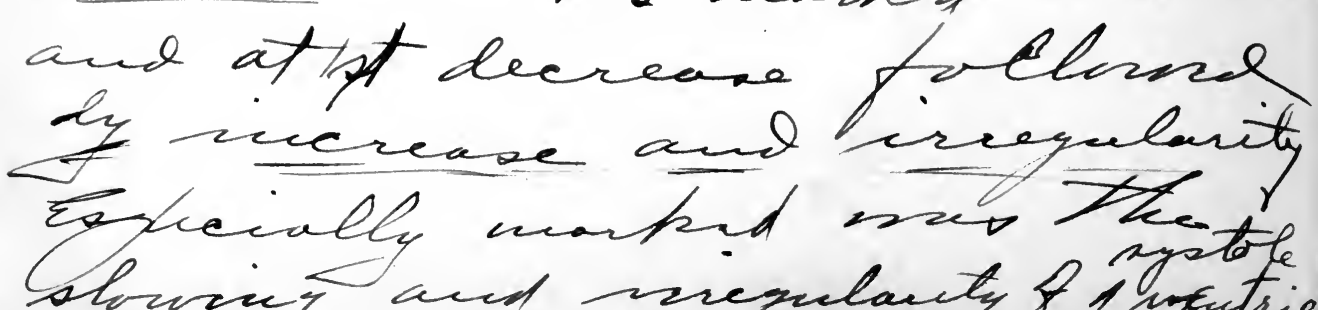

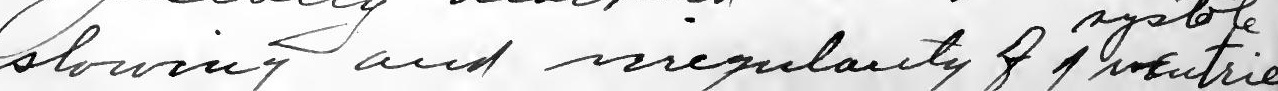


affected inject the atropine solution at once, noting also its effect.

After the atropine injection stimulate the vagus as before, noting any difference in its effect on the heart.

Insert in the air tube a bottle (Fig. 5) containing chloroform, using great care not to give too much. Describe the changes in the heart. Remove the chloroform and allow the heart to recover and repeat the experiment, using ether instead of chloroform. Which is the more powerful?

After the heart has recovered from the ether inject into the jugular vein, by means of a syringe, the following drugs in the order named. Describe fully the changes in the heart induced by the various drugs in these doses:

a. Caffeine, $25 \mathrm{mg}$. dissolved in $2 \mathrm{cc}$. of hot water.

b. Extract of the suprarenal gland. ${ }^{1}$

c. Calcium chloride, $20 \mathrm{mg}$. dissolved in $2 \mathrm{cc}$. of water.

d. Potassium chloride, $20 \mathrm{mg}$. dissolved in $2 \mathrm{cc}$. of water.

e. Aconite, 3 drops of the tincture.

NoTE.-Do not inject one drug until the action of the previous drug has passed off.

\section{The Effect of Drugs on the Turtle's Heart.}

Destroy the brain of a turtle by a blow with a hammer, and turning the animal on its back, tie it on an operating board. Draw the head out so as to put the neck on the stretch and fasten it in this position by means of a nail driven through it. Remove the lower shell (plastron), cutting the lateral attachments with bone forceps or a saw; after cutting the hard parts the shell can be raised slightly and the underlying soft parts severed with a scalpel, taking care to cut toward the shell. Carefully cut away the skin and fascia near the base

\footnotetext{
${ }^{1}$ Inject 5 cc. of a solution made by adding $\mathrm{I}$ cc. of adrenalin chloride (I-I000) to $50 \mathrm{cc}$. physiological salt solution. (See page $2 \mathrm{I}_{3}$ ).
} 
of the neck, and if the coracoids (G) and clavicles (F) are in the way they may be cut back with bone forceps and a

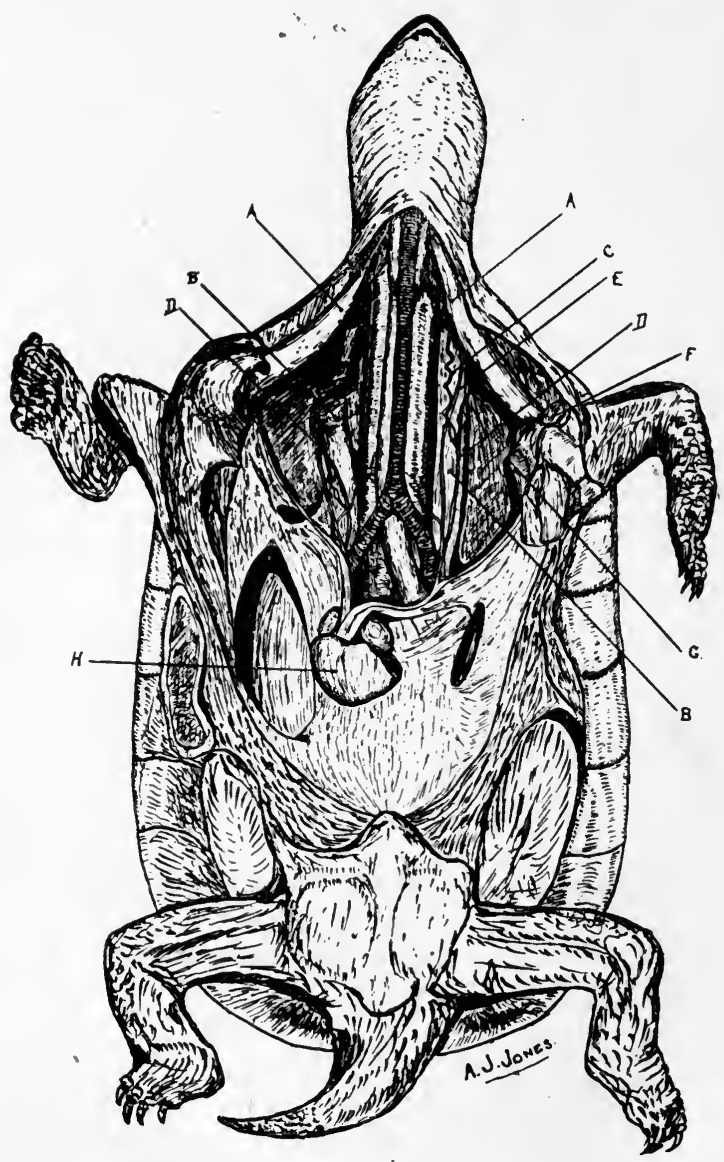

FIG. No. 6. Turtle with plastron removed and vagi dissected out. A. Coraco-hyoideus muscle, B. Retrahens capitis collique muscle (right muscle is cut across),

C. Sympathetic nerve, D. Vagus, E. Carotid artery, F. Clavicle, cut end, G. Coracoid, cut end, H. Heart.

scalpel. Large white muscles (B, B, ), the long retractors of the head (Retrahens capitis collique) will now be exposed, 
EXPERIMENTAL PHARMACOLOGY.

141

almigo in Sinttes heorit

sele sage 6/. 
running back from the head and placed deeply in the neck on either side of the median line. Two other large white muscles (coraco-hyoideus, A) will also be seen passing on either side from the front legs forward toward the median line of the neck. Two nerves (C, D) may be found emerging from under the long retractors just posterior to the point where the coraco-hyoidei unite in the median line. In the upper part of their course they lie internal to the long retractors, then wind around the muscle to reach its upper surface (in this position of the animal) and pass down the neck, lying on the muscle. One of these nerves is the vagus (D), which must be identified by gently separating it from the surrounding structures and stimulating it with the electric current, watching the effect on the heart. When it is found, place a ligature around it.

Expose the heart by cutting away the pericardium. Thread a small curved needle with about six or eight inches of medium sized thread and take a stitch in either side of the ventricle, trying to include between them the area of greatest contraction. Tie the thread in the heart with a loose knot, leaving the two free ends which are to be attached to the myocardiograph (Fig. 7).

Place the board with the turtle on the stand of the myocardiograph and arrange the instrument so that the ends of the two levers ( $A$ and $B$ ) shall be beside the ventricle. Tie the threads attached to the ventricle to the ends of the two levers. The writing lever now begins to move downwards with each contraction and upwards with each relaxation of the ventricle. Vary its height so that it will record the movements of the heart on the smoked surface of a drum properly placed. Arrange the stationary lever (D) to draw a base line just below the tracing of the cardiac movements. 
After taking a short tracing showing the normal contractions of the heart, take one showing the effects of stimulation of the vagus with both weak and strong currents.

NorE.-Mark on the tracing when any stimulation is begun or stopped or when any drug is applied.

Continuing the tracings, apply a few drops of a pilocar-

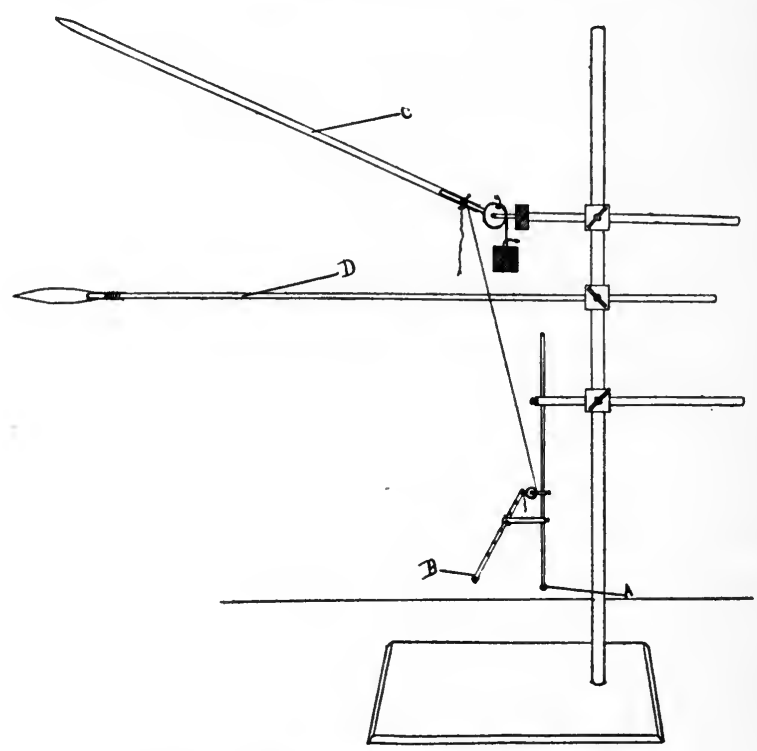

FIG. No. 7. Myocardiograph for turtle's heart.

pine solution $(0.5 \%)$ to the heart. When the contractions become very infrequent or stop entirely, apply atropine (o.I \%) to the heart, adding a drop or two at a time to the organ.

When the contractions return to normal, stimulate the vagus with the electric current as before.

Apply pilocarpine again to the heart. Compare the tracings with those obtained earlier in the experiment. 


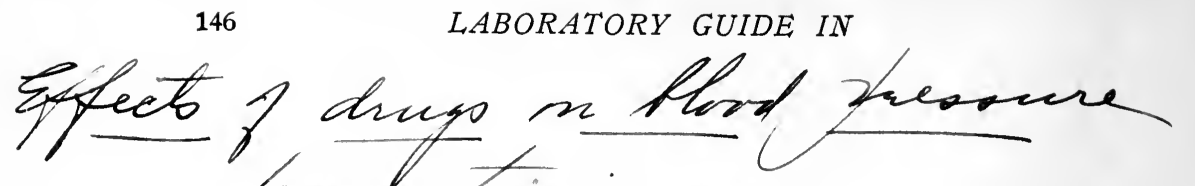

Anyl vitrite caused a steady toll in fresouse frme $6 / 2$ cme.

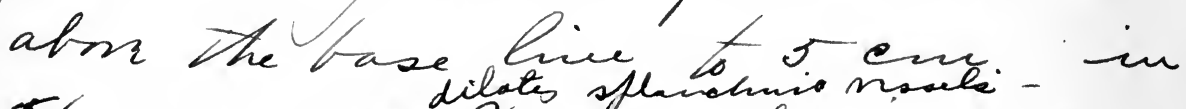

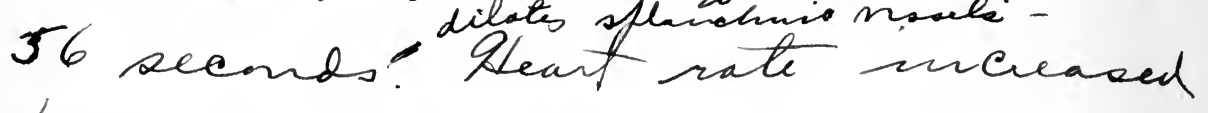
fim 210 to 222.

$\mathrm{CHCl}_{3}$ slond the heart $180 \mathrm{in}$ 20 seenda, ofter which it zrad. vally use to monal. At ist a wise in presoure frelond $b$ a decrave.

Ether cansed a sinilar merease bot a much less rofind decrass than $\mathrm{CH}_{3} \mathrm{Cl}_{3}$, rising fim $3.2 \mathrm{em}$ $3.5 \mathrm{~cm}$ in 52 secnds and then falling to $3 \mathrm{~cm}$ in 58 see. Bteant hat alowed t $1 P_{6}$.

sufrarenal sy tract cansed markul rise in pressure in $12 t$ sec. use firm $3.2 \mathrm{em}$. to 4.2 and the to $f \mathrm{~cm}$. in the next 10 secenses. Ax Enctimed hitinen or 9 for 2 o 3 min. 
Shake 3 or $4 \mathrm{cc}$. of chloroform in 20 or $30 \mathrm{cc}$. of physiological salt solution and pour some of this solution from time to time over the heart. When the cardiac contractions become very weak, remove the chloroform solution with a piece of absorbent cotton and assist the recovery of the heart by bathing it in fresh salt solution.

Note that pilocarpine does not stop the heart after atropine, nor has vagus stimulation any effect. Chloroform, on the other hand, acts after atropine. How is this to be explained?

Remove carefully the paper with the tracings from the drum and fix it by passing it through a solution of shellac in alcohol.

Study the tracings according to directions given on page 160 .

The Effect of Drugs on Blood Pressure.

Anæsthetize a rabbit or a cat according to the methods described earlier (page II), and when the animal is completely under the influence of the anæsthetic, tie it on its back on the operating board and remove the hair from the neck region. Make an incision about four inches long in the median line of the neck and expose the trachea ; insert a tube (page 23) to allow of artificial respiration should it become necessary.

Expose the jugular vein on one side and insert a cannula (page 19). On, the opposite side expose the carotid artery and in like manner tie a cannula in it (page 20).

Fill the venous cannula with physiological salt solution and the carotid cannula with a solution made by mixing equal volumes of water and a saturated solution of sodium sulphate. 
The ordinary form of mercury manometer, which is so well known as to need no description, is used. Fill the proximal limb of the U-shaped tube, i. e., the limb which is to be connected with the blood vessel, with the sodium sulphate solution, using for this purpose a pipette with a long tapering point. The lead (or rubber) tube, which is connected to the side tube of the proximal limb of the manometer, is to be completely filled with the sulphate solution, taking great care to see that all air is expelled from the tube and manometer. Close the clamp on the tubing which connects the lead tube and manometer. With a short piece of rubber tubing connect a large pipette $(25 \mathrm{cc}$.) filled with the sulphate solution to the upper opening of the proximal limb of the manometer and blow in the pipette so as to raise the pressure until there is a difference of 10 or $12 \mathrm{~cm}$. in the height of the mercury in the two limbs. Retain this pressure by closing the piece of rubber tubing with a spring or screw clamp and disconnect the pipette.

By means of a short piece of rubber tubing connect the distal end of the lead tube to the carotid cannula and open the clamps so as to allow the carotid pulsations to be transmitted to the mercury. Arrange the writing lever so that it will record the pulsations on a blackened drum with a time marker writing below the tracing. Keep the writing lever in light contact with the drum by means of a small weight suspended by a thread from a support above the drum, taking care that the thread does not press too hard against the lever.

Administer the following drugs in the manner described, taking a short piece of normal tracing before each is given, and waiting until the effects of one drug have passed off 
EXPERIMENTAL PHARMACOLOGY.

149

after which it gradually decreasef

to mmale. Otwart rate. Vate

I hat decreared to lip fursene.

reigitalis - Vussure rose frm

1. I cur. to 3.7 cun in / meinite

At enctinued to rise to $4.3 \mathrm{~cm}$.

ateart rate deceraxed to $174 \mathrm{in}$ zote 30 ockands - 
150

I.ABORATORY GUIDE: IN

Effect o krugs in iliges heast

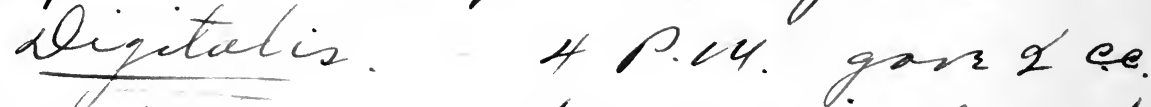

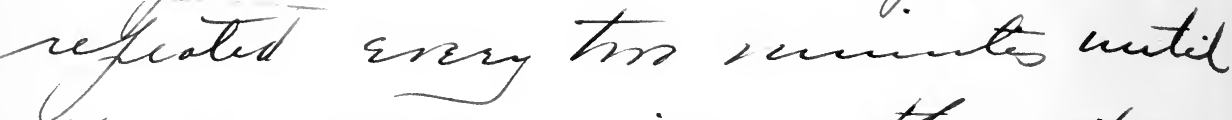
Y ce. mane pine, then 4cec mas ying her minate until If e.e. in all. Afta ins mifection a pradual decreasing Aystole fy litth anviale romit rviles reane affurent. Iz seconds after last monked dicrease in foth nutri cular os anscilar systole with great suregularity occurred Pacese of diastole mereased slowing hat to I hat sin 2 seconds. Drurjularities incruased, deliniman and pivally otiffiags.

Affenie - Rate ansick and nutriele fiat sicecensel, with crusaturing decreaser of diastole I toth nutrich anicile 
before applying the next. Observe the precautions as to the injection of any air.

I. Amyl nitrite: 3 drops on cotton wool applied to the animal's nose or to the tracheal tube if that has been inserted.

2. Chloroform: given on cotton wool as above.

3. Ether: given on cotton wool as above.

4. Suprarenal extract. Adrenalin chloride (I-IOOO); I drop in salt solution injected into the vein. Wash the cannula and syringe thoroughly before injecting the next drug.

5. Digitalis. I cc. of the tincture from which the alcohol has been evaporated (given intravenously).

Repeat this injection as many times as necessary, noting the successive effects on the tracing until the heart ceases.

Allow the drum to continue rotating after the heart has stopped, so that the writing lever traces a straight line from which measurements may be made to ascertain the absolute blood pressure. Remove the tracings from the drums and fix them by passing them through a solution of shellac in alcohol.

The blood pressure tracings are to be analyzed according to the directions given on page 160 .

\section{Effect of Drugs on the Dog's Heart.}

Anæsthetize a dog (page 12) and when anæsthesia is complete, tie the animal on its back on the operating table. Make an incision through the skin in the median line of the neck, and after exposing the trachea insert a cannula in the usual way (page 23). Expose a vein, either one of the jugulars or a saphenous in the leg, and insert a venous cannula.

Dissect out the vagus nerve on one side, tie a ligature 
around it and cut the nerve between the ligature and the head.

Continue the skin incision in the median line from the neck down the thorax to an inch or two below the end of the sternum, and deepen the cut to the bone. Stop all bleeding points with artery forceps.

Connect the tubing of the bellows with the tracheal tube and start artificial respiration.

Saw through the entire length of the sternum, keeping exactly in the median line and complete the division with bone forceps; draw the two sides of the thorax well apart and secure them to the sides of the table with sharp hooks.

Regulate the amount of air entering the lungs by means of a screw clamp placed on a piece of rubber tubing on the arm of the tracheal cannula.

NotE.-During the process of sawing through the sternum and opening the thorax the animal must be very deeply under the anasthetic, otherwise the heart is likely to go into delirium.

Cut both phrenic nerves as they pass down to the diaphragm lying in plain sight on either side of the pericardial sac.

Open the pericardium along its entire length with a pair of scissors and fasten it to the cut edges of the sternum by means of four or five stitches.

Take a stitch in either side of the right ventricle with small curved needles and thread, and tie the thread into the heart in the same way as you did with the turtle. Similarly take stitches in the right auricle. If bleeding should occur from the needle passing completely through the wall of either chamber take up the bleeding point with a pair of dissecting forceps and tie a ligature around it. 
EXPERIMENTAL, PHARMACOLOGY.

153

Adrenatuie - prodeced

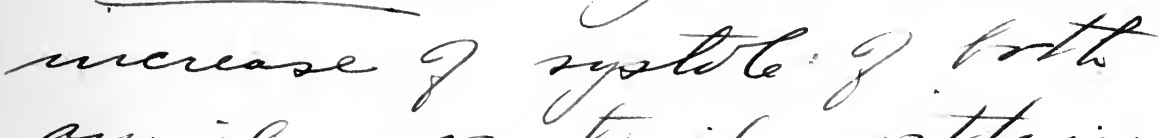
anviler suctivile within 3 s secmer frelowed in

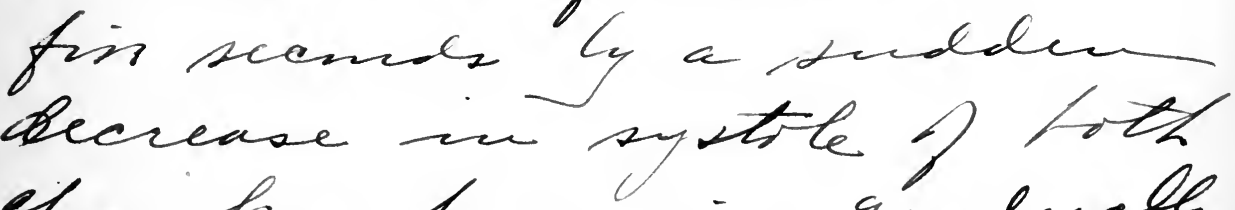
Chainhrs, hervicy gradually onaller and swobler with hiskend isregalonty. 'stear hat decreasue 60 der

Adrenalie has tiro aetins ore a crustriction If risala rucreasing the

and the oftures is the etimulation I. the sayers cacising richelitein

Atrinlativi I I/ays canses naskrd stining and dilatatein timally stofifing in diastole. 
154

LABORATORY GUIDE IN

CHCl

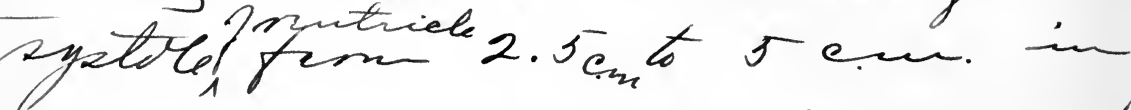
so scemes and in next konfulls to 4.9. Liasto renains of fint same

Auriale systole nereared 12.3 to $16.6 \mathrm{em}$. in 30 mees while the diastole dienensed trom 78.9 t 1 . $t$ cen. itcunt hat fill from $10 \mathrm{~s}$ to by tres

Etter, Hecrase in rectriculan systef frm 3.4 en to 4.6 in 30 in sance tine 10.7 to 10.8 en. Anrailar systole decreased frm 13.7 to 19.4 can. in zosends while diastole decreased 1 's t 18.5 en. Afart trat deercased to 96 per becul from lot unmel 
Attach the two sets of levers of the dog's myocardiograph ${ }^{1}$ (Fig. 8) to the heart by means of the threads and arrange the writing levers to record the cardiac movements on a

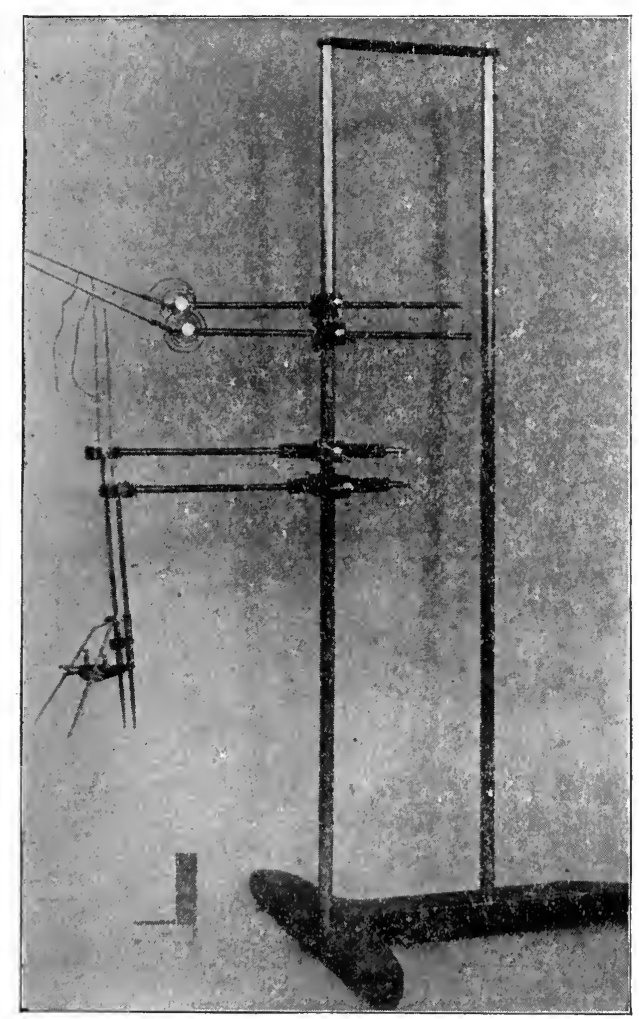

FIG. No. 8. Myocardiograph for dog's heart.

\footnotetext{
${ }^{1}$ The dog myocardiograph (Fig. 8) is constructed on exactly the same principles as is the myocardiograph for the turtle's heart (Fig. 7), excepting that, as is shown in the figure, it is double, so that it will record the movements of both auricle and ventricle. The apparatus has other modifications as is seen in the plate, but the principle is not essentially altered. A description of that part of the apparatus which is connected to the heart is found in the Jour. of Physiol., 1897, XXI, p. 2 I 3.
} 
blackened drum. Arrange a time marker to write just below the levers.

Start the kymograph and take a normal tracing, after which take tracings to show the effects of the following:

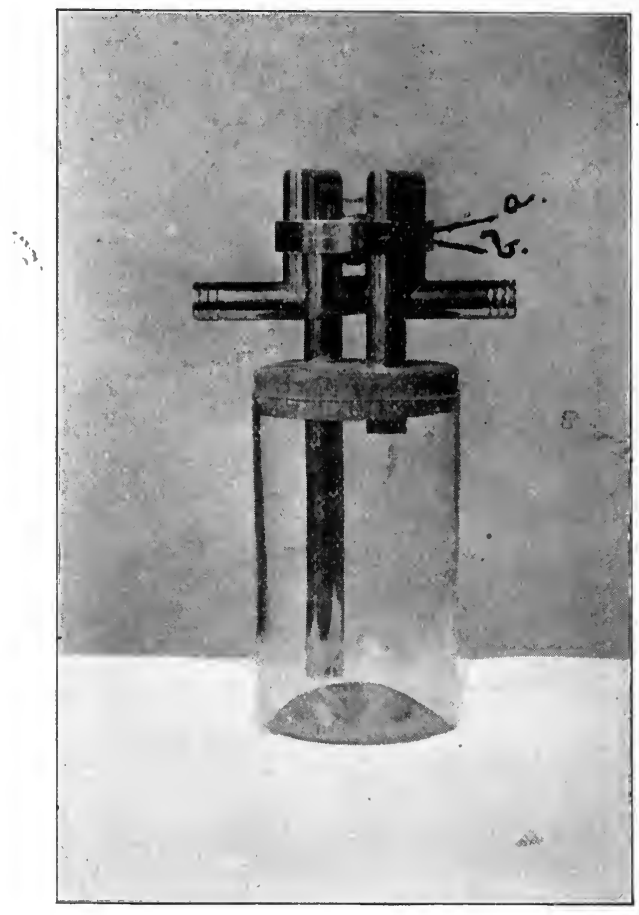

FIG. No. 9. Anæsthetic inhaler for dogs. By rotating upper part of apparatus "a" slightly upon "b" either air or anæsthetic may be forced into the animal's lungs.

I. Vagus stimulation, weak and strong currents.

2. Chloroform (given with special inhaler, Fig. 9); continue the tracing so as to show the recovery.

3. Ether (given with special inhaler, Fig. 9); continue the tracing so as to show the recovery. 
EXPERIMENTAL PHARMACOLOGY.

157

Alcohol-shond wo chaugs

in rate

auricular entractions

hcane gradualy makened.

- diastole hecanes increased

slonoly returning to nownel

in abmt 2 ncinube 
4. Suprarenal extract. (Adrenalin chloride, I-IOOO, 3 drops added to $4 \mathrm{cc}$. salt solution and injected into the vein with a syringe.)

5. Alcohol, ro cc. of $50 \%$ given intravenously.

6. Digitalis, tincture evaporated to one-half its volume and I cc. injected.

7. Caffeine, 0.2 G. dissolved in hot salt solution.

8. Digitalis (toxic doses), inject the concentrated tincture (see 6) in 2 cc. doses.

The heart finally becomes irregular and may pass into delirium. Mark the tracings carefully so that they can all be identified and fix them in shellac as before. Analyze them according to directions given on page 163 .

Cut off the head of the animal and as soon as convenient dissect out the submaxillary ducts according to the directions given on page I9I. This dissection will allow more speedy operating on the living animal in the experiment on the salivary secretion.

Remove both kidneys leaving as much of their vessels attached as possible and put them in salt solution for use in Exp., page I67.

$$
11-P
$$




\section{Analysis of Tracings.}

Graphic records are obtained in three experiments (turtle's heart, dog's heart and blood pressure) and it is of first importance that these records should be carefully analyzed in order to properly study the changes induced by the various drugs. A few hints are given below to call attention to some of the more important points to be looked for, and some suggestions are made as to the best way of studying the tracings.

Tracings Obtained from the Turtle's Heart.

It is rarely necessary in these records to take accurate measurements, as the changes induced by the drugs are generally quite marked.

Describe the effect of stimulation of the vagus, noting whether the heart stops in systole or diastole. Likewise, describe the condition of the heart under pilocarpine (before and after atropine administration) and also the effect of the atropine.

Under chloroform note especially the strength of the heart as indicated by the extent of contraction and of dilatation, which is measured by the distance of the tracing from the base line.

Summarize the actions of the different drugs.

Tracings from the Blood Pressure Experiment.

Study these first with regard to changes in pressure. Take careful measurements of the distance of the tracing from the base line at various points along the course of the curve; viz., before the drug is injected to get the normal; after the 
EXPERIMENTAL PHARMACOLOGY.

161

Suntle's heast - sffect o dougs. Stimulatim of riyas mith wiak stoforing hit wot confles

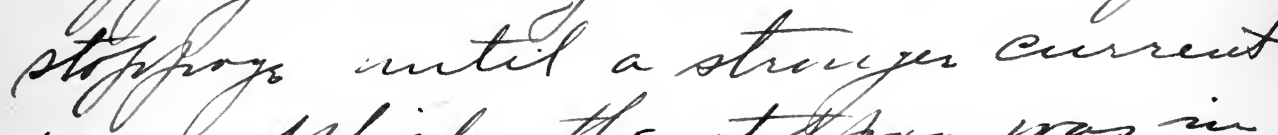
ins afplief- the stoffling mas in divistole.

Plicurkis curveh a market dowin actin, with mne warkent Costraction. and hat hecaue 1 iny irregular. atrifin hir hot hack the hat to numal and in ercased the sate. Dibcappis hereafto had ir effect, as the raye uns indiviys mu paralyzan fim the atiofain. CAClo carsed markerd dilatation

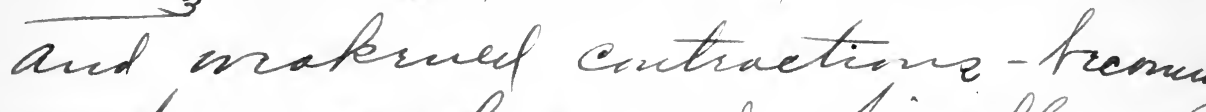
maker o arsake auch finally stoffed. Bestried ly sabf solietion ald mechavieat stuinhe howzss. Pilocenpis otinulats the payne Endrigk, whil atrifiris usalyza 
162 LABORATORY GUIDE IN

the nern undnigs. CACl 3 aet directly ufrom the cardiac muscle itoelf and herce it aetim is not interfered with by the atrofin.

Craving of tloy Acart.sec paye isoGacing of blood fresone curn see fage 146 . 
action of the drug becomes apparent; and later at short intervals of time which will depend upon the drug used. Where the curve is fairly uniform readings every thirty seconds are frequent enough.

Measuring in this way from the base line will only give relative changes in pressure, which is all that is necessary in these experiments. To get the absolute pressure, the zero line which was marked on the tracing would have to be used, measuring its distance above or below the base line and adding or subtracting this distance from the figures obtained above. This result must then be doubled as there are two arms of mercury in the manometer.

The changes in the rate of the heart are studied in the following manner: Draw two lines parallel to each other and perpendicular to the base line so that they shall intersect the tracing. The distance of the lines from each other is determined by the rate of the drum as indicated by the time marker; they are usually drawn to include between them a space equal to five or ten seconds. Count the heart beats in the tracing included between the two lines and estimate the rate of the heart per minute. These estimations are made along the curve at the same points as the pressure changes are measured.

Also describe any other changes in the curves, such as irregularities of the heart or of the respiration, etc.

Summarize the effects of the different drugs upon the pressure of the blood and upon the rate of the heart.

\section{Tracing from the Dog's Heart.}

These are to be studied and analyzed by a combination of the methods outlined above. The rate of the heart is ascertained as described under the directions for studying the 
blood pressure tracings, while the strength of the organ as indicated by the extent of systole and diastole is measured from the base line. Describe all other changes in the tracings, and in your notes make a full summary of the actions of the different drugs. 


\section{Perfusion of the Kidney.}

The kidneys which were removed from the dog (page 159) are to be employed in the following experiment. They should not be kept any longer than is absolutely necessary after being removed from the animal, certainly not more than twenty-four hours, as after that time post mortem changes have advanced so far as to interfere with the action of drugs on the vessel walls.

In preparing the kidneys for the experiment it is usually best not to remove the capsule, as in so doing the parenchyma is frequently torn. Remove the fat and connective tissue from around the vessels and insert glass cannulas in both the artery and the vein. Fill the vessels and cannulas with salt solution. Fasten a small glass reservoir (say 250 cc.) about I.5 meters above the table and connect a long piece of rubber tubing with its lower orifice.

Strain some defibrinated blood through a cloth and dilute it with two volumes of saline solution. (Instead of diluted blood, Locke's solution may be used.)

Put about Ioo cc. of this diluted blood in the reservoir and allow it to fill the rubber tube and then clamp the latter. Connect the lower end of the rubber tube with the arterial cannula taking care that all air is expelled. Remove the clamp from the tubing and place a receptacle under the venous cannula to catch the fluid after it has passed through the kidney. Measure the fluid (blood) in this receptacle at intervals of five minutes during the course of the experiment. After a fairly constant rate has been determined by two or three readings, put into the blood reservoir o.I G. 
sodium nitrite ( $\mathrm{I} \mathrm{cc}$. of $10 \%$ solution) and mix the solution. The experiment may be hastened by disconnecting the rubber tubing from the cannula and allowing the normal diluted blood in the tube to escape and to be replaced by sodium nitrite blood, and then connecting up the tube and cannula again.

Take several readings of the rate of the outflow of the blood under the nitrite action. When a constant figure has been reached, replace the nitrite blood in the reservoir and rubber tube by normal diluted blood and allow it to flow through the kidney to wash out all the sodium nitrite.

Now add to the normal blood in the reservoir some adrenalin chloride (I cc. of I-IO00 solution) and measure the outflow under its action.

What do the changes in the rate of outflow under the two drugs indicate in regard to their action on the blood vessels? How do the results help to explain the observations made in the experiment on blood pressure (page I5I $_{5}$ ).

\section{Diuresis.}

Anæsthetize a rabbit with paraldehyde (page II) and when anæsthesia is complete tie the animal on the operating board. Cut the hair from the neck and also from the lower part of the abdomen. Expose a jugular vein and insert a cannula as usual.

The effect of drugs on the excretion of the urine is to be studied in relation to the drugs used and also with regard to the height of the blood pressure. In order to do this expose a carotid artery and insert a cannula into it and connect the cannula with the mercury manometer which has been ar- 
EXPERIMENTAL, PHARMACOLOGY.

Linesis Rablet

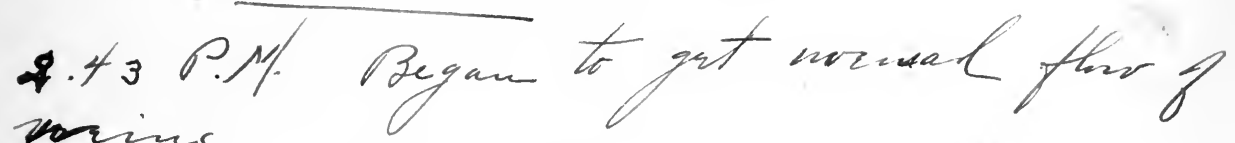
mins

$$
\begin{aligned}
& \text { 2: } 4.0 .58 \text { grane } \\
& 2: 58 \text { - } 33 \\
& 3: 03 \quad .55
\end{aligned}
$$

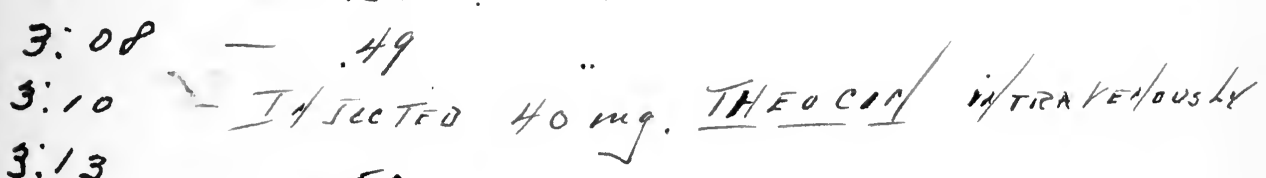

$$
\begin{aligned}
& 3: 13--50
\end{aligned}
$$$$
3: 18-.66
$$$$
\begin{aligned}
& 3.23-.64 \\
& 3.21-.7 \%
\end{aligned}
$$$$
\begin{aligned}
& 3.33-.78 \\
& 3.38-78
\end{aligned}
$$$$
3.38-.78
$$

3.43 .99

3. $48 \ldots 1.01$

3. $5.7+1.01$

$3.58-1.24$

4. $03-1.25$

4.08 .1 .27

4.13 .1 .34

$4.8-1.56$

$4.28-8.65$

$4.2 f-1 . \sqrt{3}$

$4.33-1.52$

$4.35-1.52$

$$
\begin{aligned}
& f: 43-1.71 \\
& 4: 48-1.42
\end{aligned}
$$


170

LABORATORY GUIDE IN

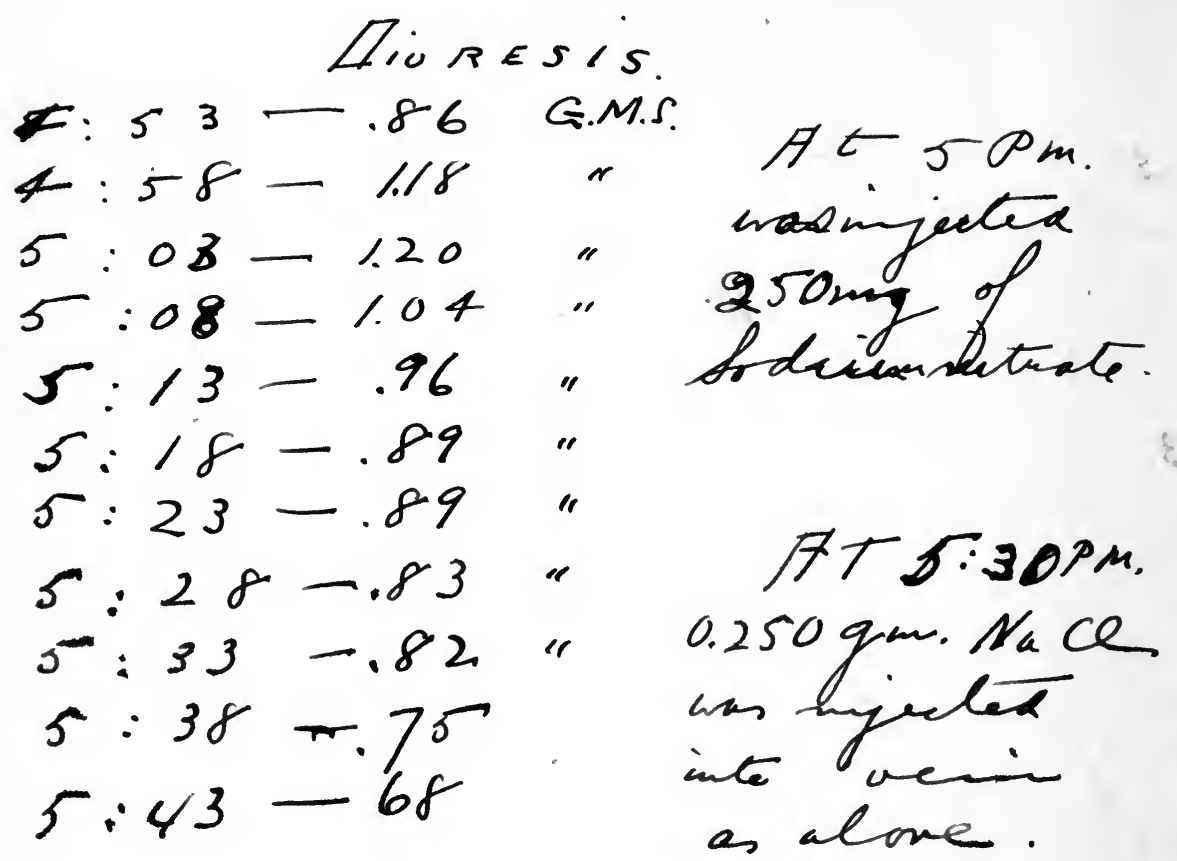


ranged according to the directions given under "Blood Pressure," page 147 .

To insert a cannula in the bladder to collect the urine, make an incision about an inch and a half long in the median line of the abdomen, beginning the incision at the symphysis and extending it upward the distance named. Deepen the cut until the peritoneal cavity is opened. The bladder is usually found partially distended and lying amid folds of fat. Draw it out through the opening made and empty it by gentle pressure, catching the urine in a dish as it flows from the urethra.

Tie a knot loosely in a piece of thread and lay it on the abdomen so that the knotted thread will encircle the bladder and be ready to tie the cannula in place when the latter shall have been inserted.

After locating the position of the ureters, so as to avoid including them in the ligature, take hold of the upper surface of the bladder on the two sides with two pairs of forceps and draw them gently up and outwards so as to exert a slight tension on the organ. While one operator holds the bladder in this way the other operator makes a cut with a sharp pair of scissors midway between the forceps in the fundus of the bladder. The cut will vary with the size of the cannula flange (a, Fig. Io) and will probably average about two centimeters in length. Into this incision now place the cannula so that its flange shall be entirely surrounded by bladder tissue and tie it in place with the loose ligature already mentioned. Examine it after it is tied to see that the ureters are not included.

Fill the bladder and cannila with the urine which was obtained earlier or with warm physiological salt solution and 
connect the end of the cannula with the piece of bent tubing (b, Fig. Io) which can now rest on a support so as to extend over the end of the operating board' where small weighed dishes are to be placed to catch the urine.

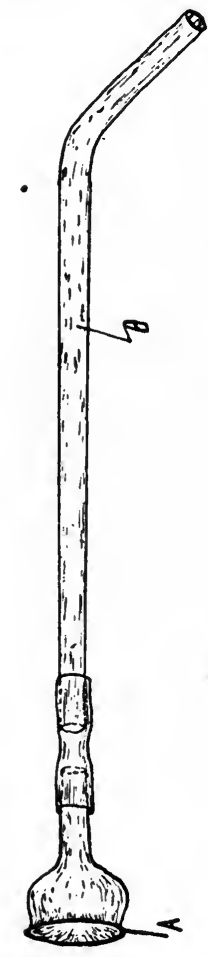

Fig. No. 10. Bladder Cannula. A. Flange to be tied in bladder. B. Bent delivery tube.

As soon as the urine begins to drop from the tube a record of the time is to be made, and thereafter to the end of the experiment, every five minutes, the dish with the urine is to be replaced by a clean receptacle and the first one weighed, and the weight of urine recorded.

The blood pressure tracing is to be taken on a very slow drum upon which the five minute intervals are to be marked under the corresponding tracing, and the amount of urine for that period is also to be marked within the intervals indicated. By keeping the record in this way the drum will show the drug used, the time, the amount of urine excreted in the different intervals and the height of the blood pressure during the same periods.

Take two or three readings until a fair regularity is obtained, and after this normal is ascertained inject into the vein $40 \mathrm{mg}$. of caffeine dissolved in hot water.

After this injection the urine probably will be increased and the next drug must not be injected until the flow has returned to about the normal. 
EXPERIMENTAL PHARMACOLOGY. 
When the amount of urine has thus fallen, inject $0.250 \mathrm{G}$. ( $5 \mathrm{cc}$. of a $5 \%$ solution) of sodium nitrate and collect the urine as before.

When normal is reached once more, inject $0.250 \mathrm{G}$. ( $5 \mathrm{cc}$. of $5 \%$ solution) of sodium chloride and compare the results with the nitrate.

NoTE.-If time allows, the diuretic effect of digitalis may be studied in the same way.

When the experiment is concluded fix the tracings and later study them, not only as regards the drug injected, but also in relation to the changes in blood pressure.

Caffeine, digitalis and sodium nitrate are taken as representatives of the large class of drugs known as Diuretics from their action in increasing the amount of urine.

They may act either on the heart or on the kidney, and they are known as cardiac or renal diuretics according to the point of action. Digitalis is an example of the former class, as it causes diuresis indirectly through its effects on the circulation. Caffeine probably acts directly on the renal epithelium, while various salts, of which sodium nitrate is an example, induce diuresis by their salt action (saline diuretic) in addition to which there may be a stimulant action on the kidney epithelium.

\section{Therapeutic uses of the Diuretics.}

See also under Caffeine and Digitalis, Therapeutic uses, (pages 100 and 128).

These drugs or their allies are chiefly employed in diseased conditions in which the amount of urine excreted is below the normal, a condition which may result from disease of the kidneys or of the heart. In conditions of œdema or ascites, 
there is an abnormal collection of fluid in the tissues; its removal may be aided by the use of the diuretics. In poisoning with an irritant drug which is eliminated by the kidneys, the latter may be protected from the action of the toxic substance by increasing the volume of urine through the administration of these drugs. 
EXPERIMENTAL PHARMACOLOGY. 
178

LABORATORY GUIDE IN

I Aur es tact is a preparation
oftained by as havolitey a

sublaice with a nlevetrumu and then ervaturatiug it to conv.

rlete on afpropinate drywess.

II $A_{a}$ a reanlt 7 atsinis in the ato syr - queatf dilation reaultul (mydravis) due to paralypation fthe motor verves whech suffoly the circhetsar musale. It the irio.

Ti. Hhen solution is altaliue the the atropsin is in the $\mathrm{CHCH}_{3}$ when acid is in the water. Esafpration o $\mathrm{CHCl}_{3}$ left white etrofuir crystal - .

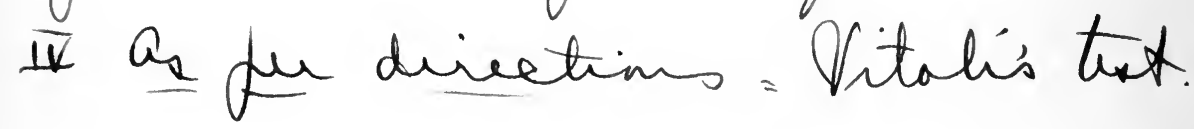




\section{The Belladonna Series.}

Several plants belonging to the Solanaceæ furnish alkaloids -which are very closely related, not only chemically, but also in their pharmacological effects. Chief among these alkaloids is Atropine which is contained in the leaves and roots of the deadly nightshade (Atropa Belladonna). Next in importance to atropine are Hyoscyamine and Hyoscine. These alkaloids are all obtained from other sources than that named, viz.; henbane (Hyoscyamus niger), the thornapple (Datura Stramonium) and other plants of less importance. They are very hard to isolate in absolutely pure form because hyoscyamine is very prone to change to atropine during the manipulations.

As stated above, they resemble one another closely in their properties and actions, so that atropine alone will be studied.

Examine Belladonna leaves and roots.

I. Prepare the alcoholic extract of belladonna leaves according to the U. S. P., using $50 \mathrm{G}$. of the powdered drug.

Define an "extract" of a drug.

II. Take some of the extract, an amount about the size of a pea and rub it up in $5 \mathrm{cc}$. of salt solution and put a drop of the watery extract in a cat's eye and watch for any changes comparing it with the normal eye. The cat is best put in a cat box (footnote, page I2) with the head exposed during. the experiment; drop the solution near the outer canthus of the eye so that it will have to cross the eyeball before escaping by the nasal duct.

"This action of the atropine series upon the pupil is known as-mydriasis and the drugs, producing it are mydriatics. It 
is the most delicate test known for the group, although a few other drugs, of which cocaine is the most important, act as mydriatics, though to a less marked degree.

III. Isolate the atropine from the extract of belladonna by the "shaking-out" process as described below. Observe the precautions mentioned under the isolation of strychnine, (page 68).

Mix the extract thoroughly with about Ioo cc. of distilled water and render it alkaline with ammonia. Put the mixture in a separating funnel and add $20 \mathrm{cc}$. of chloroform. Shake gently for 3 to 5 minutes and set the funnel aside to allow the chloroform to separate, drawing it off into a flask. Add $15 \mathrm{cc}$. more chloroform to the watery extract and shake as before, and draw off the chloroform into the flask with the first lot. The watery extract can now be thrown away.

Put the chloroform containing the alkaloid in the separating funnel and add about $50 \mathrm{cc}$. of water rendered distinctly acid with sulphuric acid. Agitate the mixture several minutes as before, drawing off the chloroform from the water when separation has taken place. Repeat the process with the chloroform and $50 \mathrm{cc}$. of fresh acidulated water. (The waste chloroform is to be placed in a jar on the side table for redistillation.) If the watery solution is colored, shake it in a flask with powdered charcoal and filter it. The filtrate containing the atropine is now rendered alkaline with ammonia and shaken out again with $20 \mathrm{cc}$. of chloroform, which is drawn off into an evaporating dish. Repeat the process with ro $\mathrm{cc}$. of chloroform and add it to the $20 \mathrm{cc}$. in the dish and set the whole amount aside, protected from the dust to allow the chloroform to evaporate and the atropine to crystallize.

IV. Place a few crystals of atropine (from Exp. III) 
EXPERIMENTAL PHARMACOLOGY.

181

Ext. At - Atifin ofing

2.15 Tryided is may

sulfinte

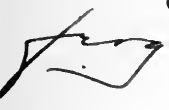

$2: 20$

3.0

3.16 2ms otais

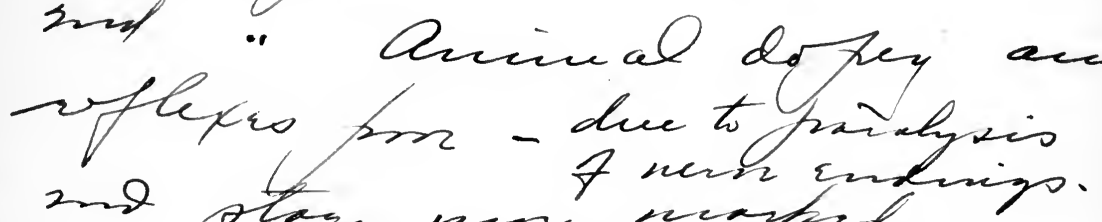
7 ment valuigo

Aon nitht paratysis of terfteral

nun inds desolplear a la le.

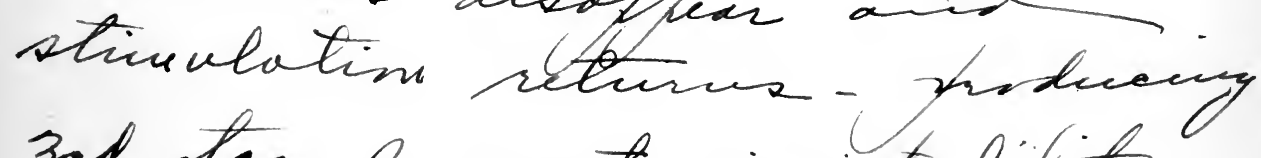

ind they of preat ir itability

narferd ryflexis yum shightest

trial -

ovivilar to stryahiviri, hat wot as nurked as nersis are hot empletely zerored. 
182

I.ABORATORY GUIDE IN 
on a porcelain cover and add to them a drop of concentrated nitric acid and evaporate it to dryness over the water bath. Allow the cover to cool and then touch the residue with a glass rod which has been dipped in an alcoholic solution of caustic potash. A rich violet color is produced, changing to a dark red, which finally fades away, but can be reproduced by the addition of fresh alcoholic potash. This reaction (known as Vitali's test) is almost peculiar to the atropine series and is said to be given by $0.000 \mathrm{Im}$. of the alkaloid.

$\mathrm{V}$. Inject into a frog $15 \mathrm{mg}$. of atropine sulphate and describe all the symptoms which are observed following the injection of the drug. Keep the animal for several days until complete recovery takes place. Compare the effects with those induced by any other drugs used earlier in the course.

VI. Dissolve the remainder of the atropine in about 20 cc. of distilled water which has been rendered acid with sulphuric or hydrocholoric acid. Divide the solution into five parts, put it in test tubes and add the alkaloidal precipitants as follows:

\begin{tabular}{|l|l|c|}
\hline & \multicolumn{1}{|c|}{ Reagent. } & Precipitate? \\
\cline { 3 - 4 } a & Tannic acid. & \\
b & Picric acid. & + \\
c & Iodine in potassium iodide. & + \\
d & Mercury-potassium iodide. & + \\
e & Phosphotungstic acid. & + \\
\hline
\end{tabular}

VII. Take o.0oI G. of atropine sulphate (which will be furnished you) and describe all the symptoms experienced. Count the rate of your heart before and after taking the drug and see if there is any change.

The action of atropine on the innervation of the heart was studied on the turtle (page 144); and on the rabbit (page I39). 
Its action on secretions will be studied on the salivary gland (page 196).

Its mydriatic effect when applied locally was shown in Exp. II, and the same effect from internal administration is studied under the heading "Cervical Sympathetic Nerves," (page I88).

Examine Atropa Belladonna, Hyoscyamus niger, Datura Stramonium, the alcoholic extract of belladonna leaves, tincture of belladonna leaves and the extract and tincture of hyoscyamus.

\section{Therapeutic Uses.}

Owing to the fact that atropine has such a wide range of activities, its uses in medicine are very numerous. Among these a few may be mentioned as being indicated by the various experiments in which the drug is employed. It is ised as a stimulant in the depressed state of the central nervous system occurring in shock, collapse and in narcotic poisoning. (Compare strychnine and caffeine.) For its peripheral action it is employed for many purposes. In cases of extreme slowness of the heart (Bradycardia) due to overactivity of the vagus, atropine may be employed. It is used to dilate the pupil of the eye to allow of ophthalmoscopic examination, or as a therapeutic agent in the treatment of many eye diseases.

In excessive secretion of the saliva such as occurs in poisoning with mercury, and in the night sweats of tuberculosis, atropine is very valuable.

Finally it is used in cases of poisoning by pilocarpine or muscarine, the latter being an alkaloid resembling pilocarpine in many of its actions. 
EXPERIMENTAL, PHARMACOLOGY. 


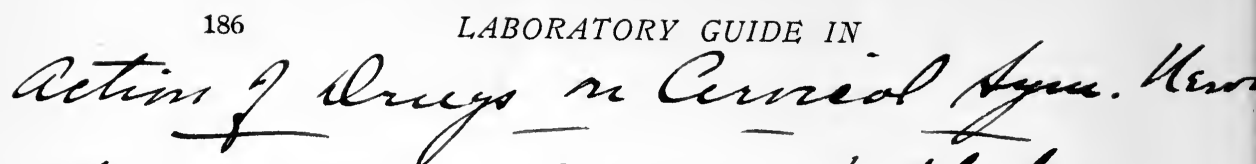
Ativalation if sym pattutic cansed dilation of pufail 7 pare sile.

after enting ness, the nssek $f$ cas showizf dilation, much une then ottur ear, cacusang the sur to fach wuch waswer the tareh. Shis shernel that the symfintletic nens casues

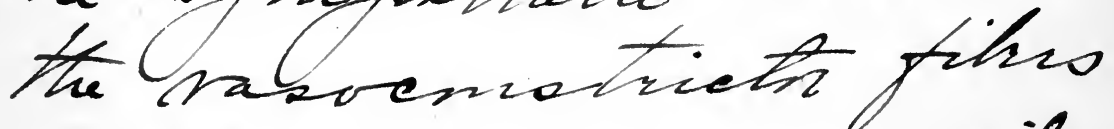
spil of syz so sane side is des suballer, due to cutting the fihs which stivincate the circular radiating waselest isio.

Stiunlation wor caused Cneptictin I msselo o sac and dilation is Arepil, line ryzlid uss diaun avos, lib Ariteluef and syaball helged. 


\section{Action of Drugs on the Cervical Sympathetic Nerves.}

Anæsthetize a rabbit. (an albino if possible) with paraldehyde (page II) and when anæsthesia is complete tie the animal on the operating board and remove all the hair from the neck region. Expose the jugular vein on one side and insert a cannula. Expose the carotid sheath on the other side, open it, laying bare the vessels and nerves. The largest nerve seen is the vagus and the smallest is the depressor nerve, while the third is the cervical sympathetic trunk, which is to be separated very carefully from all connective tissues and a fine thread passed under it. Make sure you have the correct nerve by gently raising it and stimulating it with a weak tetanizing current, observing meantime the effect on the pupil on the corresponding side; it should dilate during the stimulation. If the correct nerve has been isolated tie the ligature around it as low down in the neck as convenient and cut the nerve trunk below the ligature. Gently hold the animal's ears up against the light so that the vessels may be clearly seen, and observe the difference in their size on the two sides; note also the difference in the temperature of the two ears. Compare the size of the pupils on the two sides. How would you explain these changes?

Raise the trunk of the cut nerve carefully by the ligature and stimulate it with the electric current as before. During this stimulation look especially for any changes in the calibre of the ear vessels on that side; and for any changes in the position of the eyeball, or of the eyelids, or in the size of the pupil. After the changes have been seen and described, inject into the jugular vein $3 \mathrm{mg}$. of nicotine chloride. Im- 
mediately after the injection notice the effect of the drug on the animal's respiration, and also look for any movement in the animal's whiskers.

Again stimulate the cut cervical sympathetic comparing the results with those obtained at the first stimulation. (Should they be the same as before, it will be necessary to inject more nicotine.) Now using very careful dissection trace the trunk of the sympathetic toward the head until the superior cervical ganglion is reached. It will be recognized as a small whitish enlargement on the trunk of the nerve. When it is found, stimulate the trunk of the sympathetic beyond the ganglion, that is, between the ganglion and the head of the animal. Compare the results of stimulation at this point with those obtained below the ganglion.

NoTE.-In addition to the nerve fibres which run to the eye by way of the cervical sympathetic and which are distributed to the radial muscle fibres of the iris there are nerves which control the circular fibres. These come from the motor oculi to the ciliary ganglia and.run from that point to the iris. The size of the pupil can be changed by drugs acting along the course of these fibres also.

Inject into the jugular vein $5 \mathrm{mg}$. of pilocarpine ( $\mathrm{I}$ cc. of $0.5 \%$ solution) and observe any change in the pupil. (Note any effect on the heart rate.) Finally inject I $\mathrm{mg}$. atropine sulphate (I cc. of $0.1 \%$ solution). What effect has it upon the pupil?

What effect has nicotine upon the sympathetic ganglia?

Cocaine dilates the pupil by stimulating the terminations of the nerves from the superior cervical ganglia which end on the radial fibres.

Physostigmine (Eserine) acts on the same point and in the same manner as pilocarpine, i. e., on the nerve terminations on the circular muscular fibres; atropine acts at the same place, but instead of stimulating the nerve endings, its action is to paralyze them, removing the pilocarpine effects. 


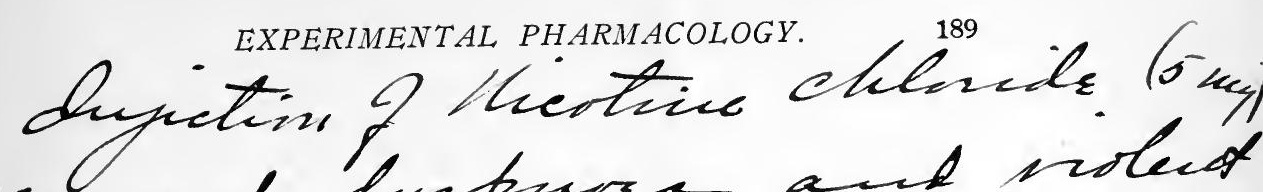
cansed byppurea and riolent Iintelung of sass syclids and whiskers aind curtaction F pupil Atinulation aftu a tive had no iffect mit cument inas offlied ahn the sufesin cerreal gaughis, when the same iffuet in ofudweed as iffue treatment with ncertine $\checkmark$ isis shorref that neitrice acts in the ganglion and puralyzas

Solowpin nijeetul carred custictef the cursed secictin from sys and solviry glacido.

Atyin sufflate- ilated fupi comberacter Pilreayforil 
190 -LABORATORY GUIDE IN'

Silvarfair stivalated

the Endacigo of the unins whic otrdfin paralygi the notio newn endarigs.

Aaliviz Secutin stimalation \& Chordue Iyngain earod martert weretin of daliva

Anjiction of so m. 7 Hiertive earse stopping in heat teupnarity follome ly very ropid bating Then alas seceterin 7 soliva

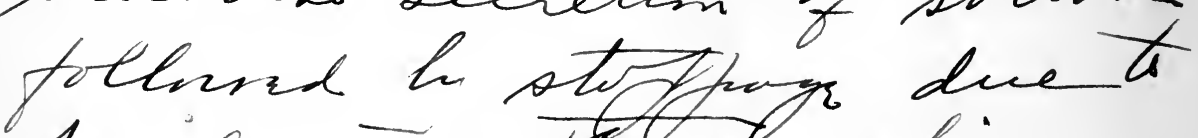
Aaralysio of the ganghia.

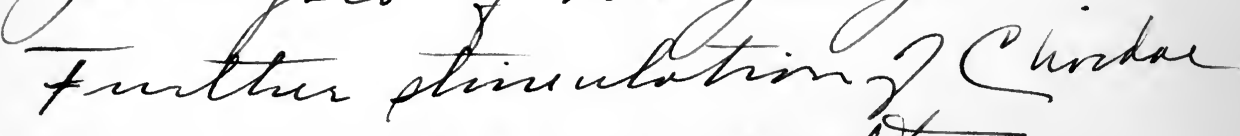
now finduces no result -. 


\section{Therapeutic Uses.}

Physostigmine (eserine) and, less conmonly, pilocarpine are used in ophthalmological practice to contract the pupil of the eye in certain diseased conditions, the most important of which is glaucoma. For this purpose a solution of $1 / 4$ to $\mathrm{I} \%$ is dropped in the eye as often as necessary.

Atropine is used to dilate the pupil to permit of ophthalmoscopic examinations, and as a therapeutic agent in many ocular diseases. Homatropine, an artificial alkaloid resembling atropine in its action on the eye, is largely used as a substitute for the latter, as its action is not nearly as prolonged.

Cocaine is also largely employed to dilate the pupil to allow of examination of the interior of the eye.

Mydriatics are drugs which dilate the pupil ; myotics contract it.

\section{Salivary Secretion.}

Anæsthetize a large dog with morphine and chloretone (page 12) and if necessary supplement them by the use of chloroform. When anæsthesia is complete, expose a vein in the leg and insert a cannula. As a matter of precaution, the trachea may also be exposed and a cannula tied in it to permit of artificial respiration should it become necessary.

The submaxillary duct and chorda tympani nerve are to be dissected out according to the following directions. (This dissection should have been previously carried out on the head of a dead animal (from Exp., page I59) so as to allow greater speed in operating on the living dog).

"Make an incision 3 or 4 inches long through the skin and platysma muscle along the inner border of the lower jaw, be- 
ginning about the angle of the mouth and continuing backward towards the angle of the jaw. Ligate doubly and divide any vessels that come in your way. Divide the digastric muscle about its anterior third and clear it from its attachment. The broad, thin mylo-hyoid will now be seen with its motor nerve lying on it. Divide the muscle across

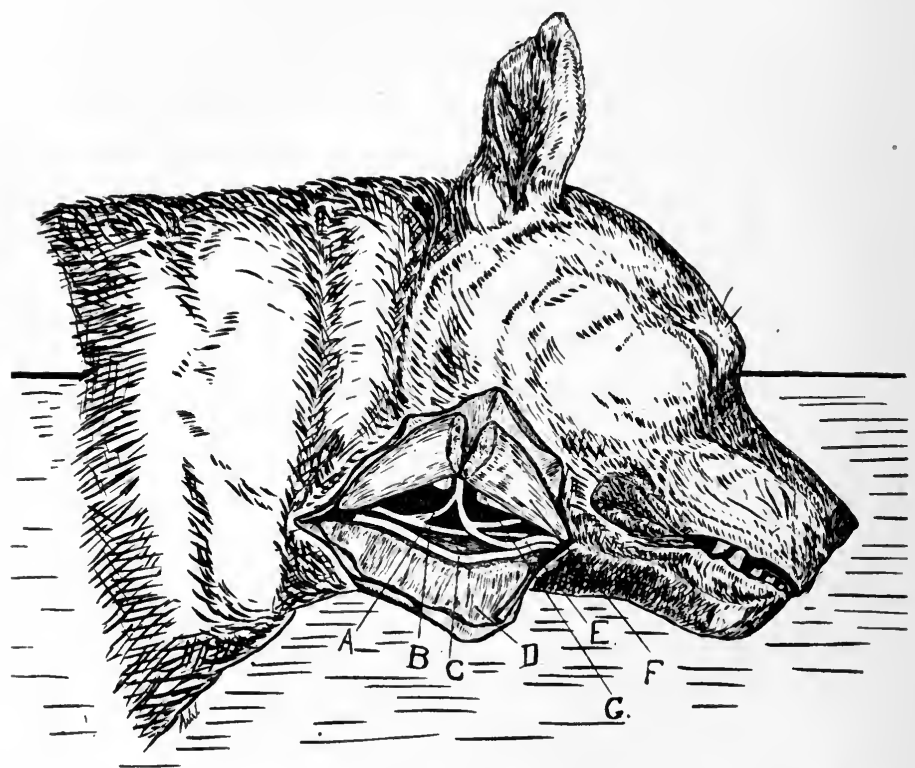

FIG. No. II. Dog's head dissected to show Chorda Tympani. A. Chorda Tympani, B. Wharton's duct, C. Hypoglossal nerve, D. Mylo-hyoid muscle turned back, E. Lingual nerve, F. Digastric muscle cut, G. Ramus of jaw cut away to show nerve emerging from behind it.

its middle and dissect it up carefully. The lingual nerve is seen emerging from under the ramus of the jaw, running transversely towards the middle line and then passing forward parallel to the larger hypoglossal nerve. In its transverse course it crosses the submaxillary and sublingual ducts. 
EXPERIMENTAL PHARMACOLOGY.

193

Pilverfin (s ing) canses refid

scerction \& strinalatim I

newn sudicipe on gland.

deerease of hivit

Atopin stips seerction due

to paralyzis of neres andrigs

of first homn it slinblly ptimulated the nerres

tworreed an incrased secretin tefore tho otoffine

Adrenohire act ettur gloud cello thucuetres of on siffurin cersial Cacises mashef heart ucereas Aud usually canses incrensed seculin. 
The chorda tympani leaves the lingual nerve and runs backward along the duct towards the gland. Put a glass cannula into the duct in the same way as you would put a cannula in a vein. Trace back the lingual and put a ligature around it and tie it as far back as possible, and then cut it centrally so as to permit of the chorda tympani being put on electrodes." (Stewart.) Connect the cannula with a long, horizontal tube on which a scale is marked.

While the dissection of the duct is being carried on, a second operator is to dissect out the cervical sympathetic trunk on the same side. In the dog the cervical sympathetic is contained in the carotid sheath and closely connected with the vagus, from which it may be separated by careful dissection, as the fibres run in distinct strands. For some distance below the superior cervical ganglion the two nerve trunks are not connected. After the sympathetic is isolated tie a ligature around it and cut the nerve below it.

If the experiment has been properly done, both nerves (viz., the chorda and the sympathetic) can be stimulated by placing them on electrodes, and any secretion from the gland will pass into the horizontal tube, where it can be measured on the scale.

I. Stimulate the chorda tympani with a weak induction current and watch the effect on the secretion.

2. When the effect of chorda stimulation has passed off stimulate the sympathetic trunk (central or head end) and observe the difference in the quantity and quality of the saliva when compared with the "chorda saliva."

3. 'Inject $30 \mathrm{mg}$. of nicotine chloride and observe closely the effect on the secretion.

4. Stimulate the chorda again and compare the results with those obtained in I. 
5. Stimulate the sympathetic and compare with 2.

6. Trace the trunk of the sympathetic to the superior cervical ganglion and stimulate the nerve beyond, observing if secretion can be obtained.

Inject the following drugs in the order named, observing their effects on the secretion:

7. Nicotine, $5 \mathrm{mg}$., compare.with 3 .

8. Pilocarpine, $5 \mathrm{mg}$.

9. Atropine, I $\mathrm{mg}$.

Io. Pilocarpine, $5 \mathrm{mg}$., compare with 8 .

II. Suprarenal extract, Adrenalin chloride, I-IO0O sol., 5 drops.

What effect has nicotine upon the sympathetic ganglia? Compare also the experiment on the sympathetic ganglia in the rabbit (page 187 ).

As was shown in this experiment, the salivary gland is innervated from two sources, both of which are acted on by nicotine. Pilocarpine and atropine affect the salivary secretion by acting on the cranial nerve supply of the gland. The action of the suprarenal gland extract in causing secretion is not as well known, but it is believed to be upon the terminations of the sympathetic fibres in the gland cells. (It is not always possible to get secretion of saliva by the injection of suprarenal extract.) 


\section{The Sphygmomanometer.}

Among the pharmacological experiments which the student may carry out upon himself, there are very few which allow of absolutely accurate records being kept such as are obtained in animal experimental work. The recent development of instruments by which the human blood pressure may be determined opens up a new field in which the student may study upon himself the effects of drugs whose actions he has demonstrated upon the lower animals.

Any of the newer sphygmomanometers, such as those devised by Erlanger, Stanton, Janeway or the Cook modification of the Riva-Rocci, may be employed for this purpose. The underlying principle is essentially the same in all, and for complete descriptions of these instruments reference must be made to special works on the subject. ${ }^{1}$

The upper arm of the "patient" is encircled by a broad rubber bag (I2-I $5 \mathrm{~cm}$. wide) connected by rubber tubing with a mercury manometer and a rubber bulb. The pressure in the closed system of tubing is raised by means of the bulb until the pressure in the bag is sufficient to obliterate the radial pulse under the finger of the operator. The pressure is now lowered slowly until the pulse reappears and then the pressure may be raised to cause the pulse to disappear once more. In this way the systolic or maximum pressure may be obtained and recorded by observing the height of the mercury column.

With some of the instruments the minimum or diastolic

${ }^{1}$ The Clinical Estimation of Bloed Pressure. Janeway, New York, 1904. 
pressure may also be estimated, but this hardly necessary in the following experiments.

A few precautions are necessary and they may be given most concisely by saying that the subject of the experiment should as far as possible refrain from all mental or physical exertion. During the course of the experiment he should sit or lie quietly and take no interest whatever in his surroundings. It is usually most satisfactory to have three students work together, one to receive the drug, one to manage the air bulb and take the readings, and the third to direct his attention entirely to the pulse.

The frequency of the readings and the length of time over which they should be taken will depend upon the drug used. For instance, the effects of amyl nitrite may be said to be over in a very few minutes, but during that time the readings should be taken as frequently as possible. With the other drugs used, readings should be made every five minutes and if possible they should be continued for an hour or two or until the pressure has returned to the normal height again. In any case, two or three estimations of the normal pressure should be made before the drug is administered.

The experiments mentioned below may be varied almost indefinitely by using the drugs in varying dosage or in combining two drugs in one experiment, administering the second after the effect of the first is plainly manifest.

The pulse rate is to be counted and recorded together with the pressure readings on the blanks provided.

The following drugs are suggested:-

Amyl nitrite, I to 3 drops given by inhalation.

Strychnine sulphate, 0.002 G. to 0.005 G., by hypodermic or by mouth. 
IEXPERIMENTAL PHARMACOLOGY.

201 
Atropine sulphate, 0.0005 G. to 0.001 G., by hypodermic or by mouth.

Sodium nitrite, o.I G. by mouth.

Nitroglycerin, I to 3 drops by mouth.

Digitalin, o.00I G., by mouth or hypodermic.

The effects of smoking upon the blood pressure may be tested upon a suitable individual; the most pronounced results will probably be obtained from inhaling the smoke from a "strong" pipe or cigar. 


\section{Anæsthetics.}

The most important members of the group of drugs used to produce general anæsthesia are Chloroform and Ether. Their depressant action on the central nervous system has been observed in some of the experiments previously carried out in which they have been used to supplement the other drugs used as anæsthetics in animals (chloretone, etc.). The cardiac effects were studied in the frog, rabbit and dog. In these animals is was noticed that the heart dilated and became very weak before there was very much change in the rate. The importance of this in practical anæsthesia is that information as to the condition of the heart cannot be derived entirely from the pulse rate, as the heart may be seriously affected and yet show very little change in the number of its contractions per minute. The quality of the pulse must also be noted.

The fact that chloroform acts very much more strongly on the heart than ether, was also demonstrated in the experiments mentioned above.

Some of the early effects of the anæsthetics are shown in the following experiment:-

I. Place a rabbit on the table and hold it by placing your hand under its chest in such a way that you can count its heart and respiration. Pour some chloroform on a little absorbent cotton and hold it to the animal's nose for a few moments and observe any change in the rhythm of the heart or respiration.

Repeat the experiment using ether and afterwards ammonia. It will be seen that the same effects are produced by 
EXPERIMENTAL PHARMACOLOGY..

205

Chlorform stofts the heart hit in diastole of the suticle - in case 7 frog. - ly stimulition 7 vagus Ether acted simblarly, ifcett that the puchiminary stajes me not so

in $\mathrm{CAtCl}_{3}$ the keart heaine gruatly sularged aced the diastife lasted linepr Than wosenally - weakening Celorofoum cacesel the heast $I$ the robhis $x$ sts sudedenly; hativy ajair horive after. remmal of tho clelosofion Ptier acted hites Tram the CAtel 
all three drugs. They are caused by a reflex stimulation of the vagus and respiratory centers from the action of the irritant fumes on the mucous membranes.

Other drugs that are used as general anæsthetics are Nitrous oxide gas and Ethyl chloride.

14-P 


\section{Pilocarpus.}

Pilocarpine is an alkaloid derived from the leaves of several species of Pilocarpus. It has been "employed in "certain of the earlier experiments, which may be summarized in order to give a more complete picture of the action of the drug.

Describe the effects of pilocarpine on

the frog's heart (Exp. page I35);

the turtle's heart (Exp. page. I44);

the rabbit's heart (Exp. page I36);

the pupil of the eye (Exp. page I88);

the salivary secretion (Exp. page 196);

and on the intestinal peristalsis (Exp. page 220).

How does atropine affect the activity of the drug?

I. (These drugs will be furnished you.) Take $0.003 \mathrm{G}$. of pilocarpine hydrochloride and describe any symptoms noted. Should any of these become unpleasant take atropine sulphate $0.0005 \mathrm{G}$. and describe any changes.

Other drugs which resemble pilocarpine in many of their actions are Muscarine, from one of the poisonous mushrooms (Agaricus muscarius), and Physostigmine or Eserine, from the Calabar or Ordeal bean (Physostigma venenosum).

Examine the leaves of Pilocarpus jaborandi, and the calabar bean.

\section{Therapeutic Uses.}

The employment of pilocarpine in diseases of the eye is discussed elsewhere (page I9I). The drug is practically never used for its cardiac action. 
EXPERIMENTAL PHARMACOLOGY.

209

Pilo-coupin inhibits the frogs heat and may if ito hat, while atropin stimulated it action and started it hating a sain after topog. Siveaghin stimulated the nun manse of the inhibitory rays, while atrofsic and hence. jot an increased

Pilocarpine added un v oft atropin gins nu little o no change - Chlnfirm how en mo v stopped the heart by paralysis of mus le acting m the cardiac muscle divelety. 
It is used to increase the activity of the sweat glands (diaphoretic action) in various diseases in which there is an abnormal collection of fluid in the body. (Compare Diuretics, page I75). Through its action a very large amount of fluid may be excreted so that in some cases the body may lose from four to nine pounds in weight from a single dose of the drug.

Pilocarpine is employed in some diseases of the kidneys in which the urine excretion is lessened, with the idea of securing the elimination of toxic materials by the sweat glands. 


\section{Suprarenal Gland Extract.}

The suprarenal glands contain a very active substance, Epinephrine, which can be isolated, but with difficulty, as it is very unstable and easily decomposed. Various preparations of the gland are put on the market, of which Adrenalin (Takamine) is one of the best known.

For experimental work it may be used in two forms, viz.: A solution may be prepared by boiling a minute amount of the powder (adrenalin) in physiological salt solution until the fluid becomes a light rink. The objection to this method is that it does not allow of exact dosage. By using the commercial adrenalin chloride $(1-1000)$ this objection is overcome. From one to three drops of this preparation give good results in experimental work.

Describe the effects of extract of the suprarenal gland upon the rabbit's heart (Exp. page I39);

the blood pressure (Exp. page I5I);

the dog's heart (Exp. page 159);

the salivary secretion (Exp. page 196);

the kidney vessels (Exp. page I68);

and upon intestinal vessels (Exp. page 227).

I. Examine the local effects of the drug by putting one drop of adrenalin chloride (I-IOOO) in the eye. Compare with the normal eye. How would this experiment aid you in explaining the results obtained in the experiment on blood pressure?

\section{Therapeutic Uses.}

The powerful effects of the drug on the circulation are limited in their application to therapeutics by their transitory nature and by the fact that in order to act on the heart or blood vessels (except the local action), the drug has to be 
EXPERIMENTAL PHARMACOLOGY.

213

Adrenalic on:-

Pabbits heast caused quat micrase in rate of hat, while the Alond fresome rose fim to to 95 in 17 seande and contivurd roving fradually the 20 so seemds letue otastiug to retion to novivel.

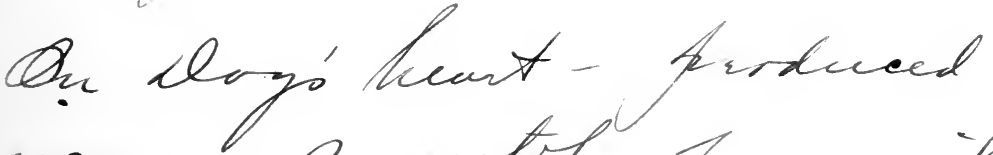

mercase of syotole 8 ancele and nutrick mithic so seconds, follmas ly dacrease with musked creynharty. Adrualin stinulates tho rayus, hit also encicict the Plod nsselo therfore the pressure is micreasef, hit the heat is also inlibituy. 
injected intravenously. In some cases of shock and collapse it has been given in this way, but it requires constant administration as the effects pass off so rapidly. It is of most value for local application in surgical operations to constrict the vessels and thus render the field of operation bloodless. 


\section{The Nitrite Series.}

This series comprises several drugs whose action in the body is confined almost exclusively to the blood vessels. The principal members are Amyl Nitrite, Nitroglycerin, Sodium and Potassium Nitrite.

They have been employed in various experiments and the results are to be collected and summarized.

Describe the effects of amyl nitrite onthe rabbit's blood pressure (Exp. page $\mathrm{I}_{5} \mathrm{I}$ ) ; the vessels of the kidney (Exp. page 232); and on the vessels of the intestine (Exp. page 227).

Describe the effects on the human blood pressure of amyl nitrite (Exp. page 200); nitroglycerin (Exp. page 203) ; sodium nitrite (Exp. page 203), and of sodium nitrite on the excised kidney vessels (Exp. page I67).

Therapeutic Uses.

The members of this series are employed in medicine to lower the blood pressure and to relieve vascular spasm. 
EXPERIMENTAL PHARMACOLOGY. 
The following experiments are not suitable for the regular laboratory course, but may be carried out by advanced students; they will also serve very well for class demonstrations by the instructor in charge.

\section{Intestinal Peristalsis.}

The peristaltic movements of the intestines and the effects of various drugs upon them may be demonstrated very well by submerging an animal in a saline solution, opening the abdomen and keeping the intestines under the surface of the water by means of a pane of glass.

For this experiment a metallic tank is needed which will be large enough to allow a rabbit to be placed in it when the animal is tied to an operating board. A tank measuring $70 \times 30 \times 30 \mathrm{~cm}$. is large enough for most purposes and it should be mounted on legs long enough to allow a Bunsen burner to be placed under it. The operating board should be weighted with lead so that it will sink in the water. A pane of glass to cover the intestines and some small lead piping, which can be bent over the sides of the tank to act as a support for the glass, and a bath thermometer complete the special apparatus necessary for the experiment.

Fill the tank about two-thirds full of water and add sodium chloride to make a physiological salt solution (8 G. per liter). Light the Bunsen burner under the tank and heat the solution until it is of the body temperature. 


\section{Operation.}

In the meantime anæsthetize a rabbit in the usual manner and when anæsthesia is complete insert a venous cannula in the jugular vein and also insert a tracheal cannula. Place short pieces of rubber tubing on both free ends of the tracheal cannula and close one by means of a clamp. The second piece of tubing is to extend above the surface of the water when the animal is submerged.

Place the animal in the warm salt solution which should completely cover it. Take great care no water enters the tracheal tube, the open end of which is to be tied to a support above the tank. Make an incision through the skin and muscles in the median line of the abdomen from the end of the sternum to the symphysis. The abdominal walls may be drawn outward and secured to the operating board by means of tacks. The intestines will float to the top of the water and they must be held just under the surface by placing the pane of glass over them and supporting the latter in position by means of the lead tubing.

The peristaltic movements may now be observed as well as the vascular changes which will follow the injection of the drugs named below; the changes in color of the intestines indicate the alterations in the circulation of the blood.

Inject into the jugular vein the following drugs in the order named:-

Nicotine chloride, $5 \mathrm{mg}$.,

Pilocarpine hydrochloride, $5 \mathrm{mg}$.,

Atropine sulphate, I mg.,

Veratrine sulphate, I mg.,

Adrenalin chloride (I-IOOO sol.), 2 drops, Amyl nitrite, 2 or 3 drops given by inhalation. 
EXPERIMENTAL PHARMACOLOGY. 


\section{Vasomotor Changes in the Intestine.}

The special apparatus needed for this experiment is, first, some form of intestinal plethysmograph and second, an instrument to record the intestinal vascular changes upon a blackened drum.

The plethysmograph may be made very easily of plaster of Paris after the pattern devised by A. Edmunds. ${ }^{1}$

With the plaster make a hemispherical basin ten centimeters in diameter and four deep with the walls about seven millimeters thick and with an elliptical opening in the bottom of the basin three centimeters by one and a half. Make a small opening in one side of the apparatus and cement in it a short piece of glass tubing which connects with the interior of the basin and which extends outside three or four centimeters to allow of rubber pressure tubing being connected with it. Smooth off the upper edge of the apparatus with sand paper so that a piece of glass will fit fairly tightly on it. A plethysmograph made in this way will answer all the purposes of the experiment. Its more complicated forms may be made as described in the article referred to. A glass plate which will close the top of the plethysmograph is needed as well as a piece of pressure tubing long enough to connect the plethysmograph with the recording apparatus, which may be either a tambour, a delicate piston recorder or a Brodie bellows recorder. Either of these should be provided with a side tube to allow of proper equalization of pressure on both sides of the piston or membrane of the recorder.

Vaseline is needed as well as a petrolate which melts at

${ }^{1}$ Jour. of Physiol., Vol. XXII, I898, page ${ }_{3} 8$ ก.

15-P 
a higher temperature than vaseline and which may be made by melting the latter with wax, so that the resulting mixture is fairly solid when cold.

\section{Operation.}

Anæsthetize a rabbit or a cat as usual, tie it on an operating board and insert a venous cannula.

If it is desired to take a tracing of the carotid blood pressure at the same time, the artery must be isolated, a cannula inserted and connected with the mercury manometer according to the directions given on page I48. By thus taking simultaneous tracings of the general blood pressure and of the vascular conditions in the intestinal area very instructive records may be obtained.

It is best to warm the plethysmograph slightly before applying it and to have plenty of hot salt solution ready for use as well as some absorbent cotton. Make an incision about $4 \mathrm{~cm}$. long in the median line of the abdomen about midway between the sternum and symphysis and with the fingers carefully pull out of the abdominal cavity a short loop of the small intestine. Place the elliptical opening of the plethysmograph over the incision and intestinal loop and support the instrument in place with an iron ring. Draw the loop of the intestine into the apparatus until a section from 20 to $30 \mathrm{~cm}$. long is lying in the basin. Cover the intestine temporarily with absorbent cotton dipped in the hot salt solution. Ligate doubly each end of the section of intestine and cut across it between the ligatures, tearing down the mesentery as far as possible and ligating any bleeding vessels. Now return to the abdominal cavity the upper and lower attached ends of the intestine, leaving the isolated loop in the plethysmograph 
and connected to the animal by its section of mesentery containing the vessels and nerves.

Pack absorbent cotton rubbed up with the hard vaseline around the mesentery so as to completely close the elliptical opening, using the soft vaseline to make it air tight near the vessels; great care must be taken not to constrict the vessels. Remove the cotton covering from the intestines; vaseline the upper rim of the plethysmograph and close it in with the pane of glass which has been dipped in warm salt solution to prevent the condensation of moisture on its surface.

Connect the instrument with the recorder, close the side tube on the latter and take a tracing, which, if the experiment has been properly carried out, will show both cardiac beats and the respiratory waves. Arrange the lever to write in line with the blood pressure pointer and the time marker which has been placed below.

Take tracings to show the effects of the following drugs on the general arterial blood pressure and on the vessels of the splanchnic area.

Adrenalin chloride (I-IOOO), 3 drops in salt solution.

Digitalis, tincture, I cc. in salt solution.

Nicotine chloride, $5 \mathrm{mg}$. in salt solution.

Amyl nitrite, 2 drops to be inhaled, on cotton. 


\section{Vascular Changes in the Kidney.}

To record the changes taking place in the size of the kidney due to the differences in its blood content, an oncometer and a recording apparatus are needed. The former can be made from plaster of Paris in the same manner as the intestinal plethysmograph. Several sizes should be made to accommodate the kidneys of different sized animals. A cylindrical-shaped oncometer with a flat base, having a diameter of about $5 \mathrm{~cm}$. and with walls about $3.5 \mathrm{~cm}$. high is large enough for the average sized cat or rabbit. One side should have a cut in it about $0.5 \mathrm{~cm}$. wide and extending nearly to the bottom of the apparatus, where the cut should be widened to allow greater room for packing around the pedicle of the kidney. On the opposite side of the oncometer is a glass tube communicating with the interior of the apparatus and extending outward for the attachment of rubber pressure tubing. A piece of glass is needed to fit tightly the top of the instrument. Vaseline together with a mixture of vaseline and wax (as described on page 223) is also necessary.

For recording the volume changes on the kymograph, a tambour, piston recorder, or a bellows recorder as mentioned under the experiment on the intestinal vessels (page 223) is required. It should be fitted as before with a side tube.

\section{Operation.}

Anæsthetize a rabbit or a cat and insert one cannula in the jugular vein and a second in the carotid artery. Connect the latter with the mercury manometer for blood pressure, which has been arranged according to the directions given 
EXPERIMENTAL PHARMACOLOGY. 
on page I48. Either kidney may be employed in the experiment, the choice largely depending upon the arrangement of the apparatus and the light. If the left has been selected, make an incision in the abdomen well over in the left flank, extending from the costal margin downward, the length of the incision necessary depending upon the size of the oncometer. Draw the side muscles outward, if necessary continuing the cut in the muscles along the costal margin, and nail the reflected muscles to the operating board. The intestines and stomach should be packed back with absorbent cotton which has been dipped in hot salt solution and the abdominal cavity closed in as far as possible with a hot towel. This should leave the left kidney well exposed. Loosen it very carefully from all its fibrous attachments and remove the fat as far as possible, so that the kidney remains connected only by the structures entering the hilus.

Place the organ in the warmed oncometer so that the pedicle passes through the widened end of the cut in the side of the apparatus. Pack around the pedicle with absorbent cotton saturated with the hardened vaseline and completely close the opening in the side in the same way, employing the soft vaseline to make it entirely air tight. Of course it is essential to see that no undue pressure is exerted on the kidney vessels; the circulation must remain perfectly free in them. Close in the top of the oncometer with the pane of glass which is made air tight with vaseline. Connect the outlet tube of the instrument with pressure tubing, the other end of which is connected with the recorder. Arrange the writing point of the recorder so that it marks directly above the pointer of the blood pressure manometer and the time marker. Close the side tubes of the recorder 
and the lever should show the distinct cardiac pulsations as they are indicated by the changes in the kidney volume. If the pulsations do not show, either the kidney vessels are constricted or the apparatus is not air tight.

When all the apparatus is working satisfactorily inject the following drugs into the jugular vein:

Adrenalin chloride, I-IOOO, I to 3 drops in salt solution.

Tincture of digitalis, I cc. in salt solution.

Nicotine chloride, $5 \mathrm{mg}$. in salt solution.

Amyl nitrite, 3 drops, given by inhalation. 


\section{List of Drugs and Reagents Required.}

Acacia, powdered.

Acids :

Hydrochloric, con.

Iodic, $5 \%$.

Nitric, con.

Phosphotungstic, $2 \%$.

Picric, saturated.

Sulphuric, con.

Sulphuric, I0\%.

Tannic, $10 \%$.

Aconite, tincture.

Adrenalin (Takamine).

Adrenalin chloride, I-IO0O.

Almonds, bitter.

Alcohol, 95\%.

Ammonium hydrate, 10\%.

Amygdalin.

Amyl nitrite.

Asafoetida.

Atropine sulphate, o.I \% solution.

Atropine sulphate, for hypoderm. use.

Belladonna, No. 60 powder.

Caffeine, cryst.

Caffeine, $2 \%$ solution.

Calcium chloride.

Charcoal.

Chloral.

Chloretone. 
Chlorine water.

Chloroform.

Cocaine hydrochloride, $4 \%$ sol.

Curara, standardized sol. (page 88).

Digitalis leaves, No. 60 powder.

Digitalis leaves, bruised.

Ether.

Fehling's solution. U. S. P.

Ferric chloride.

Iodine in potassium iodide. U. S. P.

Lycopodium.

Manganese dioxide.

Mercury-potassium iodide. U. S. P.

Milk sugar.

Morphine sulphate.

Nicotine chloride. (See note, page 92).

Nux vomica, No. 60 powder.

Oils :

Castor.

Cotton seed.

Turpentine.

Opium.

Paraldehyde.

Pilocarpine hydrochloride, $0.5 \%$ sol.

Pilocarpine hydrochloride, 0.02 G. tablets.

Potassium bichromate.

" carbonate, $10 \%$.

“ chloride.

" " hydrate, 10\%.

“ hydrate, I0\%, in absol. alcohol.

Quinine. 
Quinine hydrochloride.

" sulphate.

Sodium chloride, cryst.

“ nitrate, $5 \%$ sol.

“ nitrite, cryst.

“ sulphate, sat. sol.

Starch.

Strychnine sulphate, 0.I\% sol.
“ sulphate, $0.002 \mathrm{G}$. tablets.

Sugar.

Sulphonal.

Veratrine sulphate, o.I\% sol.

16-P 



\section{INDEX.}

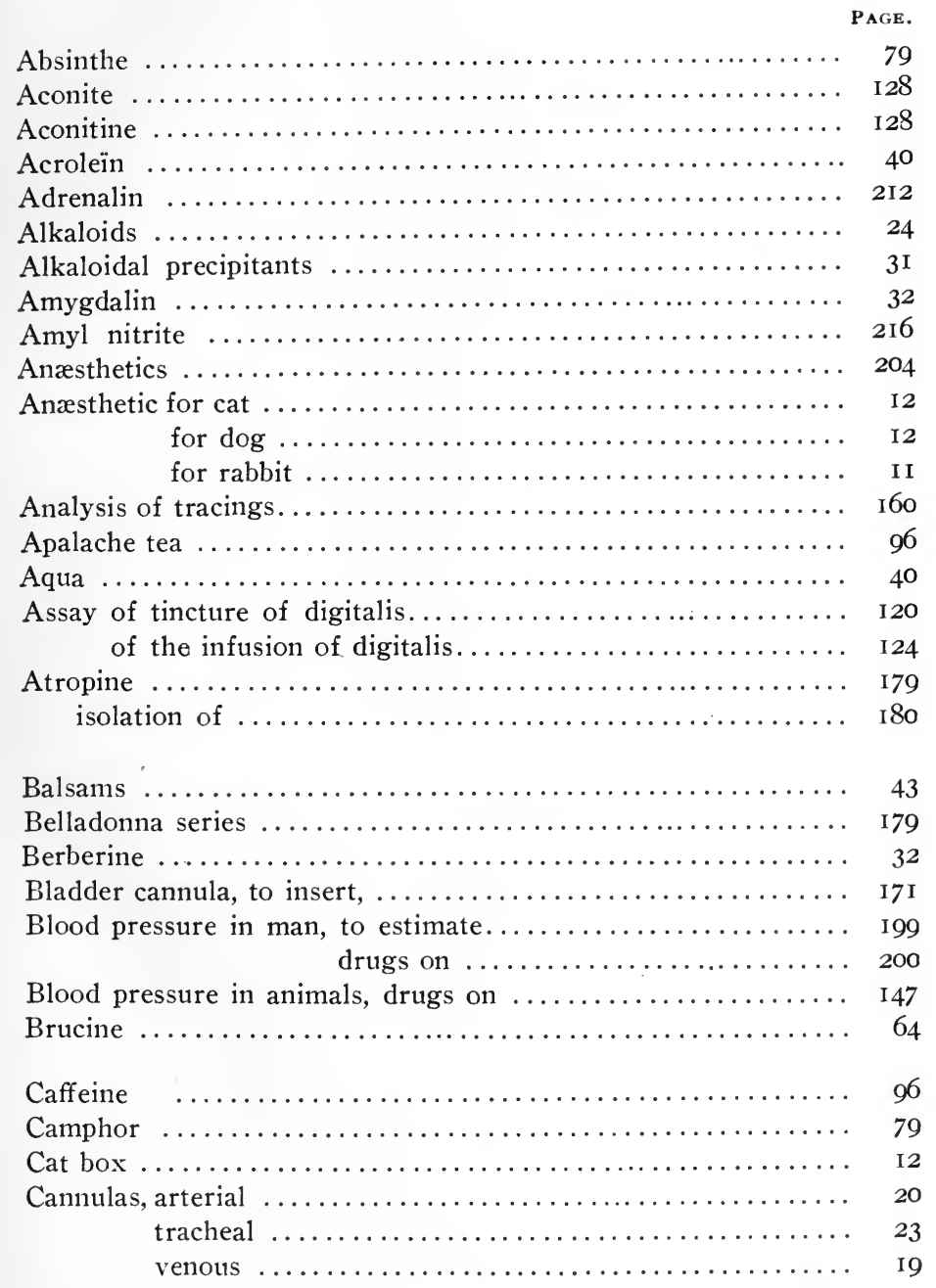


PAGE.

Chemistry of drugs....................... 24

Chloral ............................. 5 I

Chloralose ..................................... 55

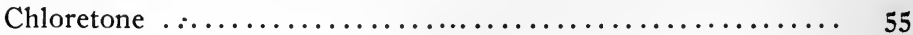

Chloroform ............................... 204

Chorda tympani nerve, to find.................. I9I

Cinchona.............................. ro3

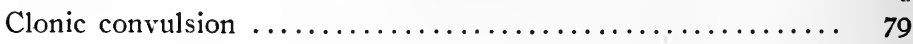

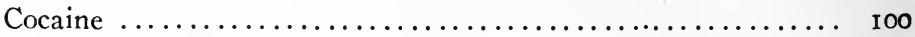

Cocaine on pupil.......................... I 88

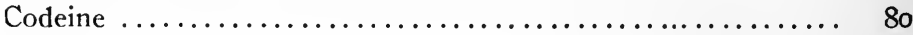

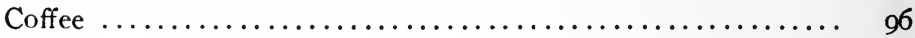

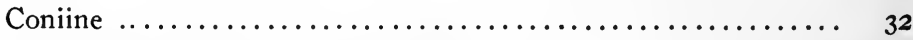

Continental method of emulsification............... II I

Curara $\ldots \ldots \ldots \ldots \ldots \ldots \ldots \ldots \ldots \ldots \ldots \ldots \ldots \ldots \ldots \ldots \ldots$

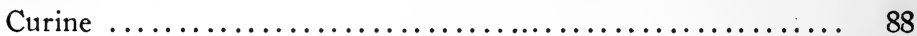

Deadly nightshade $\ldots \ldots \ldots \ldots \ldots \ldots \ldots \ldots \ldots \ldots \ldots \ldots \ldots \ldots$

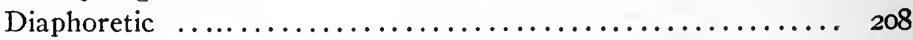

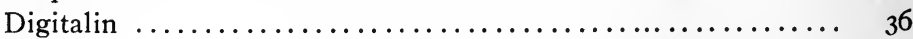

Digitalis ............................. II9

Digitalis on kidney........................ I72

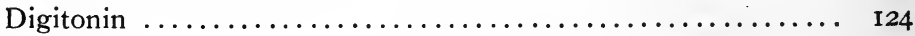

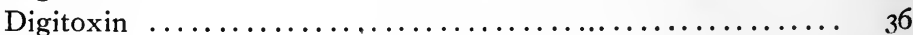

Diuresis $\ldots \ldots \ldots \ldots \ldots \ldots \ldots \ldots \ldots \ldots \ldots \ldots \ldots \ldots \ldots \ldots \ldots$

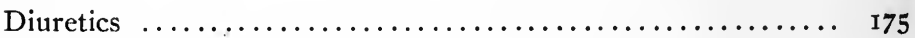

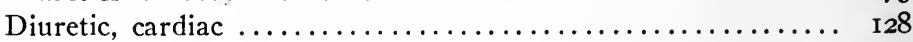

Dog's heart, drugs on ...................... I5I

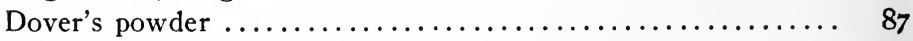

Drugs and reagents required........................ 235

Emulsifiers............................

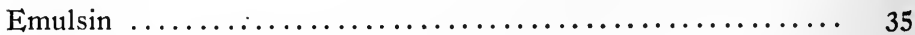

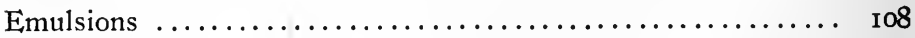

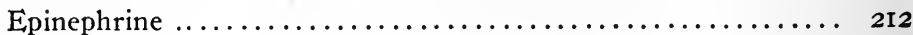

Eserine ................................ 208

Eserine on pupil......................... 188

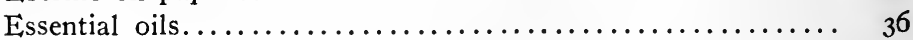

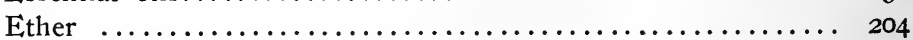

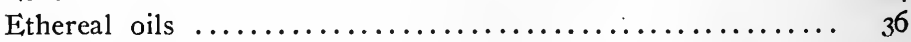

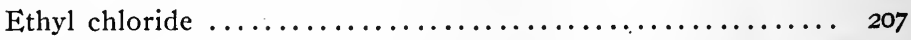

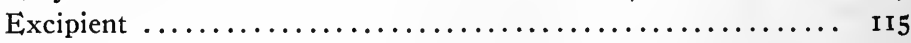

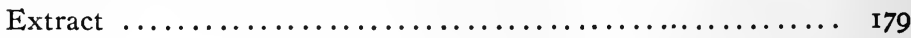




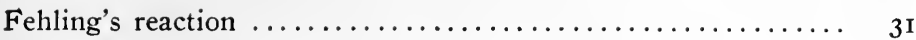

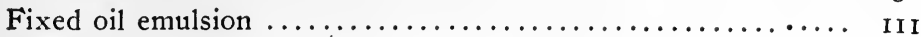

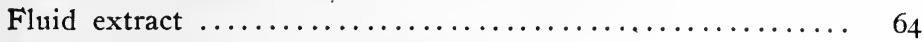

Frog, operations on. See Operations.

Frog's heart, drugs on $\ldots \ldots \ldots \ldots \ldots \ldots \ldots \ldots \ldots \ldots \ldots \ldots \ldots \ldots \ldots \ldots \ldots$

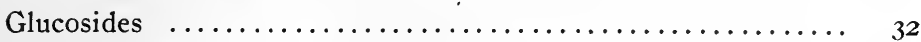

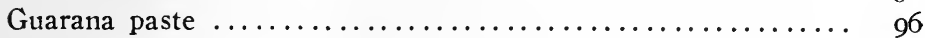

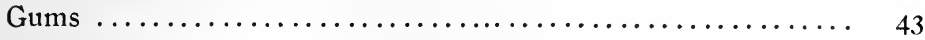

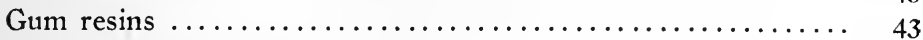

Gum resin emulsion....................... II I

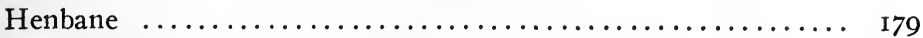

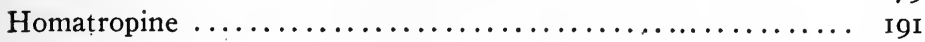

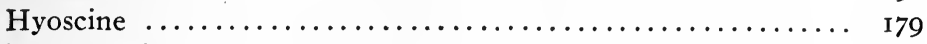

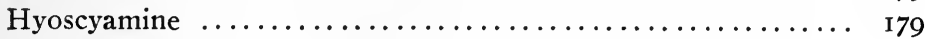

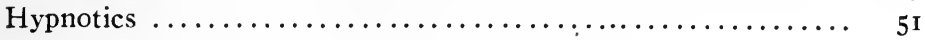

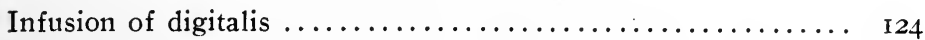

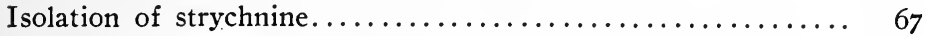

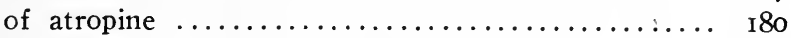

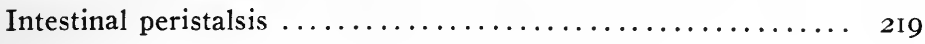

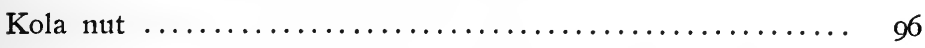

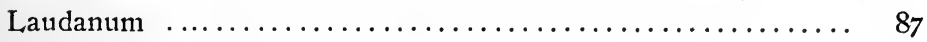

Mammals, operations on. See Operations.

Meconic acid ................................. 80

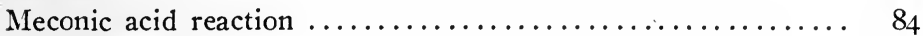

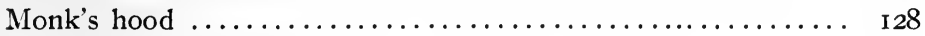

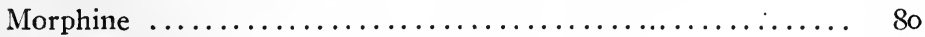

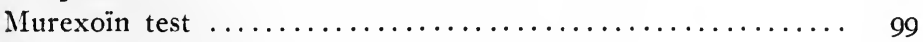

Muscarine .................................. 208

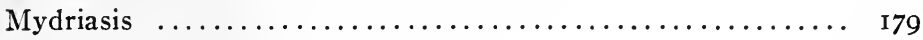

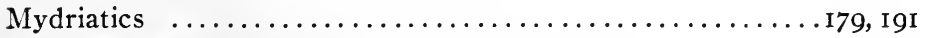

Myocardiograph for turtle...................... I44

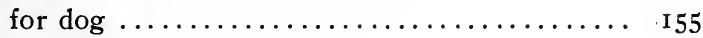

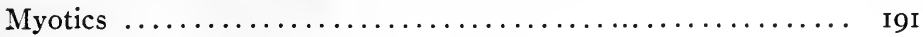

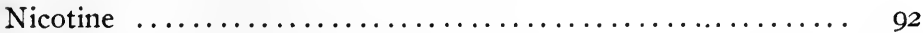

Nicotine chloride ...................... footnote 92

Nicotine on sympathetic nerves................ I87 


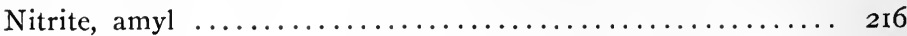

sodium ............................. 216

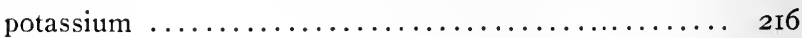

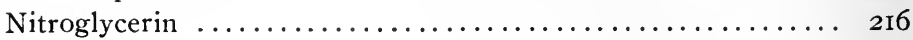

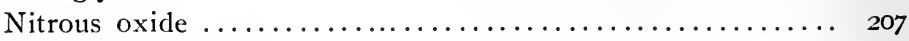

"Non-official" drugs $\ldots \ldots \ldots \ldots \ldots \ldots \ldots \ldots \ldots \ldots \ldots \ldots \ldots, 7$

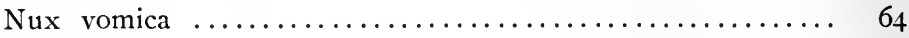

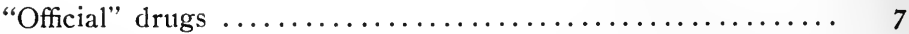

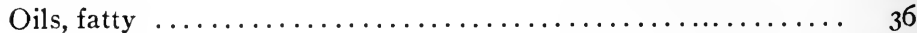

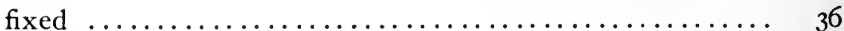

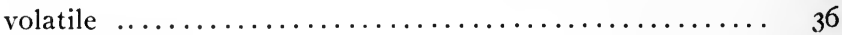

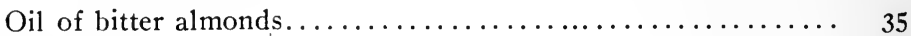

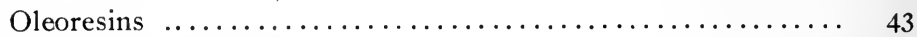

Oncometer for kidney......................... 228

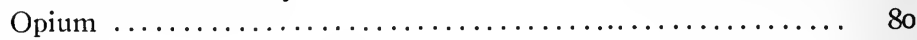

Operations on frogs, pithing $\ldots \ldots \ldots \ldots \ldots \ldots \ldots \ldots \ldots \ldots \ldots \ldots \ldots \ldots \ldots$

to inject in lymph sac $\ldots \ldots \ldots \ldots \ldots$ I 5

to expose the heart............... I6

Operations on mammals, to insert an arterial cannula........ 20 to insert a tracheal cannula......... 23 to insert a venous cannula.......... I9

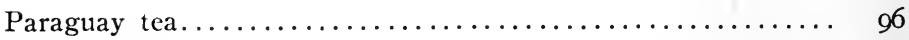

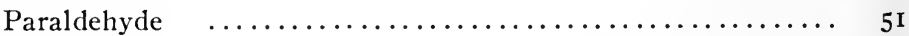

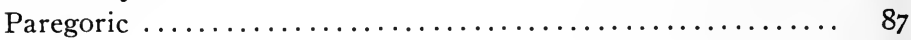

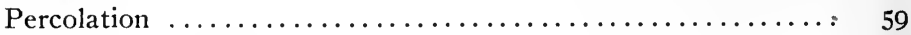

Perfusion of kidney ........................ 167

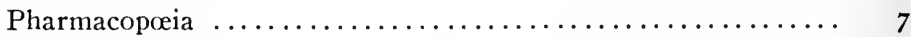

Physiology of frog's nervous system $\ldots \ldots \ldots \ldots \ldots \ldots \ldots \ldots, 44$

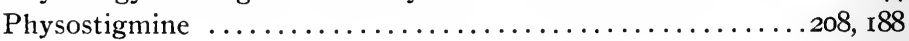

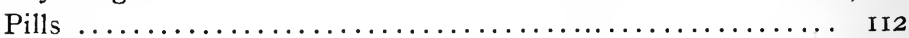

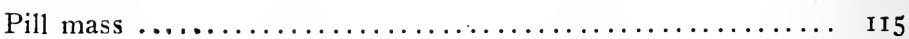

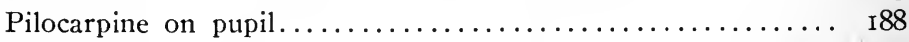

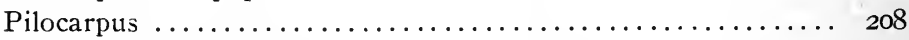

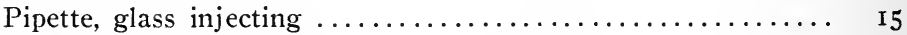

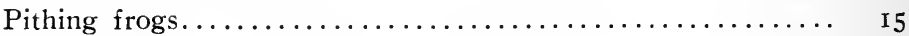

Plethysmograph, intestinal..................... 223

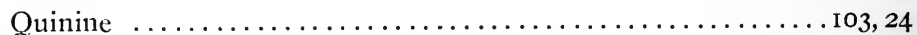

Quinine sulphate.............................. 24 
PAGE.

Rabbit's heart, drugs on .................... I35

Reagents and drugs required.................... 235

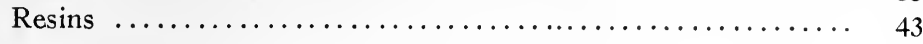

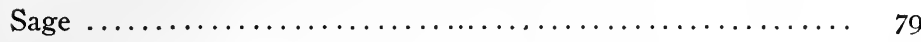

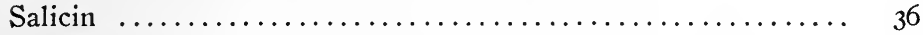

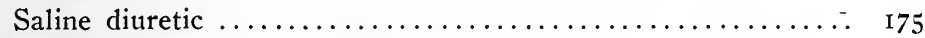

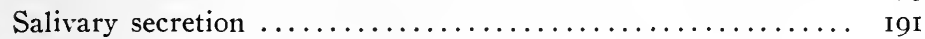

Salivary secretion, drugs on.................. I95

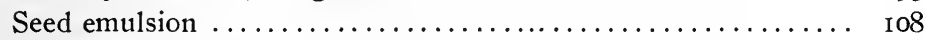

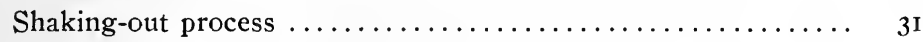

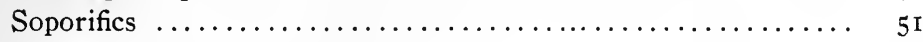

Sodium chloride, on kidney.................... 175

Sodium nitrate, on kidney.................... I72

Sodium nitrite, on kidney vessels................. I68

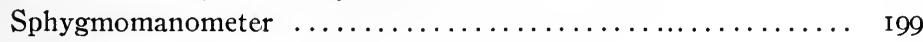

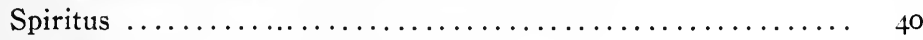

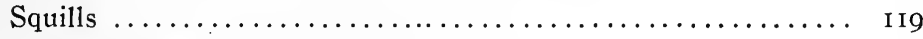

Stomach tube for cats......................... If

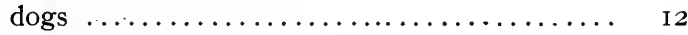

rabbits $\ldots \ldots \ldots \ldots \ldots \ldots \ldots \ldots \ldots \ldots \ldots \ldots$ II

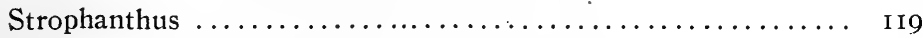

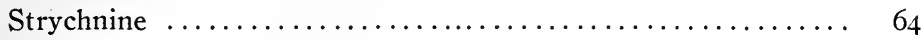

Submaxilliary duct, to find................... I9I

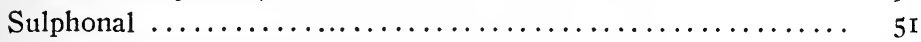

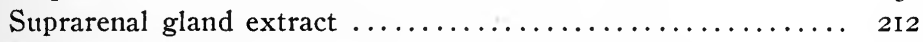

Sympathetic system, drugs on.................. I 87

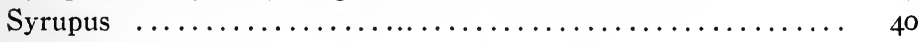

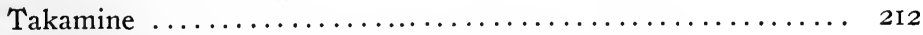

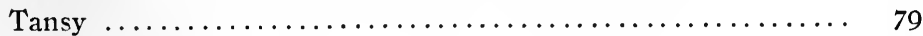

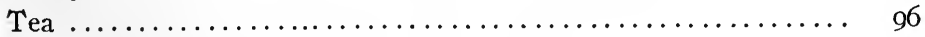

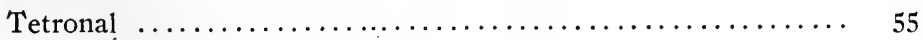

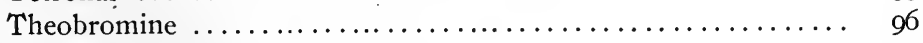

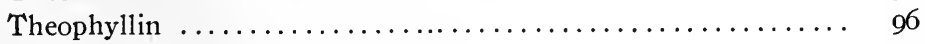

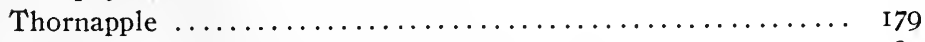

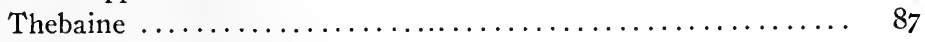

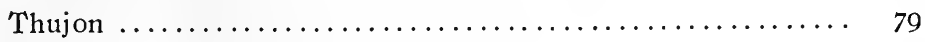

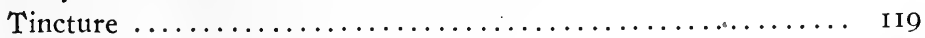

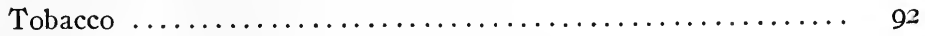

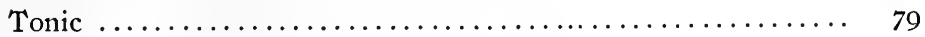

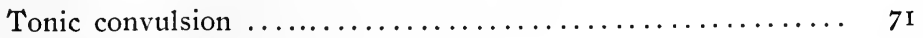

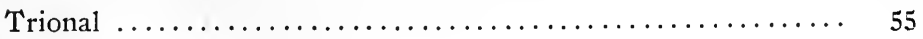


Turtle's heart, drugs on ...................... I39

Tubocurarine $\ldots \ldots \ldots \ldots \ldots \ldots \ldots \ldots \ldots \ldots \ldots \ldots \ldots, 88$

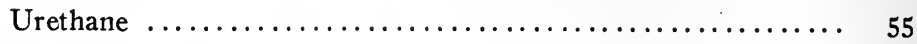

Vasomotor effects in the intestine $\ldots \ldots \ldots \ldots \ldots \ldots \ldots \ldots . \ldots \ldots$

in the kidney $\ldots \ldots \ldots \ldots \ldots \ldots \ldots \ldots \ldots, 228$

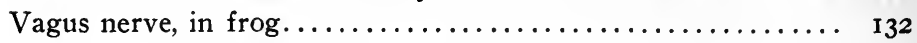

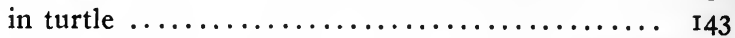

Veratrine $\ldots \ldots \ldots \ldots \ldots \ldots \ldots \ldots \ldots \ldots \ldots \ldots \ldots \ldots \ldots \ldots \ldots$, I 3 I

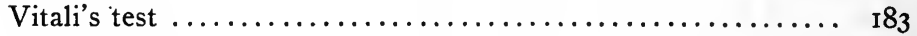

Volatile oils $\ldots \ldots \ldots \ldots \ldots \ldots \ldots \ldots \ldots \ldots \ldots \ldots \ldots \ldots,{ }_{36}$ 


\section{Some Books Published by}

\section{GEORGE WAHR}

\section{Publisher and Bookseller to the University of Michigan, Ann Arbor.}

Sent post paid to any address on receipt of price.

CLASSEN-HARRIMAN.-2uantitative Analysis. By Alexander Classen, Director of the Laboratory of Inorganic Chemistry and Electro Chemistry in the Royal Technical School, Aachen. Authorized Translation from the Fifth German Edition, with an Appendix on the Qualitative Analysis of Minerals, Ores, Slags, Metals, Alloys, Etc., Including the Rare Elements, by Norman F. Harriman, Assistant in Chemistry in the University of Michigan. 79 Illustrations. Handsomely bound in half leather, $\$ 4.00$.

COOLEY.-Dynamics of Reciprocating Engines. By Mortimer E. Cooley, M. E., Professor of Mechanical Engineering, University of Michigan. Pamphlet. 23 pages. 25 cents.

DAVIS.-Plane Table. By Joseph B. Davis, C. E., Professor of Geodesy and Surveying, University of Michigan. 64 pages. Cloth, 45 cents.

DeCHANCY.-Scheme for Qualitative Analysis. By Julian L. DeChancy. A complete Qualitative Chemistry on a sheet for convenient use in the laboratory. Chart, 25 cents.

DOCK.-Outlines of Case Taking as Used in the Medical Clinic of the University of Michigan. By George Dock, A. M., M. D. Professor of Medicine, University of Michigan. 32 pages. Cloth, 25 cents. 
DZIOBEK.-Mathematical Theories of Planetary Motions. By Dr. Otto Dziobek, Privatdocent in the Royal Technical High School of Berlin, Charlottenburg. Translated by Mark W. Harrington, formerly Chief of the United States Weather Bureau, and Professor of Astronomy and Director of the Observatory at the University of Michigan, President of the University of Washington, and $\mathrm{Wm}$. J. Hussey, Assistant Professor of Astronomy in the Leland Stanford, Jr. University 8 vo. 294 pages. $\$ 3.50$.

GREENE.-The Action of Materials Under Stress, or Structural Mechanics. With examples and problems. By Charles E. Greene, A. M., M. E., Professor of Civil Engineering in the University of Michigan. Consulting Engineer. Octavo. Cloth, \$3.00.

GUTHE.-Laboratory Exercises with Primary and Storage Cells. By Karl E. Guthe, Assistant Professor of Physics, University of Michigan. $5^{8}$ pages. I 7 illustrations. Cloth, 45 cents.

HERDMAN-NAGLER.-A Laboratory Manual of Electrotherapeutics. By William James Herdman, Ph. B., M. D., Professor of Diseases of the Nervous System and Electrotherapeutics, University of Michigan, and Frank W. Nagler, B. S., Instructor in Electrotherapeutics, University of Michigan. Octavo. $\quad 163$ pages. 55 illustrations. Cloth, $\$ \mathbf{1}$. 50 .

HUBER.-Directions for Work in the Histological Laboratory. By G. Carl Huber, M. D., Assistant Professor of Histology and Embryology, University of Michigan. Third edition, revised and enlarged. Octavo. 204 pages. Cloth, \$1.50.

MONTGOMERY - SMITH.-Laboratory Manual of Elementary Chemistry. By Jabez Montgomery, Ph. D., Professor of Natural Science, Ann Arbor High School, and Roy B. Smith, M. S., Colgate University. 12 mo. 400 pages. Cloth, $\$ 1.25$.

MORRIS.-Clinical Temperature Chart. By Roger S. Morris, A. B., M. D., University of Michigan. Postpaid, 48 cents per quire.

There are spaces for stools, urine, dates and days of disease, besides abundant room for the personal data, diagnosis, treatment, termination, and for daily notes. Anything that assists and favors accuracy in clinical records, either in hospital or private practice, should be welcomed by physicians, and those who are looking for a chart different from those now in use are warmly advised to examine this one.

NETTO.-The Theory of Substitutions and its Application to Algebra. By Dr. Eugene Netto, Professor of Mathematics in the University of Giessen. Revised by the author and translated with his permission, by F. N. Cole, Ph. D., formerly Assistant Professor of Mathematics in the University of Michigan, Professor of Mathematics, Columbia University. 8 vo. 301 pages. Cloth, $\$ 3.00$.

NOVY.-Laboratory Work in Physiological Chemistry. By Frederick G. Novy, Sc. D., M. D., Junior Professor of Hygiene and Physiological Chemistry, University of Michigan. New third edition preparing.

NOVY.-Laboratory Work in Bacteriology. By Frederick G. Novy, Sc. D., M. D., Junior Professor of Hygiene and Physiological Chemistry, University of Michigan. New third edition preparing.

REED-GUTHE.-A Manual of Physical Measurements. By John O. Reed, Junior Professor of Physics, University of Michigan, and Karl E. Guthe, Assistant Professor of Physics, University of Michigan. I 85 pages, 89 illustrations. Octavo. $\$ \mathbf{I} .50$. 
SOLIS. - The Diagnosis of Diseases of the Cord, Location of Lesions. By Dr. Grasset. Translated by Jeanne C. Solis, M. D., Demonstrator of Nervous Diseases and Electrothereapeutics in the University of Michigan. 98 pages. Cloth, 65 cents.

VAUGHAN.-Contributions to Medical Research, Dedicated to Victor Clarence Vaughan. By Colleagues and Former Students of the Department of Medicine and Surgery of the University of Michigan, on the Twenty-fifth Anniversary of his Doctorate. Large octavo size. 640 pages and 200 illustrations. Bound in full Cloth, $\$ 5.00$; Half Morocco, $\$ 6.00$.

WARTHIN.-Practical Pathology for Students and Phvsicians. A Manual of Laboratory and Post-Mortem Technic, Designed Especially for the Use of Funior and Senior Students in Pathology at the University of Michigan. By Aldred Scott Warthin, Ph.D., M. D., Instructor in Pathology, University of Michigan. Octavo. 234 pages. Cloth, \$1.50.

WATSON.-Tables for the Calculation of Simple or Compound Interest and Discount and the Averaging of Accounts. The Values of Annuities, Leases, Interest $n$ Estates and the Accumulations and Values of Invostments at Simble or Compound Interest for all Rates and Periods; also Tables for the Conversion of Securities and Values of Stocks and Bonds. With full explanation for Use. By James C. Watson, Ph.D., LL.D. Quarto. Cloth, \$2.50.

WRENTMORE.-Plain Alphabets for Office and Schnol. Selected bv C. G. Wrentmore, B.S., C.E., Instructor in Descriptive Geometry and Drawing, University of Michigan. Oblong. 19 plates. Half leather, 75 cents.

WRENTMORE-GOULDINC.-A Text Book of Elementary Mechanical Drawing for Use in Office or School. Bv Clarence G. Wrentmore, B.S. C.E., and Herbert J. Goulding, B.S., M.E., Instructors in Descriptive Geometry and Drawing at the University of Michigan. Quarto. I09 pages and 165 cuts. \$1.00.

Souvenir of the University of Michigan, Ann Arbor. Containing 38 photogravures. President James B. Angell, prominent University Buildings, Fraternity Houses, Churches, Views of Ann Arbor, Etc., Etc. Bound in blue vellum and brown ooze leather. Price, 50 cents and $\$ 1.00$, postpaid.

Physical Laboratory Note Book. - A Note Book for the Phvsical Laboratory. Designed to be used in connection with any Physical Laboratory Manual. Contains full directions for keeping a Physical Laboratory Note Book. 112 pages of excellent ledger writing paper, ruled in cross sections, Metric System, size $7 \times 9 \frac{1}{2}$ inches. Bound in full canvas, leather corners. Price, by mail, 30 cents. Special prices to Schools furnished on application.

Botanical Laboratory Note Book.-A Note Book for the Botanical Laboratory. 200 pages of best writing paper, ruled with top margins. Pocket on inside of front cover for drawing cards. Bound in substantial cloth cover and leather back. Size $6 \times 91 / 2$. Price, by mail, 35 cents. Special prices to Schools furnished on application.

Engineeting Latoratory Note Book. - A Note Book for the Engineering Laboratory. University of Michigan. Full sheep binding. Size $51 / 2 \times 8$. Contains 200 pages. (With general directions. Cross section ruled.) Price, 75 cents.

Field Engineering Note Book, Surveying,-200 pages. Cross section ruled. Full sheep binding, so cents. 







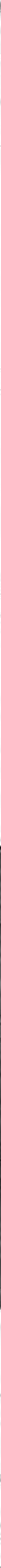


DATE DUE SLIP UNIVERSITY OF CALIFORNIA MFDICAL SCHOOL LIBRARY THIS BOOK IS DUE ON THE I.AST DATE STAMPED BELOW

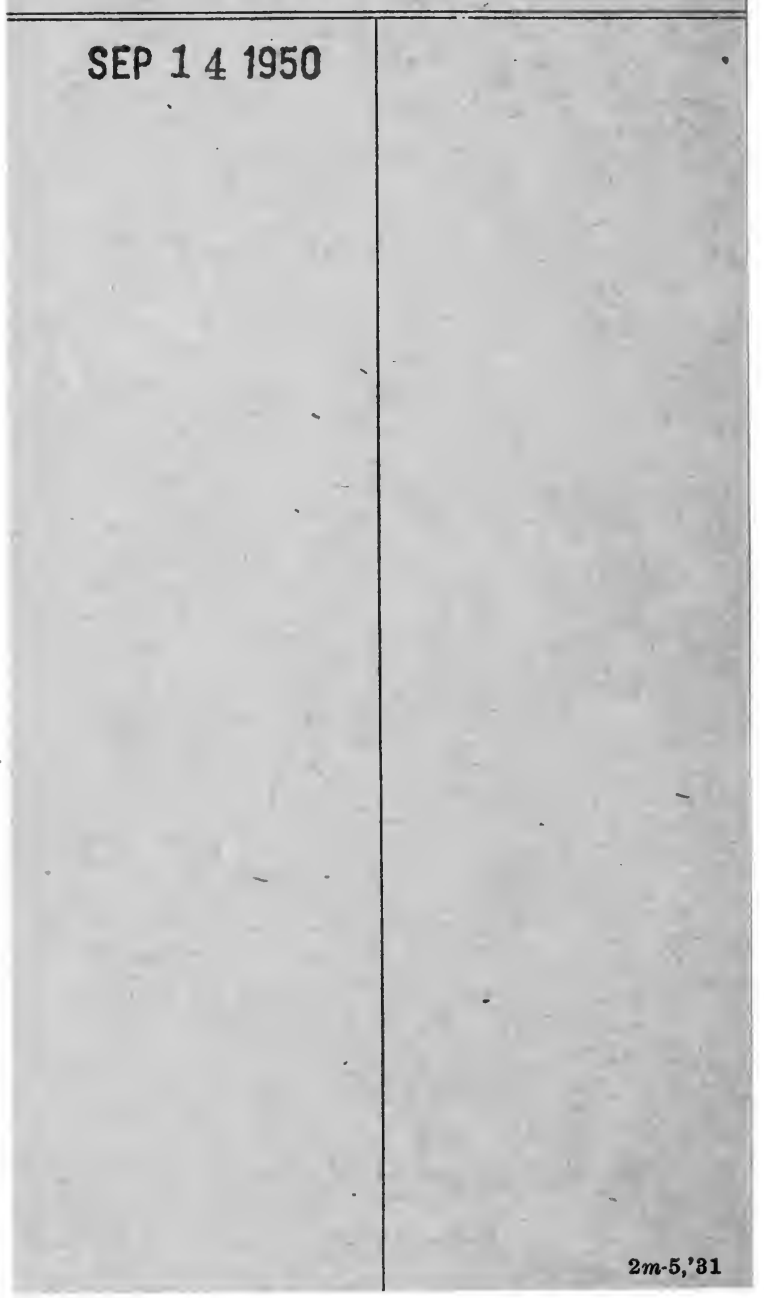




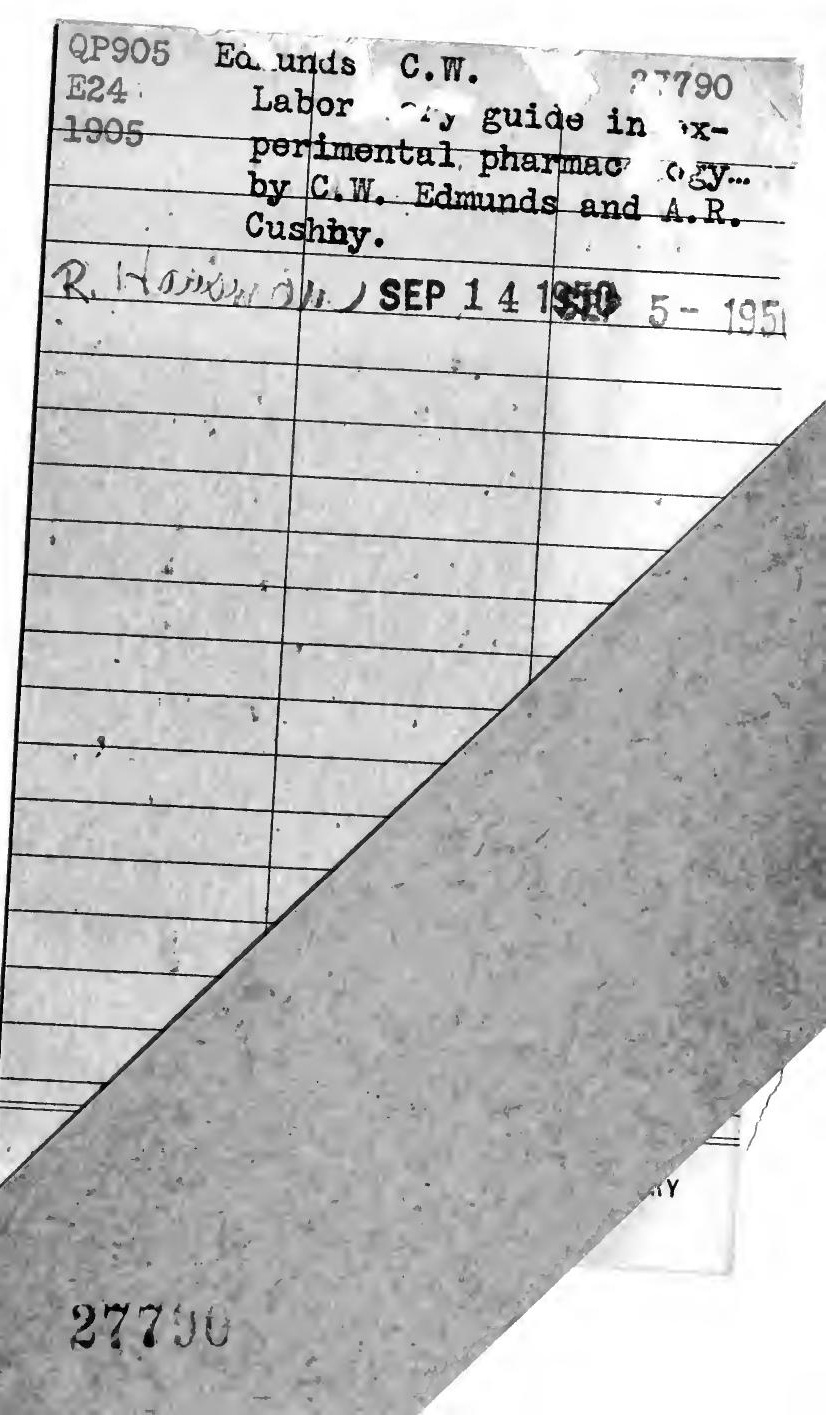


